Article

\title{
Synthesis of New 1,3,5-Triazine-Based 2-Pyrazolines as Potential Anticancer Agents
}

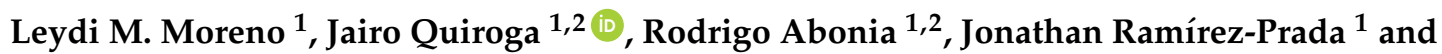 \\ Braulio Insuasty ${ }^{1,2, *}$ \\ 1 Heterocyclic Compounds Research Group, Department of Chemistry, Universidad del Valle, \\ A.A. 25360 Cali, Colombia; leydi.moreno@correounivalle.edu.co (L.M.M.); \\ jairo.quiroga@correounivalle.edu.co (J.Q.); rodrigo.abonia@correounivalle.edu.co (R.A.); \\ jonathan.ramirez@correounivalle.edu.co (J.R.-P.) \\ 2 Centre for Bioinformatics and Photonics-CIBioFI, Calle 13 No. 100-00, Edificio 320, No. 1069, \\ A.A. 25360 Cali, Colombia \\ * Correspondence: braulio.insuasty@correounivalle.edu.co; Tel.: +57-315-484-6665; Fax: +57-2339-3248
}

Received: 28 June 2018; Accepted: 26 July 2018; Published: 6 August 2018

\begin{abstract}
A new series of 1,3,5-triazine-containing 2-pyrazoline derivatives (8-11)a-g was synthesized by cyclocondensation reactions of [(4,6-bis((2-hydroxyethyl)amino)-1,3, 5-triazin-2-yl)amine]chalcones $7 \mathbf{a}-\mathbf{g}$ with hydrazine hydrate and derivatives. Chalcones $7 \mathbf{a}-\mathbf{g}$ were obtained by Claisen-Schmidt condensation between aromatic aldehydes and triazinic derivative 5 , which was synthesized in high yield by a microwave-assisted reaction. Seventeen of the synthesized compounds were selected and tested by the US National Cancer Institute (NCI) for their anticancer activity against 58 different human tumor cell lines. Compounds $\mathbf{7 g}$ and $\mathbf{1 0 d}, \mathbf{e}, \mathbf{g}$ showed important $\mathrm{GI}_{50}$ values ranging from 0.569 to $16.6 \mu \mathrm{M}$ and $\mathrm{LC}_{50}$ values ranging from 5.15 to $>100 \mu \mathrm{M}$.
\end{abstract}

Keywords: 1,3,5-triazines; chalcones; 2-pyrazolones; Claisen-Schmidt reaction; cyclocondensation reactions; microwave irradiation; anticancer activity

\section{Introduction}

Cancer continue being one of the main causes of death worldwide [1]. Chemotherapy is the most common procedure used for its treatment, despite of its known side-effects. For that reason, many researchers are focusing on the design of new more selective anticancer agents, able to combat the resistance of cancer cells and hence, able to reduce their secondary clinical drawbacks. One strategy to obtain new anticancer therapeutic agents is the combination of two or more biologically active molecules/pharmacophores in only one structure (i.e., molecular hybridization), which by synergistic effects between them, could afford biologically and pharmacologically improved therapeutic entities [2,3]. For example, triazine-pyrazoline-based hybrids have been synthesized and reported to possess important biological activities, particularly, anticancer activity $[4,5]$.

The 1,3,5-triazine scaffold has been extensively studied due to its wide range of biological activities, such as antiviral [6], antibacterial [7-9], antifungal [10], anti-inflammatory [11], anti-Alzheimer's [12] and specially anticancer properties [13-15]. Currently, some 1,3,5-triazinic compounds such as altretamine (I) [16], decitabine (II) [17] and azacitidine (III) [18] are used as antineoplastic drugs for treating ovarian cancer, acute myeloid leukemia and chronic myelomonocytic leukemia, respectively (Figure 1A). 


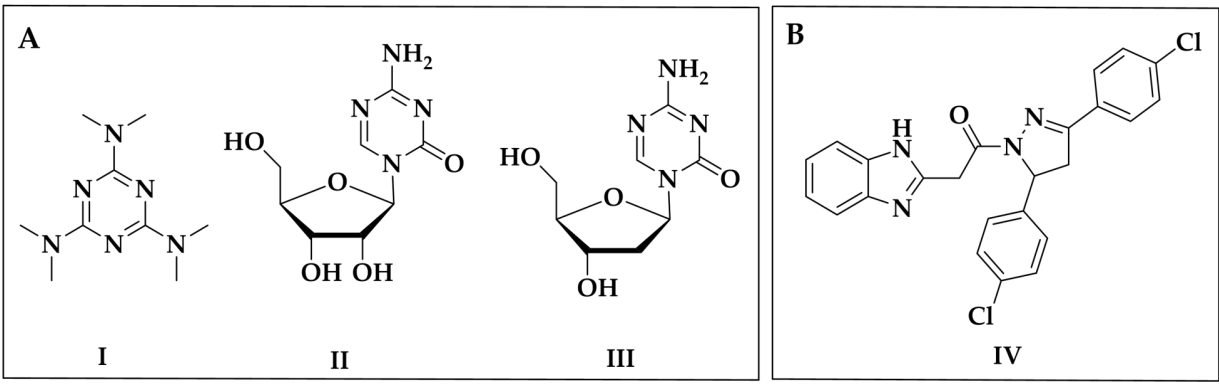

Figure 1. (A) Structures of some triazine-based antineoplastic drugs. (B) Pyrazolinic derivative with anticancer activity.

On the other hand, 2-pyrazoline derivatives also have shown important anticancer properties $[19,20]$. The anticancer mechanisms of these compounds can be associated with their ability to arrest the G0/G1 and G2/M cell cycle phases [21-23], and inhibit heat shock proteins [24], cyclin-dependent kinase [25] and P-glycoprotein [26]. For example, pyrazolinic compound IV (Figure 1B), showed effective growth inhibition of lung cancer cell lines by inducing G2/M phase arrest [21].

Pyrazoline rings can be obtained by a cyclocondensation reaction of $\alpha, \beta$-unsaturated ketones (chalcones) with hydrazine derivatives. Their synthetic precursors (i.e., chalcones) have also shown marked biological activity as anticancer [27,28], antiviral [29], antimalarial [30] and antioxidant agents [31].

Recently, we have reported the synthesis and anticancer activity of some novel pyrazolines and their chalcone-precursors with outstanding $\mathrm{GI}_{50}$ values in the range of 0.13 to $0.99 \mu \mathrm{M}$ [32], 0.28 to $11.7 \mu \mathrm{M}$ [33] and 0.04 to $11.4 \mu \mathrm{M}$ [34], when they were subjected to in vitro assays. Thus, as a continuation of our current studies on the synthetic utility of chalcones and derivatives [32-34], and based on the proven anticancer properties of triazinic and pyrazolinic derivatives, we report here the synthesis from chalcone derivatives of 1,3,5-triazine-2-pyrazoline hybrids and their subsequent evaluation (along with their triazino-ketone and chalcone precursors), by the US National Cancer Institute (NCI) against 58 different human tumor cell lines.

\section{Results and Discussion}

\subsection{Chemistry}

For this study, we initially synthetized 1-(4-((4,6-bis((2-hydroxyethyl)amino)-1,3,5-triazin-2-yl) amino)phenyl)ethan-1-one (5) as the precursor of 1,3,5-triazinic chalcones $7 \mathbf{a}-\mathbf{g}$ using 2,4,6-trichloro-1,3,5-triazine (1) as starting material. The amino-1,3,5-triazine derivative 3 was prepared in $83 \%$ yield, from 2,4,6-trichloro-1,3,5-triazine (1) and 4-aminoacetophenone (2) using a previously reported methodology [35]. Subsequently, compound 3 was treated with ethanolamine (4) in dioxane under microwave irradiation for $5 \mathrm{~min}$ to give the compound 5 , which was subjected to Claisen-Schmidt condensation with aldehydes $\mathbf{6 a}-\mathbf{g}$ afforded the corresponding 1,3,5-triazinic chalcones 7a-g in good yields and high purity (Scheme 1).

The structural elucidation of compounds $7 \mathbf{a}-\mathbf{g}$ was performed by analysis of their spectroscopic data (FTIR, ${ }^{1} \mathrm{H}-\mathrm{NMR},{ }^{13} \mathrm{C}-\mathrm{NMR}$ and mass spectrometry). We discuss here the spectroscopic data of compound $7 \mathbf{a}$ as representative of this series. The IR spectrum of compound 7a shows absorption bands at 3362, 3287 and $1645 \mathrm{~cm}^{-1}$ corresponding to stretching vibration of $\mathrm{N}-\mathrm{H}, \mathrm{O}-\mathrm{H}$ and $\mathrm{C}=\mathrm{O}$ bonds, respectively. In the ${ }^{1} \mathrm{H}-\mathrm{NMR}$ spectrum the signals of the methylene groups protons appeared at 3.33-3.39 and 3.48-3.59 ppm, respectively. Two doublets assigned to both vinylic protons of the $\alpha, \beta$-unsaturated moiety, with a coupling constant of ${ }^{3} \mathrm{~J}=15.6 \mathrm{~Hz}$ are observed at 7.70 and $7.94 \mathrm{ppm}$; this coupling constant corroborates the E-configuration of the carbon-carbon double bond. The mass 
spectrum shows a molecular ion peak at $m / z 420$, which is in agreement with the structure proposed for $7 a$.
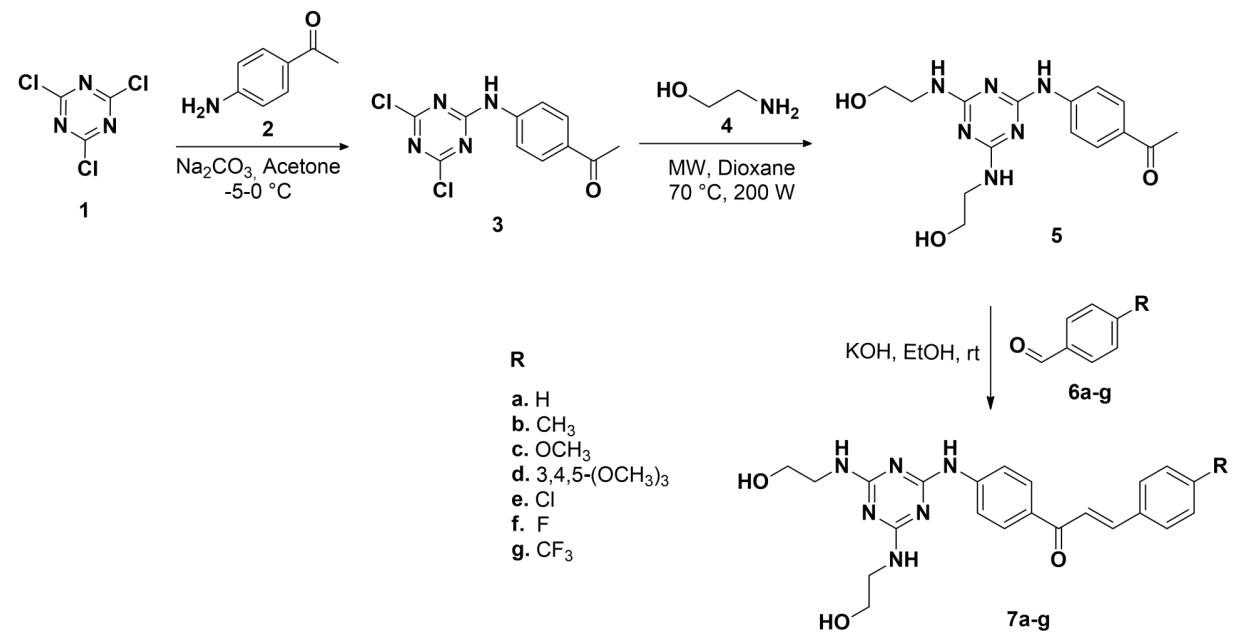

Scheme 1. Synthesis of the novel 1,3,5-triazinic chalcones 7a-g.

The synthesis of target 2-pyrazolines $\mathbf{8}(\mathbf{a}-\mathbf{g})-\mathbf{1 1}(\mathbf{a}-\mathbf{g})$ was performed through 1,2-dinucleophilic cyclocondensation reactions under different experimental conditions (Scheme 2). Thus, the $N$-acetyl pyrazolines $\mathbf{8 a -} \mathbf{a}$ and $N$-formyl pyrazolines $9 \mathbf{a}-\mathbf{g}$ were obtained by reaction of chalcones $7 \mathbf{a}-\mathbf{g}$ with hydrazine monohydrate and their subsequent functionalization with acetic anhydride and formic acid, respectively, under stirring in ethanol at room temperature for 2.5-3.5 h. On the other hand, the treatment of chalcones 7a-g with 3,5-dichlorophenyl hydrazine and 4-chlorophenyl hydrazine under reflux in ethanol for $2 \mathrm{~h}$ afforded the $\mathrm{N}-3,5$-dichlorophenylpyrazolines 10a-g and the $N$-4-chlorophenylpyrazolines 11a-g, respectively, Scheme 2.

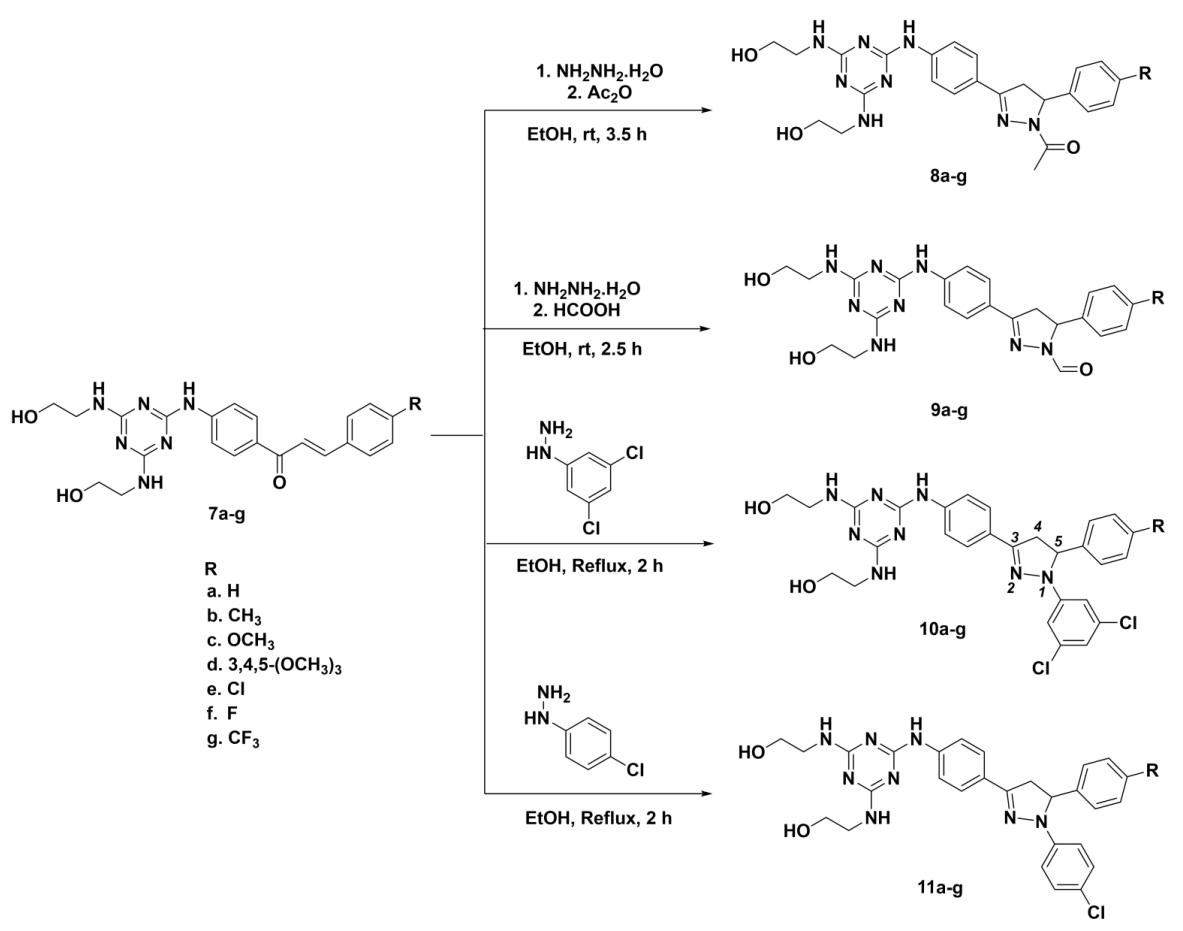

Scheme 2. Synthesis of N-acetyl-8a-g, N-formyl-9a-g, N-3,5-dichlorophenyl-10a-g and N-4-chlorophenyl-11a-g pyrazolines. 
The obtained pyrazolinic compounds $\mathbf{8}(\mathbf{a}-\mathbf{g}) \mathbf{- 1 1}(\mathbf{a}-\mathbf{g})$ showed wide FT-IR absorption bands in the range of 3228-3309 $\mathrm{cm}^{-1}$ assigned to $\mathrm{O}-\mathrm{H}$ groups. The IR spectra also showed absorption bands at 1514-1604 and 1562-1651 $\mathrm{cm}^{-1}$ assigned to $\mathrm{C}=\mathrm{C}$ and $\mathrm{C}=\mathrm{N}$ functionalities, respectively. In the ${ }^{1} \mathrm{H}-\mathrm{NMR}$ spectrum of $N$-3,5-dichlorophenylpyrazoline 10e, for example, the protons on the diastereotopic center C-4, of the pyrazoline ring appears as two double doublets at $\delta 3.17 \mathrm{ppm}$ (with ${ }^{2} J_{\mathrm{AM}}=17.6 \mathrm{~Hz}$ and ${ }^{3} J_{\mathrm{AX}}=4.8 \mathrm{~Hz}$ ), and at $\delta 3.93 \mathrm{ppm}$ (with ${ }^{2} J_{\mathrm{AM}}=17.6 \mathrm{~Hz}$, and ${ }^{3} J_{\mathrm{MX}}=12.0 \mathrm{~Hz}$ ), while the H-5 proton is observed as a double doublet at $\delta 5.63 \mathrm{ppm}$ (with ${ }^{3} \mathrm{~J}_{\mathrm{MX}}=12.0 \mathrm{~Hz}$ and ${ }^{3} J_{\mathrm{AX}}=4.8 \mathrm{~Hz}$ ), confirming the existence of an AMX coupling system in the pyrazoline ring. The mass spectrum showed molecular ion peak at $m / z 612$ (in agreement with the expected mass), and a 100:81:32:5 $\left([\mathrm{M}]^{+}:[\mathrm{M}+2]^{+}:[\mathrm{M}+4]^{+}:[\mathrm{M}+6]^{+}\right)$, isotopic profile, respectively, characteristic of a compound bearing three chlorine atoms in its structure.

\subsection{Anticancer Activity}

The two-stage screening process started with the selection of seventeen of the obtained compounds (i.e., 5, 7f, g, 8c,e,f, $\mathbf{g}, \mathbf{9 e}, \mathbf{f}, \mathbf{g}, \mathbf{1 0 a}, \mathbf{d}, \mathbf{e}, \mathbf{g}, \mathbf{1 1 b}, \mathbf{c}, \mathbf{e})$ by the Drug Evaluation Branch of National Cancer Institute (NCI-USA) through the COMPARE program [36].

The selected compounds were subjected to a primary in vitro evaluation against 58 cell lines at a single dose of $10 \mu \mathrm{M}$ during an incubation time of $48 \mathrm{~h}$, (it is referred to as one-dose assay). The 58 cell panel is derived from nine different cancer strains: leukemia, lung, melanoma, colon, CNS, ovary, renal, breast and prostate cancers. The output from the one-dose screening was reported as a mean graph of the growth percent (GP) of the treated cells supplied by the NCI for analysis; the values are illustrated in Table 1. The mean graph is drawn with the GP data corresponding to the growth relative to the no-drug control, and relative to the time zero number of cells. This graph allows detection of both growth inhibition (GI) (i.e., GP values between 0 and 100) and lethality (i.e., negative values). For example, a GP value of 100 means no growth inhibition. A GP value of 30 would mean $70 \%$ growth inhibition. A GP value of 0 means no net growth over the course of the experiment. A GP value of -30 would mean $30 \%$ lethality and a GP value of -100 means all cells are dead.

Table 1. Percentages of mean growth and growth inhibition of NCI human cancer cell lines treated with selected compounds (5, 7f, $\mathbf{g}, \mathbf{8 c}, \mathbf{e}-\mathbf{g}, \mathbf{9 e}-\mathbf{g}, \mathbf{1 0 d}, \mathbf{e}, \mathbf{g}, \mathbf{1 1 b}, \mathbf{c}, \mathbf{e})$ at one-dose of $10 \mu \mathrm{M}$.

\begin{tabular}{cccc}
\hline Compound & Mean Growth (\%) & Most Sensitive Cell Line & $\begin{array}{c}\text { Growth Inhibition (GI) } \\
\text { of Most Sensitive Cell } \\
\text { Line (\%) }\end{array}$ \\
\hline $\mathbf{5}$ & 101.03 & T-47D (Breast) & 14.43 \\
$\mathbf{7 f}$ & 76.18 & HCT-116 (Colon) & 86.27 \\
\hline & & SR (Leukemia) & -2.01 \\
$\mathbf{7 g}$ & 48.43 & HCT-116 (Colon) & -25.44 \\
& & U251 (CNS) & -21.24 \\
$\mathbf{8}$ & 97.95 & LOX (Melanoma) & -44.16 \\
$\mathbf{8 e}$ & 98.23 & T-47D (Breast) & 30.83 \\
$\mathbf{8 f}$ & 97.92 & T-47D (Breast) & 33.81 \\
$\mathbf{8 g}$ & 95.06 & T-47D (Breast) & 32.18 \\
$\mathbf{9 e}$ & 97.45 & T-47D (Breast) & 34.82 \\
$\mathbf{9 f}$ & 99.59 & A549/ATCC (Non-Small Cell Lung) & 22.64 \\
$\mathbf{9 g}$ & 100.63 & T-47D (Breast) & 17.64 \\
& & NCI-H522 (Non-Small Cell Lung) & 20.02 \\
\hline
\end{tabular}


Table 1. Cont.

\begin{tabular}{|c|c|c|c|}
\hline Compound & Mean Growth (\%) & Most Sensitive Cell Line & $\begin{array}{c}\text { Growth Inhibition (GI) } \\
\text { of Most Sensitive Cell } \\
\text { Line (\%) a }\end{array}$ \\
\hline 10a & 45.23 & LOX IMVI (Melanoma) & -36.95 \\
\hline \multirow{5}{*}{$10 d$} & \multirow{5}{*}{3.94} & HT29 (Colon) & -47.03 \\
\hline & & SF-539 (CNS) & -61.30 \\
\hline & & LOX IMVI (Melanoma) & -60.24 \\
\hline & & MALME-3M (Melanoma) & -66.26 \\
\hline & & SK-MEL-28 (Melanoma) & -69.97 \\
\hline \multirow{4}{*}{$10 \mathrm{e}$} & \multirow{4}{*}{9.09} & SF-295 (CNS) & -68.27 \\
\hline & & LOX IMVI (Melanoma) & -53.44 \\
\hline & & SK-MEL-28 (Melanoma) & -55.82 \\
\hline & & RXF 393 (Renal) & -57.77 \\
\hline \multirow{4}{*}{$10 \mathrm{~g}$} & \multirow{4}{*}{33.33} & CCRF-CEM (Leukemia) & -6.50 \\
\hline & & SF-295 (CNS) & -15.49 \\
\hline & & LOX IMVI (Melanoma) & -48.52 \\
\hline & & RXF 393 (Renal) & -27.23 \\
\hline $11 b$ & 58.24 & RXF 393 (Renal) & -12.62 \\
\hline 11c & 75.54 & RXF 393 (Renal) & 64.68 \\
\hline $11 e$ & 55.01 & RXF 393 (Renal) & -26.15 \\
\hline
\end{tabular}

${ }^{a}$ Negative values of growth inhibition indicate that compound causes the death of the respective cancer cell.

The background color highlight the compounds with the most relevant growth inhibition values.

As shown in Table 1, compounds $\mathbf{7 g}$ and 10d,e,g displayed an outstanding anticancer behavior against diverse cell lines, at lethality level, because of their larger number of negative growth inhibition values. Compounds 10a and $\mathbf{1 1} \mathbf{b}, \mathbf{e}$ also showed remarkable anticancer behavior against a single cell line with lethality values of $-36.95 \%$ (LOX IMVI, melanoma), $-12.62 \%$ (RXF 393, renal) and $-26.15 \%$ (RXF 393, renal), respectively. Compounds $7 f$ and 11c displayed moderate GI values against HCT-116 of renal cancer cell line (i.e., $86.27 \%$ ) and RXF 393 also of renal cancer cell line (i.e., $64.68 \%$ ), respectively. While the remaining compounds showed less activity with GI values in the range of 14.43-34.82. This primary assay showed that compounds $\mathbf{7 g}$ and $\mathbf{1 0 d}, \mathbf{e}, \mathbf{g}$ satisfied the predetermined threshold inhibition criteria, therefore they were considered active. For that, these compounds were subjected to a second in vitro screening in order to determine their cytostatic activity $\left(\mathrm{GI}_{50}\right.$ and $\left.\mathrm{LC}_{50}\right)$, against the full 58 cells panel at five concentrations of 10-fold dilution (i.e., 100, 10, 1.0, 0.1 and $0.01 \mu \mathrm{M}$ ) (it is referred to as five-dose assay). The test consisted of a $48 \mathrm{~h}$ continuous drug exposure protocol by using sulforhodamine B (SRB) protein assay to estimate cell growth. More details of this evaluation method and the complementary information which is encoded by the activity pattern over all cell lines have been published elsewhere [37-39]. The $\mathrm{GI}_{50}$ value (growth inhibitory activity) corresponds to the molar concentration of the compounds required to inhibit $50 \%$ of the growth of cell lines (relative to untreated cells), and $\mathrm{LC}_{50}$ value (cytotoxic activity) is the molar concentration needed to kill $50 \%$ of the cells at the end of the incubation period of $48 \mathrm{~h}$ [40].

As shown in Table 2, compounds $\mathbf{7 g}$ and $\mathbf{1 0 d , e , g}$ showed outstanding values of $\mathrm{GI}_{50}$ against several cell lines, some of them lower than $1.00 \mu \mathrm{M}$. Chalcone $7 \mathrm{~g}$ showed $\mathrm{GI}_{50}$ values in the range of 1.54-15.2 $\mu \mathrm{M}$ and $\mathrm{LC}_{50}$ values of 5.76 to $>100 \mu \mathrm{M}$, being $\mathrm{UO}-31$ (renal, $\mathrm{GI}_{50}=1.54 \mu \mathrm{M}$ and $\mathrm{LC}_{50}=19.5 \mu \mathrm{M}$ ) the most sensitive strain. The best cytotoxicity value was shown against LOX IMVI (melanoma, $\mathrm{LC}_{50}=5.76$ ). Compound 10d showed $\mathrm{GI}_{50}$ values in the range of $0.569-16.6 \mu \mathrm{M}$ and $\mathrm{LC}_{50}$ values of $5.22-81.2 \mu \mathrm{M}$, being RXF 393 (renal, $\mathrm{GI}_{50}=0.569 \mu \mathrm{M}$ ) and HS 578T (breast, $\mathrm{GI}_{50}=0.644 \mu \mathrm{M}$ ) the most sensitive strains. The best cytotoxicity value was shown against 786-0 (Renal, $\mathrm{LC}_{50}=5.22 \mu \mathrm{M}$ ). Compound 10e showed $\mathrm{GI}_{50}$ values in the range of $1.35-2.48 \mu \mathrm{M}$ and $\mathrm{LC}_{50}$ values of 5.15 to $>100 \mu \mathrm{M}$, while compound $10 \mathrm{~g}$ showed $\mathrm{GI}_{50}$ values in the range of $1.18-2.58 \mu \mathrm{M}$ and $\mathrm{LC}_{50}$ values of 5.16 to $>100 \mu \mathrm{M}$. Both compounds (10e and 10g) were found especially effective against SF-539 $(C N S)$ with $\mathrm{GI}_{50}=1.35$ and $1.18 \mu \mathrm{M}$, 
respectively. Compound 10e showed the best cytotoxicity value against SF-539 $\left(C N S, \mathrm{LC}_{50}=5.15 \mu \mathrm{M}\right)$, while compound $10 \mathrm{~g}$ showed the best cytotoxicity value against $\mathrm{ACHN}$ (renal, $\mathrm{LC}_{50}=5.16 \mu \mathrm{M}$ ).

Table 2. In vitro testing expressed as growth inhibition $\mathrm{GI}_{50}$ and lethal concentration $\mathrm{LC}_{50}$ of cancer cell lines for compounds $7 \mathbf{g}$ and $\mathbf{1 0 e}, \mathbf{d}, \mathbf{g}^{\mathrm{a}}$.

\begin{tabular}{|c|c|c|c|c|c|c|c|c|}
\hline \multirow{3}{*}{ Panel Cell Line } & \multicolumn{8}{|c|}{ Compounds } \\
\hline & \multicolumn{2}{|c|}{$7 \mathrm{~g}$} & \multicolumn{2}{|c|}{$10 \mathrm{~d}$} & \multicolumn{2}{|c|}{$10 \mathrm{e}$} & \multicolumn{2}{|c|}{$10 \mathrm{~g}$} \\
\hline & $\mathrm{GI}_{50} \mathrm{~b}$ & $\mathrm{LC}_{50} \mathrm{c}$ & $\mathrm{GI}_{50}$ & $\mathrm{LC}_{50}$ & $\mathrm{GI}_{50}$ & $\mathrm{LC}_{50}$ & $\mathrm{GI}_{50}$ & $\mathrm{LC}_{50}$ \\
\hline \multicolumn{9}{|c|}{ Leukemia } \\
\hline CCRF-CEM & 3.24 & $>100$ & 2.53 & 32.8 & 2.11 & 59.1 & 2.17 & $>100$ \\
\hline HL-60(TB) & 2.97 & 49.6 & 1.50 & 7.88 & 1.86 & 7.93 & 2.58 & $>100$ \\
\hline K-562 & 2.84 & 77.0 & 1.47 & 8.68 & 1.73 & 8.07 & 2.31 & $>100$ \\
\hline MOLT-4 & 2.68 & 61.7 & 1.00 & 18.7 & 1.52 & 11.9 & 1.56 & $>100$ \\
\hline RPMI-8226 & 2.12 & $>100$ & 1.15 & 26.3 & 1.91 & 15.2 & 1.82 & $>100$ \\
\hline SR & 2.30 & $>100$ & 1.29 & 15.5 & 1.45 & 7.55 & 1.48 & $>100$ \\
\hline \multicolumn{9}{|c|}{ Non-small cell lung } \\
\hline A549/ATCC & 2.91 & 55.1 & 1.38 & 7.55 & 1.96 & 10.3 & 1.92 & - \\
\hline EKVX & 3.49 & 54.6 & 2.03 & 23.0 & 2.04 & 12.5 & 1.89 & $>100$ \\
\hline HOP-62 & 2.42 & 91.8 & - & - & - & - & - & $\longrightarrow$ \\
\hline HOP-92 & 5.28 & 78.6 & 1.46 & 26.6 & 2.04 & 9.60 & - & - \\
\hline NCI-H226 & 2.62 & $>100$ & 3.85 & 44.6 & 2.45 & $>100$ & 2.41 & $>100$ \\
\hline NCI-H23 & 3.85 & 61.9 & 2.02 & 15.2 & 1.72 & 6.73 & 1.71 & - \\
\hline NCI-H322M & 2.33 & 34.4 & 3.01 & 31.3 & 2.46 & 25.6 & - & $>100$ \\
\hline NCI-H460 & 3.23 & 45.2 & 1.77 & 8.15 & 1.89 & 7.10 & 2.06 & $\longrightarrow$ \\
\hline NCI-H522 & 2.15 & $>100$ & 2.25 & 30.6 & 2.03 & 11.9 & - & $\longrightarrow$ \\
\hline \multicolumn{9}{|c|}{ Colon } \\
\hline COLO 205 & 2.05 & 8.65 & 2.70 & 30.5 & 1.91 & 7.75 & - & $\longrightarrow$ \\
\hline HCC-2998 & 3.25 & 51.3 & 2.14 & 12.7 & 1.96 & 6.33 & 1.64 & $\longrightarrow$ \\
\hline НCТ-116 & 1.79 & 8.50 & 1.28 & 5.61 & 1.59 & 5.86 & 1.55 & $\longrightarrow$ \\
\hline НСТ-15 & 3.07 & 41.2 & 1.50 & 6.51 & 1.48 & 5.29 & 1.51 & $\longrightarrow$ \\
\hline HT29 & 2.50 & $>100$ & 1.52 & 6.97 & 2.04 & $>100$ & 1.87 & $>100$ \\
\hline KM12 & 2.01 & 8.61 & 1.53 & 6.73 & 1.85 & 8.64 & 1.52 & - \\
\hline SW-620 & 1.97 & 9.17 & 1.80 & 8.00 & 2.03 & 10.2 & - & $\longrightarrow$ \\
\hline \multicolumn{9}{|c|}{ CNS } \\
\hline SF-268 & 2.80 & 80.8 & 1.52 & 12.3 & 1.86 & 7.72 & 1.78 & - \\
\hline SF-295 & 3.20 & 40.7 & 1.16 & 7.10 & 1.47 & 5.49 & 1.36 & 5.37 \\
\hline SF-539 & 1.68 & 6.79 & 1.20 & 5.51 & 1.35 & 5.15 & 1.18 & $\longrightarrow$ \\
\hline SNB-19 & 1.79 & - & 1.72 & 9.84 & 2.07 & 8.22 & 2.26 & $>100$ \\
\hline SNB-75 & 2.31 & 97.9 & 1.05 & 8.90 & 1.51 & 6.19 & 1.32 & $\longrightarrow$ \\
\hline U251 & 1.58 & - & 1.25 & 6.34 & 1.51 & 6.12 & 1.53 & $\longrightarrow$ \\
\hline \multicolumn{9}{|c|}{ Melanoma } \\
\hline LOX IMVI & 1.56 & 5.76 & 1.60 & 5.98 & 1.65 & 5.49 & 1.56 & 5.66 \\
\hline MALME-3M & 4.95 & 50.3 & 1.96 & 7.51 & 2.10 & 7.28 & 1.85 & $\longrightarrow$ \\
\hline M14 & 3.96 & 66.2 & 1.58 & 6.65 & 1.69 & 6.20 & 1.65 & $\longrightarrow$ \\
\hline MDA-MB-435 & 3.82 & 37.9 & 1.55 & 6.80 & 1.64 & 5.88 & 1.54 & $\longrightarrow$ \\
\hline SK-MEL-28 & - & - & 15.5 & 53.7 & 2.13 & 9.79 & - & - \\
\hline SK-MEL-5 & 3.45 & 38.1 & 1.53 & 6.44 & 1.61 & 5.66 & 1.46 & $\longrightarrow$ \\
\hline UACC-257 & 3.12 & 32.8 & 1.70 & 6.58 & 1.81 & 6.31 & 1.72 & 5.62 \\
\hline UACC-62 & 10.3 & 53.1 & 1.86 & 8.05 & 1.95 & 7.34 & - & $\longrightarrow$ \\
\hline \multicolumn{9}{|c|}{ Ovarian } \\
\hline IGROV1 & 3.00 & $>100$ & 2.02 & 13.6 & 2.48 & $>100$ & 2.00 & $\longrightarrow$ \\
\hline OVCAR-3 & 2.02 & 8.70 & 1.62 & 6.07 & 1.75 & 5.83 & 1.54 & - \\
\hline OVCAR-4 & 4.29 & 84.8 & 1.63 & 8.21 & 2.00 & 18.8 & 1.52 & - \\
\hline OVCAR-5 & 2.85 & 43.2 & 2.15 & 27.4 & 1.96 & 9.98 & 1.55 & - \\
\hline OVCAR-8 & 3.31 & $>100$ & 2.01 & 21.5 & 2.08 & 12.4 & - & $>100$ \\
\hline NCI/ADR-RES & 15.2 & 80.7 & 3.37 & 38.3 & 2.60 & $>100$ & 2.04 & $>100$ \\
\hline SK-OV-3 & 4.00 & 39.8 & 11.1 & 48.1 & 2.31 & $>100$ & - & $\longrightarrow$ \\
\hline
\end{tabular}


Table 2. Cont.

\begin{tabular}{|c|c|c|c|c|c|c|c|c|}
\hline \multirow{3}{*}{ Panel Cell Line } & \multicolumn{8}{|c|}{ Compounds } \\
\hline & \multicolumn{2}{|c|}{$7 \mathrm{~g}$} & \multicolumn{2}{|c|}{$10 \mathrm{~d}$} & \multicolumn{2}{|c|}{$10 \mathrm{e}$} & \multicolumn{2}{|c|}{$10 \mathrm{~g}$} \\
\hline & $\mathrm{GI}_{50} \mathrm{~b}$ & $\mathrm{LC}_{50}{ }^{\mathrm{c}}$ & $\mathrm{GI}_{50}$ & $\mathrm{LC}_{50}$ & $\mathrm{GI}_{50}$ & $\mathrm{LC}_{50}$ & $\mathrm{GI}_{50}$ & $\mathrm{LC}_{50}$ \\
\hline \multicolumn{9}{|c|}{ Renal } \\
\hline $786-0$ & 3.12 & 75.1 & 1.29 & 5.22 & 1.64 & 6.53 & 1.51 & - \\
\hline A498 & 8.85 & 46.1 & 16.6 & 55.0 & 1.73 & 7.37 & - & 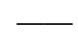 \\
\hline $\mathrm{ACHN}$ & 4.38 & 39.5 & 2.58 & 36.2 & 1.55 & 6.47 & 1.37 & 5.16 \\
\hline RXF 393 & 1.60 & 7.42 & 0.569 & 7.73 & 1.44 & 5.86 & 1.46 & $\longrightarrow$ \\
\hline SN12C & 2.71 & $>100$ & 1.75 & 8.33 & 1.82 & 6.62 & 1.69 & - \\
\hline TK-10 & 2.93 & 38.4 & 2.01 & 9.85 & 1.89 & 7.33 & - & - \\
\hline UO-31 & 1.54 & 19.5 & 2.08 & 28.7 & 1.63 & 6.12 & 1.55 & 5.50 \\
\hline \multicolumn{9}{|c|}{ Prostate } \\
\hline PC-3 & 3.29 & 49.8 & 1.04 & 14.4 & 1.62 & 13.3 & 1.60 & - \\
\hline DU-145 & 4.03 & 37.9 & 1.84 & 9.18 & 1.67 & 6.22 & 1.64 & $\longrightarrow$ \\
\hline \multicolumn{9}{|c|}{ Breast } \\
\hline MCF7 & 1.66 & 55.5 & 1.26 & 6.82 & 1.42 & 7.76 & 1.27 & $>100$ \\
\hline MDA-MB-231/ATCC & 3.29 & 53.5 & 1.45 & 8.14 & 1.71 & 6.81 & 1.63 & 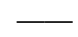 \\
\hline HS 578T & 5.44 & $>100$ & 0.644 & 81.2 & 2.22 & $>100$ & 2.12 & $>100$ \\
\hline BT-549 & 2.53 & 50.6 & 1.67 & 14.9 & 1.77 & 8.18 & 1.80 & - \\
\hline $\mathrm{T}-47 \mathrm{D}$ & 2.51 & $>100$ & 1.18 & 34.7 & 1.50 & 10.2 & - & $>100$ \\
\hline MDA-MB-468 & 2.02 & 24.8 & 1.68 & 14.2 & 1.92 & 7.43 & 2.18 & - \\
\hline
\end{tabular}

${ }^{a}$ Data obtained from NCI's in vitro disease-oriented human cancer cell lines screen in $\mu \mathrm{M} .{ }^{\mathrm{b}} \mathrm{GI}_{50}$ was the drug concentration resulting in a 50\% reduction in the net protein increase (as measured by SRB staining) in control cells during the drug incubation, determined at five concentration levels $(100,10,1.0,0.1$, and $0.01 \mu \mathrm{M}) .{ }^{\mathrm{c}} \mathrm{LC}_{50}$ is a parameter of cytotoxicity that reflects the molar concentration needed to kill $50 \%$ of the cells. The background color highlight the most relevant GI50 values of each compound.

A raw SAR analysis (from the preliminary one-dose and five-dose data) shows that $N$-acetyl and $N$-formyl structures $\mathbf{8}$ and $\mathbf{9}$, respectively, were the less actives of the whole evaluated series, while structures $\mathbf{1 0}$ were the most active ones, followed by pyrazolines $\mathbf{1 1}$ and chalcones $\mathbf{7}$. It is remarkable that the presence of halogen atoms $(\mathrm{Cl}$ and $\mathrm{F})$, in most cases, increased the activity of their structures. In consequence, the halogenated structures $\mathbf{7 g}, \mathbf{f}, \mathbf{1 0 a}, \mathbf{d}, \mathbf{e}, \mathbf{g}$ and $\mathbf{1 1 b}, \mathbf{c}, \mathbf{e}$ were the most active compounds of their corresponding series. Finally, it seems that the presence of the $\mathrm{N}$-(3,5-dicholorophenyl) substituent in the pyrazoline ring of compounds $\mathbf{1 0}$ is very convenient for improving their relative activity in comparison with the $\mathrm{N}$-(4-cholorophenyl) substituent in pyrazolines 11. This suggestion is supported by the fact that three pyrazolines 10 (i.e., $\mathbf{1 0 d}, \mathbf{e}, \mathbf{g}$ ) were promoted by the NCI to five-dose assays (due to their outstanding inhibitory values at one-dose), against none pyrazoline 11 (see Tables 1 and 2). The above findings and in particular the high activity displayed by structures $\mathbf{7 g}$ and $\mathbf{1 0 d , e , g}$ will be used as reference for further structural-reforming experiments addressed to find the most potent as possible chalcone or pyrazoline-triazine lead hybrid for the developing of potential anticancer agents based in our synthesized compounds $\mathbf{7}$ or $\mathbf{1 0}$.

\section{Experimental Section}

\subsection{General Information}

Reagents and solvents used were obtained from commercial sources and used without further purification. Melting points were measured using a Stuart SMP10 melting point device (Cole-Parmer Ltd., Stone, Staffordshire, UK) and are uncorrected. FTIR spectra were obtained with a IRAffinity-1 spectrophotometer (Shimadzu, Columbia, MD, USA). The ${ }^{1} \mathrm{H}$ - and ${ }^{13} \mathrm{C}-\mathrm{NMR}$ spectra were run on a DPX 400 spectrometer (Bruker, Billerica, MA, USA) operating at 400 and $100 \mathrm{MHz}$ respectively, using DMSO- $d_{6}$ as solvent and TMS as internal standard. The mass spectra were obtained on a Shimadzu-GCMS-QP2010 spectrometer (Shimadzu, Kyoto, Honshu, Japan) operating at $70 \mathrm{eV}$. The elemental analyses were obtained using an Agilent CHNS elemental analyzer (Thermo Fischer Scientific Inc., Madison, WI, USA) and the values are within $\pm 0.4 \%$ of the theoretical values. Thin layer 
chromatography (TLC) were performed on $0.2 \mathrm{~mm}$ pre-coated aluminium plates of silica gel $60 \mathrm{~F}_{254}$ (Merck, Darmstadt, Hesse, Germany).

\subsection{Chemistry}

\subsubsection{Synthesis of 1-(4-((4,6-Dichloro-1,3,5-triazin-2-yl)amino)phenyl)ethan-1-one (3)}

Using a methodology similar to that reported by Kathiriya and coworkers [33], the synthesis of precursor 3 was carried out as follows: Aamixture of 2,4,6-trichloro-1,3,5-triazine (1, $1 \mathrm{mmol})$ and 4 -aminoacetophenone $(2,1 \mathrm{mmol})$ in acetone $(25 \mathrm{~mL})$ was stirred at $-5-0{ }^{\circ} \mathrm{C}$ for $5 \mathrm{~h}$. The mixture was neutralized witH- $\mathrm{Na}_{2} \mathrm{CO}_{3} 20 \%$. The content was poured onto crushed ice, filtered and washed with water.

\subsubsection{Synthesis of 4-[(4,6-bis((2-Hydroxyethyl)amino)-1,3,5-triazin-2-yl)amino]acetophenone (5)}

A mixture of ketone $3(0.71 \mathrm{mmol})$ and ethanolamine $(4,2.84 \mathrm{mmol})$ in dioxane $(1.5 \mathrm{~mL})$ was subjected to microwave irradiation for $5 \mathrm{~min}$, at $70{ }^{\circ} \mathrm{C}, 50 \mathrm{PSI}$ and $200 \mathrm{~W}$. Then, the reaction mixture was treated with crushed ice. The solid formed was filtered and washed with water. Purification of product 5 was performed by column chromatography employing a mixture $\mathrm{CHCl}_{3} / \mathrm{EtOH}(7: 1)$ as eluent. Beige solid; 86\% yield; m.p. 175-177 ${ }^{\circ} \mathrm{C}$. FT-IR (ATR) v $\left(\mathrm{cm}^{-1}\right) 3367(\mathrm{~N}-\mathrm{H}), 3290(\mathrm{O}-\mathrm{H}), 3107(=\mathrm{C}-\mathrm{H})$, $1664(\mathrm{C}=\mathrm{O}), 1597$ and $1539(\mathrm{C}=\mathrm{N}$ and $\mathrm{C}=\mathrm{C}) .{ }^{1} \mathrm{H}-\mathrm{NMR}\left(400 \mathrm{MHz}, \mathrm{DMSO}-d_{6}\right) \delta \mathrm{ppm} 2.50\left(\mathrm{~s}, 3 \mathrm{H}, \mathrm{CH}_{3}\right)$, 3.31-3.39 (m, 4H, $\left.\mathrm{CH}_{2}\right), 3.47-3.56\left(\mathrm{~m}, 4 \mathrm{H}, \mathrm{CH}_{2}\right), 4.67(\mathrm{~s}, 2 \mathrm{H}, \mathrm{OH}), 6.72(\mathrm{bs}, 1 \mathrm{H}, \mathrm{NH}), 6.84(\mathrm{bs}, 1 \mathrm{H}, \mathrm{NH})$, $7.84(\mathrm{~d}, J=8.0 \mathrm{~Hz}, 2 \mathrm{H}, \mathrm{Ar}-\mathrm{H}), 7.95(\mathrm{~d}, J=8.0 \mathrm{~Hz}, 2 \mathrm{H}, \mathrm{Ar}-\mathrm{H}), 9.32(\mathrm{bs}, 1 \mathrm{H}, \mathrm{NH}) .{ }^{13} \mathrm{C}-\mathrm{NMR}(100 \mathrm{MHz}$, DMSO- $\left.d_{6}\right) \delta$ ppm $26.4\left(\mathrm{CH}_{3}\right), 42.8\left(\mathrm{CH}_{2}\right), 60.1\left(\mathrm{CH}_{2}\right), 118.1,123.6(\mathrm{Cq}), 129.1,135.9(\mathrm{Cq}), 145.7(\mathrm{Cq})$, 145.8 (Cq), 196.1 (Cq). MS (70 eV) m/z (\%): 332 [M+'] (55), 302 (99), 289 (100), 245 (81), 186 (59), 134 (89). Anal. Calcd. $\mathrm{C}_{15} \mathrm{H}_{20} \mathrm{~N}_{6} \mathrm{O}_{3}: \mathrm{C}, 54.21 ; \mathrm{H}, 6.07 ; \mathrm{N}, 25.29$; Found: $\mathrm{C}, 54.28 ; \mathrm{H}, 5.98 ; \mathrm{N}, 25.31$.

3.2.3. General Procedure for the Synthesis of

(4,6-bis((2-Hydroxyethyl)amino)-1,3,5-triazin-2-yl)aminochalcones 7a-g

A mixture of acetophenone $5(3 \mathrm{mmol})$, the respective benzaldehyde $6 \mathbf{a}-\mathbf{g}(3.0 \mathrm{mmol})$ and potassium hydroxide $(100 \mathrm{mg})$ in ethanol $(7 \mathrm{~mL})$ was stirred at room temperature for $5 \mathrm{~h}$. The solid formed was filtered and washed with ethanol. No further purification was required.

(E)-1-(4-((4,6-bis((2-Hydroxyethyl)amino)-1,3,5-triazin-2-yl)amino)phenyl)-3-phenylprop-2-en-1-one (7a). Yellow solid; 80\% yield; m.p. 167-169 ${ }^{\circ} \mathrm{C}$. FT-IR (ATR) v ( $\left.\mathrm{cm}^{-1}\right) 3362(\mathrm{~N}-\mathrm{H}), 3287(\mathrm{O}-\mathrm{H}), 3110(=\mathrm{C}-\mathrm{H})$, $1645(\mathrm{C}=\mathrm{O}), 1575$ and $1514(\mathrm{C}=\mathrm{N}$ and $\mathrm{C}=\mathrm{C}) .{ }^{1} \mathrm{H}-\mathrm{NMR}\left(400 \mathrm{MHz}, \mathrm{DMSO}-d_{6}\right) \delta \mathrm{ppm} 3.33-3.39(\mathrm{~m}, 4 \mathrm{H}$, $\left.\mathrm{CH}_{2}\right), 3.48-3.59\left(\mathrm{~m}, 4 \mathrm{H}, \mathrm{CH}_{2}\right), 4.72(\mathrm{~s}, 2 \mathrm{H}, \mathrm{OH}), 6.74(\mathrm{bs}, 1 \mathrm{H}, \mathrm{NH}), 6.87$ (bs, $\left.1 \mathrm{H}, \mathrm{NH}\right), 7.51-7.41(\mathrm{~m}, 3 \mathrm{H}$, $\mathrm{Ar}-\mathrm{H}), 7.70(\mathrm{~d}, J=15.6 \mathrm{~Hz}, 1 \mathrm{H}, \mathrm{CH}), 7.84-7.90(\mathrm{~m}, 2 \mathrm{H}, \mathrm{Ar}-\mathrm{H}), 7.94(\mathrm{~d}, J=15.6 \mathrm{~Hz}, 1 \mathrm{H}, \mathrm{CH}) 8.01(\mathrm{~d}$, $J=8.9 \mathrm{~Hz}, 2 \mathrm{H}, \mathrm{Ar}-\mathrm{H}), 8.04-8.14(\mathrm{~m}, 2 \mathrm{H}, \mathrm{Ar}-\mathrm{H}), 9.40(\mathrm{t}, J=39.23 \mathrm{~Hz}, 1 \mathrm{H}, \mathrm{NH}) .{ }^{13} \mathrm{C}-\mathrm{NMR}(100 \mathrm{MHz}$, DMSO- $\left.d_{6}\right) \delta$ ppm $42.9\left(\mathrm{CH}_{2}\right), 60.1\left(\mathrm{CH}_{2}\right), 118.3,122.2,128.7,128.9,129.6,129.7(\mathrm{Cq}), 130.1(\mathrm{Cq})$, $130.2(\mathrm{Cq}), 130.3,134.9(\mathrm{Cq}), 142.8,145.7(\mathrm{Cq}), 145.8(\mathrm{Cq}), 187.3(\mathrm{Cq}) . \mathrm{MS}(70 \mathrm{eV}) \mathrm{m} / \mathrm{z}(\%): 420\left[\mathrm{M}^{+}\right]$ (66), 390 (100), 377 (61), 333 (46), 131 (56), 43 (42). Anal. Calcd. $\mathrm{C}_{22} \mathrm{H}_{24} \mathrm{~N}_{6} \mathrm{O}_{3}: \mathrm{C}, 62.84 ; \mathrm{H}, 5.75 ; \mathrm{N}, 19.99$; Found: C, 62.80; H, 5.80; N, 20.04.

(E)-1-(4-((4,6-bis((2-Hydroxyethyl)amino)-1,3,5-triazin-2-yl)amino)phenyl)-3-(p-tolyl)prop-2-en-1-one (7b). Yellow solid; $70 \%$ yield; m.p. $195-197^{\circ} \mathrm{C}$. FT-IR (ATR) v ( $\left.\mathrm{cm}^{-1}\right) 3383(\mathrm{~N}-\mathrm{H}), 3283(\mathrm{O}-\mathrm{H}), 3103(=\mathrm{C}-\mathrm{H})$, $1635(\mathrm{C}=\mathrm{O}), 1568$ and $1508(\mathrm{C}=\mathrm{N}$ and $\mathrm{C}=\mathrm{C}) .{ }^{1} \mathrm{H}-\mathrm{NMR}\left(400 \mathrm{MHz}, \mathrm{DMSO}-d_{6}\right) \delta \mathrm{ppm} 2.35\left(\mathrm{~s}, 3 \mathrm{H}, \mathrm{CH}_{3}\right)$, 3.29-3.40 (m, 4H, $\left.\mathrm{CH}_{2}\right), 3.48-3.58\left(\mathrm{~m}, 4 \mathrm{H}, \mathrm{CH}_{2}\right), 4.70(\mathrm{~s}, 2 \mathrm{H}, \mathrm{OH}), 6.73$ (bs, $\left.1 \mathrm{H}, \mathrm{NH}\right), 6.86(\mathrm{bs}, 1 \mathrm{H}$, $\mathrm{NH}), 7.27(\mathrm{~d}, J=8.0 \mathrm{~Hz}, 2 \mathrm{H}, \mathrm{Ar}-\mathrm{H}), 7.67(\mathrm{~d}, J=15.5 \mathrm{~Hz}, 1 \mathrm{H}, \mathrm{CH}), 7.76(\mathrm{~d}, J=8.0 \mathrm{~Hz}, 2 \mathrm{H}, \mathrm{Ar}-\mathrm{H})$, $7.88(\mathrm{~d}, J=15.5 \mathrm{~Hz}, 1 \mathrm{H}, \mathrm{CH}), 8.00(\mathrm{~d}, J=8.9 \mathrm{~Hz}, 2 \mathrm{H}, \mathrm{Ar}-\mathrm{H}), 8.03-8.11(\mathrm{~m}, 2 \mathrm{H}, \mathrm{Ar}-\mathrm{H}), 9.32$ (bs, 1H, $\mathrm{NH}) .{ }^{13} \mathrm{C}-\mathrm{NMR}\left(100 \mathrm{MHz}, \mathrm{DMSO}-d_{6}\right) \delta \mathrm{ppm} 21.1\left(\mathrm{CH}_{3}\right), 42.9\left(\mathrm{CH}_{2}\right), 60.1\left(\mathrm{CH}_{2}\right), 118.3,121.1,128.7$, 129.5, $129.6(\mathrm{Cq}), 130.3(\mathrm{Cq}), 132.2(\mathrm{Cq}), 135.9(\mathrm{Cq}), 140.3(\mathrm{Cq}), 142.8,145.6(\mathrm{Cq}), 163.9(\mathrm{Cq}), 165.8(\mathrm{Cq})$, 
187.2 (Cq). MS (70 eV) m/z (\%): 434 [M+ $\mathrm{M}^{+}$(84), 404 (100), 347 (38), 145 (36), 69 (18), 43 (23). Anal. Calcd. $\mathrm{C}_{23} \mathrm{H}_{26} \mathrm{~N}_{6} \mathrm{O}_{3}$ : C, 63.58; H, 6.03; N, 19.34; Found: $\mathrm{C}, 63.51 ; \mathrm{H}, 6.08 ; \mathrm{N}, 19.39$.

(E)-1-(4-((4,6-bis((2-Hydroxyethyl)amino)-1,3,5-triazin-2-yl)amino)phenyl)-3-(4-methoxyphenyl)prop-2-en -1-one (7c). Yellow solid; 62\% yield; m.p. 177-179 ${ }^{\circ} \mathrm{C}$. FT-IR (ATR) v $\left(\mathrm{cm}^{-1}\right) 3396(\mathrm{~N}-\mathrm{H}), 3262(\mathrm{O}-\mathrm{H})$, $3190(=\mathrm{C}-\mathrm{H}), 1635(\mathrm{C}=\mathrm{O}), 1606(\mathrm{C}=\mathrm{N}), 1577(\mathrm{C}=\mathrm{C})$ and $1167(\mathrm{C}-\mathrm{O}) .{ }^{1} \mathrm{H}-\mathrm{NMR}\left(400 \mathrm{MHz}, \mathrm{DMSO}-d_{6}\right) \delta$ ppm 3.30-3.42 (m, 4H, CH $), 3.47-3.58\left(\mathrm{~m}, 4 \mathrm{H}, \mathrm{CH}_{2}\right), 3.82\left(\mathrm{~s}, 3 \mathrm{H}, \mathrm{OCH}_{3}\right), 4.71(\mathrm{~s}, 2 \mathrm{H}, \mathrm{OH}), 6.85(\mathrm{bs}, 1 \mathrm{H}$, $\mathrm{NH}), 6.72(\mathrm{bs}, 1 \mathrm{H}, \mathrm{NH}), 7.01(\mathrm{~d}, J=8.6 \mathrm{~Hz}, 2 \mathrm{H}, \mathrm{Ar}-\mathrm{H}), 7.67(\mathrm{~d}, J=15.5 \mathrm{~Hz}, 1 \mathrm{H}, \mathrm{CH}), 7.75-7.86(\mathrm{~m}, 3 \mathrm{H}$, $\mathrm{CH}, \mathrm{Ar}-\mathrm{H}), 7.99(\mathrm{~d}, J=8.8 \mathrm{~Hz}, 2 \mathrm{H}, \mathrm{Ar}-\mathrm{H}), 8.06(\mathrm{~d}, J=8.8 \mathrm{~Hz}, 2 \mathrm{H}, \mathrm{Ar}-\mathrm{H}), 9.35$ (bs, $1 \mathrm{H}, \mathrm{NH}) .{ }^{13} \mathrm{C}-\mathrm{NMR}$ $\left(100 \mathrm{MHz}, \mathrm{DMSO}-d_{6}\right) \delta$ ppm $42.9\left(\mathrm{CH}_{2}\right), 55.4\left(\mathrm{CH}_{3}\right), 60.1\left(\mathrm{CH}_{2}\right), 114.4,118.3,119.7,127.5(\mathrm{Cq}), 129.5$, $130.4(\mathrm{Cq}), 130.6,135.9(\mathrm{Cq}), 142.7,145.6(\mathrm{Cq}), 161.1(\mathrm{Cq}), 165.9(\mathrm{Cq}), 187.3(\mathrm{Cq}) . \mathrm{MS}(70 \mathrm{eV}) \mathrm{m} / \mathrm{z}(\%)$ : $450\left[\mathrm{M}^{+}\right]$(89), 420 (100), 363 (36), 161 (64), 133 (40), 43 (39). Anal. Calcd. $\mathrm{C}_{23} \mathrm{H}_{26} \mathrm{~N}_{6} \mathrm{O}_{4}: \mathrm{C}, 61.32 ; \mathrm{H}, 5.82 ;$ N, 18.66; Found: C, 61.30; H, 5.81; N, 18.70 .

(E)-1-(4-((4,6-bis((2-Hydroxyethyl)amino)-1,3,5-triazin-2-yl)amino)phenyl)-3-(3,4,5-trimethoxyphenyl)-prop-2 -en-1-one (7d). Yellow solid; 57\% yield; m.p. 197-200 ${ }^{\circ} \mathrm{C}$. FT-IR (ATR) v $\left(\mathrm{cm}^{-1}\right) 3433(\mathrm{~N}-\mathrm{H}), 3302(\mathrm{O}-\mathrm{H})$, $3105(=\mathrm{C}-\mathrm{H}), 1645(\mathrm{C}=\mathrm{O}), 1573 \mathrm{br}(\mathrm{C}=\mathrm{N}, \mathrm{C}=\mathrm{C}), 1124(\mathrm{C}-\mathrm{O}) .{ }^{1} \mathrm{H}-\mathrm{NMR}\left(400 \mathrm{MHz}, \mathrm{DMSO}-d_{6}\right) \delta \mathrm{ppm}$ 3.32-3.40 (m, 4H, $\left.\mathrm{CH}_{2}\right), 3.48-3.59\left(\mathrm{~m}, 4 \mathrm{H}, \mathrm{CH}_{2}\right), 3.71\left(\mathrm{~s}, 3 \mathrm{H}, \mathrm{OCH}_{3}\right), 3.87\left(\mathrm{~s}, 6 \mathrm{H}, \mathrm{OCH}_{3}\right), 4.69(\mathrm{~s}, 2 \mathrm{H}$, $\mathrm{OH}), 6.72(\mathrm{bs}, 1 \mathrm{H}, \mathrm{NH}), 6.85(\mathrm{bs}, 1 \mathrm{H}, \mathrm{NH}), 7.21(\mathrm{~s}, 2 \mathrm{H}, \mathrm{Ar}-\mathrm{H}), 7.65(\mathrm{~d}, J=15.4 \mathrm{~Hz}, 1 \mathrm{H}, \mathrm{CH}), 7.89$ (d, $J=15.4 \mathrm{~Hz}, 1 \mathrm{H}, \mathrm{CH}), 8.02(\mathrm{~d}, J=8.6 \mathrm{~Hz}, 2 \mathrm{H}, \mathrm{Ar}-\mathrm{H}), 8.09(\mathrm{~d}, J=8.6 \mathrm{~Hz}, 2 \mathrm{H}, \mathrm{Ar}-\mathrm{H}), 9.38(\mathrm{t}, J=35.9 \mathrm{~Hz}$, 1H, NH). ${ }^{13} \mathrm{C}-\mathrm{NMR}\left(100 \mathrm{MHz}, \mathrm{DMSO}-d_{6}\right) \delta \mathrm{ppm} 42.9\left(\mathrm{CH}_{2}\right), 56.1\left(\mathrm{OCH}_{3}\right), 60.1\left(\mathrm{CH}_{2}\right), 60.2\left(\mathrm{OCH}_{3}\right)$, 106.4, 118.3, 121.4, $129.6(\mathrm{Cq}), 130.5,135.9(\mathrm{Cq}), 139.5,143.2(\mathrm{Cq}), 143.3(\mathrm{Cq}), 145.6(\mathrm{Cq}), 145.7(\mathrm{Cq})$, 153.1 (Cq), 187.2 (Cq). MS (70 eV) m/z (\%): 510 [M ] (21), 313 (24), 236 (21), 97 (50), 58 (100), 43 (95). Anal. Calcd. $\mathrm{C}_{25} \mathrm{H}_{30} \mathrm{~N}_{6} \mathrm{O}_{6}$ : C, 58.81; H, 5.92; N, 16.46; Found: C, 58.87; H, 6.01; N, 16.45 .

(E)-1-(4-((4,6-bis((2-Hydroxyethyl)amino)-1,3,5-triazin-2-yl)amino)phenyl)-3-(4-chlorophenyl)prop-2-en-1-one (7e). Yellow solid; 87\% yield; m.p. $193-195{ }^{\circ} \mathrm{C}$. FT-IR (ATR) v $\left(\mathrm{cm}^{-1}\right) 3383(\mathrm{~N}-\mathrm{H}), 3285(\mathrm{O}-\mathrm{H})$, $3100(=\mathrm{C}-\mathrm{H}), 1651(\mathrm{C}=\mathrm{O}), 1568$ and $1510(\mathrm{C}=\mathrm{N}$ and $\mathrm{C}=\mathrm{C}) .{ }^{1} \mathrm{H}-\mathrm{NMR}\left(400 \mathrm{MHz}, \mathrm{DMSO}-d_{6}\right) \delta \mathrm{ppm}$ 3.28-3.42 (m, 4H, $\left.\mathrm{CH}_{2}\right), 3.48-3.58\left(\mathrm{~m}, 4 \mathrm{H}, \mathrm{CH}_{2}\right), 4.70(\mathrm{~s}, 2 \mathrm{H}, \mathrm{OH}), 6.73(\mathrm{bs}, 1 \mathrm{H}, \mathrm{NH}), 6.87(\mathrm{bs}, 1 \mathrm{H}, \mathrm{NH})$, $7.52(\mathrm{~d}, J=8.4 \mathrm{~Hz}, 2 \mathrm{H}, \mathrm{Ar}-\mathrm{H}), 7.68(\mathrm{~d}, J=15.6 \mathrm{~Hz}, 1 \mathrm{H}, \mathrm{CH}), 7.88-7.96(\mathrm{~m}, 3 \mathrm{H}, \mathrm{CH}, \mathrm{Ar}-\mathrm{H}), 8.01(\mathrm{~d}$, $J=8.6 \mathrm{~Hz}, 2 \mathrm{H}, \mathrm{Ar}-\mathrm{H}), 8.08(\mathrm{~d}, J=8.6 \mathrm{~Hz}, 2 \mathrm{H}, \mathrm{Ar}-\mathrm{H}), 9.39(\mathrm{bs}, 1 \mathrm{H}, \mathrm{NH}) .{ }^{13} \mathrm{C}-\mathrm{NMR}\left(100 \mathrm{MHz}, \mathrm{DMSO}-d_{6}\right)$ $\delta$ ppm $42.9\left(\mathrm{CH}_{2}\right), 60.0\left(\mathrm{CH}_{2}\right), 118.3,122.9,128.9,129.7,130.0(\mathrm{Cq}), 130.1(\mathrm{Cq}), 130.4,133.9(\mathrm{Cq})$, $134.8(\mathrm{Cq}), 135.9(\mathrm{Cq}), 141.3,145.8(\mathrm{Cq}), 187.1(\mathrm{Cq}) . \mathrm{MS}(70 \mathrm{eV}) \mathrm{m} / \mathrm{z}(\%): 454: 456\left[\mathrm{M}^{+}\right]:[\mathrm{M}+2]^{+}(34 / 11)$, 454 (62), 367 (36), 137 (37), 55 (81), 43 (100). Anal. Calcd. $\mathrm{C}_{22} \mathrm{H}_{23} \mathrm{ClN}_{6} \mathrm{O}_{3}$ : C, 58.09; H, 5.10; N, 18.47; Found: C, 58.02; H, 5.15; N, 18.49 .

(E)-1-(4-((4,6-bis((2-Hydroxyethyl)amino)-1,3,5-triazin-2-yl)amino)phenyl)-3-(4-fluorophenyl)prop-2-en-1-one (7f). Yellow solid; 88\% yield; m.p. 176-178 ${ }^{\circ} \mathrm{C}$. FT-IR (ATR) v $\left(\mathrm{cm}^{-1}\right) 3373(\mathrm{~N}-\mathrm{H}), 3283(\mathrm{O}-\mathrm{H})$, $3105(=\mathrm{C}-\mathrm{H}), 1651(\mathrm{C}=\mathrm{O}), 1575$ and $1504(\mathrm{C}=\mathrm{N}$ and $\mathrm{C}=\mathrm{C}) .{ }^{1} \mathrm{H}-\mathrm{NMR}\left(400 \mathrm{MHz}, \mathrm{DMSO}-d_{6}\right) \delta \mathrm{ppm}$ 3.32-3.42 (m, 4H, CH 2$), 3.48-3.57\left(\mathrm{~m}, 4 \mathrm{H}, \mathrm{CH}_{2}\right), 4.73(\mathrm{~s}, 2 \mathrm{H}, \mathrm{OH}), 6.73$ (bs, $\left.1 \mathrm{H}, \mathrm{NH}\right), 6.87$ (bs, $1 \mathrm{H}$, $\mathrm{NH}), 7.25-7.33(\mathrm{~m}, 2 \mathrm{H}, \mathrm{Ar}-\mathrm{H}), 7.70(\mathrm{~d}, J=15.6 \mathrm{~Hz}, 1 \mathrm{H}, \mathrm{CH}), 7.90(\mathrm{~d}, J=15.6 \mathrm{~Hz}, 1 \mathrm{H}, \mathrm{CH}), 7.96(\mathrm{dd}$, $J=8.3$ and $\left.J_{\mathrm{HF}}=6.0 \mathrm{~Hz}, 2 \mathrm{H}, \mathrm{Ar}-\mathrm{H}\right), 8.01(\mathrm{~d}, J=9.0 \mathrm{~Hz}, 2 \mathrm{H}, \mathrm{Ar}-\mathrm{H}), 8.08(\mathrm{~d}, J=9.0 \mathrm{~Hz}, 2 \mathrm{H}, \mathrm{Ar}-\mathrm{H})$, $9.38(\mathrm{t}, J=36.9 \mathrm{~Hz}, 1 \mathrm{H}, \mathrm{NH}) .{ }^{13} \mathrm{C}-\mathrm{NMR}\left(100 \mathrm{MHz}, \mathrm{DMSO}-d_{6}\right) \delta \mathrm{ppm} 42.8\left(\mathrm{CH}_{2}\right), 60.0\left(\mathrm{CH}_{2}\right), 115.8(\mathrm{~d}$, $\left.{ }^{2} J_{\mathrm{CF}}=21.6 \mathrm{~Hz}\right), 118.3,122.1,129.7,130.1(\mathrm{Cq}), 131.0\left(\mathrm{~d},{ }^{3} J_{\mathrm{CF}}=8.5 \mathrm{~Hz}\right), 131.6\left(\mathrm{~d},{ }^{4} J_{\mathrm{CF}}=2.9 \mathrm{~Hz}, \mathrm{Cq}\right)$, $131.6(\mathrm{Cq}), 141.5,145.7(\mathrm{Cq}), 163.3\left(\mathrm{~d},{ }^{1} J_{\mathrm{CF}}=248.7 \mathrm{~Hz}, \mathrm{C}-\mathrm{F}\right), 163.9(\mathrm{Cq}), 187.2(\mathrm{Cq}) . \mathrm{MS}(70 \mathrm{eV}) \mathrm{m} / \mathrm{z}(\%)$ : $438\left[\mathrm{M}^{+}\right](46), 408(86), 395$ (56), 302 (71), 149 (58), 43 (100). Anal. Cald. $\mathrm{C}_{22} \mathrm{H}_{23} \mathrm{FN}_{6} \mathrm{O}_{3}: \mathrm{C}, 60.27 ; \mathrm{H}, 5.29$; N, 19.17; Found: C, 60.23; H, 5.27; N, 19.20 .

(E)-1-(4-((4,6-bis((2-Hydroxyethyl)amino)-1,3,5-triazin-2-yl)amino)phenyl)-3-(4-(trifluoromethyl)phenyl)-prop -2-en-1-one (7g). Yellow solid; 71\% yield; m.p. 193-196 ${ }^{\circ} \mathrm{C}$. FT-IR (ATR) v $\left(\mathrm{cm}^{-1}\right) 3390(\mathrm{~N}-\mathrm{H})$, $3317(\mathrm{O}-\mathrm{H}), 3110(=\mathrm{C}-\mathrm{H}), 1661(\mathrm{C}=\mathrm{O}), 1568$ and $1512(\mathrm{C}=\mathrm{N}$ and $\mathrm{C}=\mathrm{C}) .{ }^{1} \mathrm{H}-\mathrm{NMR}$ (400 MHz, DMSO- $\left.d_{6}\right)$ $\delta$ ppm 3.28-3.41 (m, 4H, CH $)$, 3.49-3.57 (m, 4H, CH $), 4.73(\mathrm{~s}, 2 \mathrm{H}, \mathrm{OH}), 6.74$ (bs, 1H, NH), 6.88 (bs, $1 \mathrm{H}, \mathrm{NH}), 7.74(\mathrm{~d}, 1 \mathrm{H}, J=15.6 \mathrm{~Hz}, 1 \mathrm{H}, \mathrm{CH}), 7.80(\mathrm{~d}, 2 \mathrm{H}, J=8.8 \mathrm{~Hz}, \mathrm{Ar}-\mathrm{H}), 8.02(\mathrm{~d}, J=8.8 \mathrm{~Hz}, 2 \mathrm{H}$, 
Ar-H), 8.05-8.14 (m, 5H, Ar-H, CH), 9.41 (bs, $1 \mathrm{H}, \mathrm{NH}) .{ }^{13} \mathrm{C}-\mathrm{NMR}\left(100 \mathrm{MHz}, \mathrm{DMSO}-d_{6}\right) \delta$ ppm 42.9 $\left(\mathrm{CH}_{2}\right), 60.1\left(\mathrm{CH}_{2}\right), 118.4,122.8(\mathrm{Cq}), 124.9,125.7\left(\mathrm{q}, J_{\mathrm{CF}}=3.4 \mathrm{~Hz}\right), 128.3\left(\mathrm{q},{ }^{1} J_{\mathrm{CF}}=241.2 \mathrm{~Hz}, \mathrm{CF}_{3}\right), 129.3$, 129.9 (unresolved q), 130.0 (unresolved q, Cq), $136.0(\mathrm{Cq}), 139.0$ (Cq), 140.8 (Cq), $146.0(\mathrm{Cq}), 187.1$ (Cq). MS (70 eV) m/z (\%): 488 [M+1 (28), 458 (65), 445 (41), 97 (36), 69 (62), 57 (69), 43 (100). Anal. Calcd. $\mathrm{C}_{23} \mathrm{H}_{23} \mathrm{~F}_{3} \mathrm{~N}_{6} \mathrm{O}_{3}$ : C, 56.55; H, 4.75; N, 17.21; Found: C, 56.53; H, 4.71; N, 17.19 .

3.2.4. General Procedure for the Synthesis of 1-(3-(4-((4,6-bis((2-Hydroxyethyl) amino)-1,3,5-triazin-2-yl)amino)phenyl)-5-(aryl)-4,5-dihydro-1H-pyrazol-1-yl)ethanones 8a-g

A mixture of chalcone $7(0.48 \mathrm{mmol})$ and hydrazine monohydrate $(4.80 \mathrm{mmol})$ in ethanol $(1.0 \mathrm{~mL})$ was stirred at room temperature for $30 \mathrm{~min}$. Subsequently, acetic anhydride was added $(1.5 \mathrm{~mL})$ and the solution was stirred at room temperature for $3 \mathrm{~h}$. The solid obtained was filtered and washed with water. Purification of products was performed by column chromatography employing a mixture $\mathrm{CH}_{2} \mathrm{Cl}_{2} / \mathrm{EtOH}(20: 1)$ as eluent.

1-(3-(4-((4,6-bis((2-Hydroxyethyl)amino)-1,3,5-triazin-2-yl)amino)phenyl)-5-phenyl-4,5-dihydro-1H-pyrazol-1 -yl)ethanone (8a). Beige solid; $56 \%$ yield; m.p. $137-139^{\circ} \mathrm{C}$. FT-IR (ATR) v $\left(\mathrm{cm}^{-1}\right)$ Not observed $(\mathrm{N}-\mathrm{H})$, $3288(\mathrm{O}-\mathrm{H}), 3105(=\mathrm{C}-\mathrm{H}) 1612(\mathrm{C}=\mathrm{O}), 1587$ and $1560(\mathrm{C}=\mathrm{N}$ and $\mathrm{C}=\mathrm{C}) .{ }^{1} \mathrm{H}-\mathrm{NMR}\left(400 \mathrm{MHz}, \mathrm{DMSO}-d_{6}\right)$ $\delta$ ppm $2.29\left(\mathrm{~s}, 3 \mathrm{H}, \mathrm{CH}_{3}\right), 3.09(\mathrm{dd}, J=17.9,4.4 \mathrm{~Hz}, 1 \mathrm{H}, \mathrm{H}-4), 3.30-3.38\left(\mathrm{~m}, 4 \mathrm{H}, \mathrm{CH}_{2}\right), 3.47-3.55(\mathrm{~m}$, $\left.4 \mathrm{H}, \mathrm{CH}_{2}\right), 3.81(\mathrm{dd}, J=17.9,11.8 \mathrm{~Hz}, 1 \mathrm{H}, \mathrm{H}-4), 4.66(\mathrm{~s}, 2 \mathrm{H}, \mathrm{OH}), 5.51(\mathrm{dd}, J=11.8,4.4 \mathrm{~Hz}, 1 \mathrm{H}, \mathrm{H}-5)$, $6.65(\mathrm{bs}, 1 \mathrm{H}, \mathrm{NH}), 6.78(\mathrm{bs}, 1 \mathrm{H}, \mathrm{NH}), 7.17(\mathrm{~d}, J=7.3 \mathrm{~Hz}, 2 \mathrm{H}, \mathrm{Ar}-\mathrm{H}), 7.24(\mathrm{t}, J=7.3 \mathrm{~Hz}, 1 \mathrm{H}, \mathrm{Ar}-\mathrm{H})$, $7.32(\mathrm{t}, J=7.3 \mathrm{~Hz}, 2 \mathrm{H}, \mathrm{Ar}-\mathrm{H}), 7.64(\mathrm{~d}, J=8.7 \mathrm{~Hz}, 2 \mathrm{H}, \mathrm{Ar}-\mathrm{H}), 7.90(\mathrm{~d}, J=8.7 \mathrm{~Hz}, 2 \mathrm{H}, \mathrm{Ar}-\mathrm{H}), 9.17$ (bs, $1 \mathrm{H}, \mathrm{NH}) .{ }^{13} \mathrm{C}-\mathrm{NMR}\left(100 \mathrm{MHz}, \mathrm{DMSO}-d_{6}\right) \delta \mathrm{ppm} 21.7\left(\mathrm{CH}_{3}\right), 42.2\left(\mathrm{CH}_{2}\right), 42.8\left(\mathrm{CH}_{2}\right), 59.2,60.1\left(\mathrm{CH}_{2}\right)$, 118.9, 125.4, 127.0, 127.1, 128.6, $128.7(\mathrm{Cq}), 135.9(\mathrm{Cq}), 142.6(\mathrm{Cq}), 142.9(\mathrm{Cq}), 143.0(\mathrm{Cq}), 154.2(\mathrm{Cq})$, 167.1 (Cq). MS (70 eV) m/z (\%): 476 [M+1 ] (49), 446 (6), 434 (12), 405 (16), 55 (17), 43 (100). Anal. Calcd. $\mathrm{C}_{24} \mathrm{H}_{28} \mathrm{~N}_{8} \mathrm{O}_{3}$ : C, 60.49; H, 5.92; N, 23.51; Found: C, 60.44; H, 5.93; N, 22.98.

1-(3-(4-((4,6-bis((2-Hydroxyethyl)amino)-1,3,5-triazin-2-yl)amino)phenyl)-5-(p-tolyl)-4,5-dihydro-1H-pyrazol1-yl)ethanone (8b). Beige solid; $67 \%$ yield; m.p. $133-135{ }^{\circ} \mathrm{C}$. FT-IR (ATR) v $\left(\mathrm{cm}^{-1}\right)$ Not observed $(\mathrm{N}-\mathrm{H}), 3288(\mathrm{O}-\mathrm{H}), 3106(=\mathrm{C}-\mathrm{H}), 1611(\mathrm{C}=\mathrm{O}), 1562$ and $1514(\mathrm{C}=\mathrm{N}$ and $\mathrm{C}=\mathrm{C}) .{ }^{1} \mathrm{H}-\mathrm{NMR}(400 \mathrm{MHz}$, DMSO- $\left.d_{6}\right) \delta$ ppm $2.25\left(\mathrm{~s}, 3 \mathrm{H}, \mathrm{CH}_{3}\right), 2.28\left(\mathrm{~s}, 3 \mathrm{H}, \mathrm{CH}_{3}\right), 3.06(\mathrm{dd}, J=17.9,4.2 \mathrm{~Hz}, 1 \mathrm{H}, \mathrm{H}-4), 3.23-3.39$ (m, $\left.4 \mathrm{H}, \mathrm{CH}_{2}\right), 3.46-3.57\left(\mathrm{~m}, 4 \mathrm{H}, \mathrm{CH}_{2}\right), 3.78(\mathrm{dd}, J=17.9,11.7 \mathrm{~Hz}, 1 \mathrm{H}, \mathrm{H}-4), 4.74(\mathrm{bs}, 2 \mathrm{H}, \mathrm{OH}), 5.46(\mathrm{dd}$, $J=11.7,4.2 \mathrm{~Hz}, 1 \mathrm{H}, \mathrm{H}-5), 6.65(\mathrm{bs}, 1 \mathrm{H}, \mathrm{NH}), 6.78(\mathrm{bs}, 1 \mathrm{H}, \mathrm{NH}), 7.05(\mathrm{~d}, J=8.0 \mathrm{~Hz}, 2 \mathrm{H}, \mathrm{Ar}-\mathrm{H}), 7.12(\mathrm{~d}$, $J=8.0 \mathrm{~Hz}, 2 \mathrm{H}, \mathrm{Ar}-\mathrm{H}), 7.63(\mathrm{~d}, J=8.6 \mathrm{~Hz}, 2 \mathrm{H}, \mathrm{Ar}-\mathrm{H}), 7.90(\mathrm{~d}, J=8.6 \mathrm{~Hz}, 2 \mathrm{H}, \mathrm{Ar}-\mathrm{H}), 9.17(\mathrm{bs}, 1 \mathrm{H}$, $\mathrm{NH}) .{ }^{13} \mathrm{C}-\mathrm{NMR}\left(100 \mathrm{MHz}, \mathrm{DMSO}-d_{6}\right) \delta \mathrm{ppm} 21.1\left(\mathrm{CH}_{3}\right), 22.2\left(\mathrm{CH}_{3}\right), 42.6\left(\mathrm{CH}_{2}\right), 43.3\left(\mathrm{CH}_{2}\right), 59.5$, $60.6\left(\mathrm{CH}_{2}\right), 119.4,124.0(\mathrm{Cq}), 125.9,127.5,129.6,136.4(\mathrm{Cq}), 136.8(\mathrm{Cq}), 140.1(\mathrm{Cq}), 143.3(\mathrm{Cq}), 143.4(\mathrm{Cq})$, 154.7 (Cq), $167.6(\mathrm{Cq})$. MS (70 eV) m/z (\%): 490 [M+1 $(100), 448$ (29), 419 (26), 208 (5), 43 (60). Anal. Calcd. $\mathrm{C}_{25} \mathrm{H}_{30} \mathrm{~N}_{8} \mathrm{O}_{3}: \mathrm{C}, 61.21 ; \mathrm{H}, 6.16 ; \mathrm{N}, 22.84$; Found: $\mathrm{C}, 61.26 ; \mathrm{H}, 6.20 ; \mathrm{N}, 22.79$.

1-(3-(4-((4,6-bis((2-Hydroxyethyl)amino)-1,3,5-triazin-2-yl)amino)phenyl)-5-(4-methoxyphenyl)-4,5-dihydro1H-pyrazol-1-yl)ethanone (8c). Beige solid; yield 62\%; m.p. $136-138{ }^{\circ} \mathrm{C}$. FT-IR (ATR) v $\left(\mathrm{cm}^{-1}\right.$ ) $3312(\mathrm{~N}-\mathrm{H}), 3296(\mathrm{O}-\mathrm{H}), 3103(=\mathrm{C}-\mathrm{H}), 1611(\mathrm{C}=\mathrm{O}), 1587(\mathrm{C}=\mathrm{N}), 1560(\mathrm{C}=\mathrm{C})$ and $1240(\mathrm{C}-\mathrm{O}) .{ }^{1} \mathrm{H}-\mathrm{NMR}$ $\left(400 \mathrm{MHz}, \mathrm{DMSO}-d_{6}\right) \delta \mathrm{ppm} 2.27\left(\mathrm{~s}, 3 \mathrm{H}, \mathrm{CH}_{3}\right), 3.07(\mathrm{dd}, J=17.9,3.9 \mathrm{~Hz}, 1 \mathrm{H}, \mathrm{H}-4), 3.26-3.40(\mathrm{~m}, 4 \mathrm{H}$, $\left.\mathrm{CH}_{2}\right), 3.47-3.56\left(\mathrm{~m}, 4 \mathrm{H}, \mathrm{CH}_{2}\right), 3.71\left(\mathrm{~s}, 3 \mathrm{H}, \mathrm{OCH}_{3}\right), 3.77(\mathrm{dd}, J=17.9,11.6 \mathrm{~Hz}, 1 \mathrm{H}, \mathrm{H}-4), 4.69(\mathrm{~s}, 2 \mathrm{H}, \mathrm{OH})$, $5.45(\mathrm{dd}, J=11.6,3.9 \mathrm{~Hz}, 1 \mathrm{H}, \mathrm{H}-5), 6.65(\mathrm{bs}, 1 \mathrm{H}, \mathrm{NH}), 6.78(\mathrm{bs}, 1 \mathrm{H}, \mathrm{NH}), 6.87(\mathrm{~d}, J=8.4 \mathrm{~Hz}, 2 \mathrm{H}, \mathrm{Ar}-\mathrm{H})$, $7.10(\mathrm{~d}, J=8.4 \mathrm{~Hz}, 2 \mathrm{H}, \mathrm{Ar}-\mathrm{H}), 7.64(\mathrm{~d}, J=8.5 \mathrm{~Hz}, 2 \mathrm{H}, \mathrm{Ar}-\mathrm{H}), 7.90(\mathrm{~d}, J=8.5 \mathrm{~Hz}, 2 \mathrm{H}, \mathrm{Ar}-\mathrm{H}), 9.17$ (bs, $1 \mathrm{H}, \mathrm{NH}) .{ }^{13} \mathrm{C}-\mathrm{NMR}\left(100 \mathrm{MHz}, \mathrm{DMSO}-d_{6}\right) \delta \mathrm{ppm} 21.8\left(\mathrm{CH}_{3}\right), 42.1\left(\mathrm{CH}_{2}\right), 42.9\left(\mathrm{CH}_{2}\right), 55.1\left(\mathrm{CH}_{3}\right), 58.7$, $60.1\left(\mathrm{CH}_{2}\right), 114.0,119.0,123.6(\mathrm{Cq}), 126.8,127.1,134.7(\mathrm{Cq}), 136.0(\mathrm{Cq}), 142.9(\mathrm{Cq}), 143.0(\mathrm{Cq}) 154.3(\mathrm{Cq})$, 158.4 (Cq), 167.1 (Cq). MS (70 eV) m/z (\%): 506 [M+1 (100), 464 (28), 435 (22), 316 (12), 134 (14), 43 (70). Anal. Calcd. $\mathrm{C}_{25} \mathrm{H}_{30} \mathrm{~N}_{8} \mathrm{O}_{4}$ : C, 59.28; H, 5.97; N, 22.12; Found: C, 59.24; $\mathrm{H}, 6.01 ; \mathrm{N}, 22.14$.

1-(3-(4-((4,6-bis((2-Hydroxyethyl)amino)-1,3,5-triazin-2-yl)amino)phenyl)-5-(3,4,5-trimethoxyphenyl)-4,5dihydro-1H-pyrazol-1-yl)ethanone (8d). Beige solid; $75 \%$ yield; m.p. $134-136{ }^{\circ}$ C. FT-IR (ATR) v $\left(\mathrm{cm}^{-1}\right.$ ) 
$3422(\mathrm{~N}-\mathrm{H}), 3289(\mathrm{O}-\mathrm{H}), 3196(=\mathrm{C}-\mathrm{H}), 1699(\mathrm{C}=\mathrm{O}), 1647(\mathrm{C}=\mathrm{N}) 1560(\mathrm{C}=\mathrm{C})$ and $1278(\mathrm{C}-\mathrm{O}) .{ }^{1} \mathrm{H}-\mathrm{NMR}$ $\left(400 \mathrm{MHz}, \mathrm{DMSO}-d_{6}\right) \delta$ ppm $2.31\left(\mathrm{~s}, 3 \mathrm{H}, \mathrm{CH}_{3}\right), 3.12(\mathrm{dd}, J=17.9,4.5 \mathrm{~Hz}, 1 \mathrm{H}, \mathrm{H}-4), 3.29-3.40(\mathrm{~m}, 4 \mathrm{H}$, $\left.\mathrm{CH}_{2}\right), 3.46-3.57\left(\mathrm{~m}, 4 \mathrm{H}, \mathrm{CH}_{2}\right), 3.62\left(\mathrm{~s}, 3 \mathrm{H}, \mathrm{OCH}_{3}\right), 3.73\left(\mathrm{~s}, 6 \mathrm{H}, \mathrm{OCH}_{3}\right), 3.79(\mathrm{dd}, J=17.9 \mathrm{~Hz}, 11.4 \mathrm{~Hz}$, 1H, H-4), 4.67 (s, 2H, OH), 5.45 (dd, J = 11.4, $4.5 \mathrm{~Hz}, 1 \mathrm{H}, \mathrm{H}-5), 6.45$ (s, 2H, Ar-H), 6.65 (bs, 1H, NH), $6.78(\mathrm{bs}, 1 \mathrm{H}, \mathrm{NH}), 7.63(\mathrm{~d}, J=8.6 \mathrm{~Hz}, 2 \mathrm{H}, \mathrm{Ar}-\mathrm{H}), 7.90(\mathrm{~d}, J=8.6 \mathrm{~Hz}, 2 \mathrm{H}, \mathrm{Ar}-\mathrm{H}), 9.17$ (bs, $1 \mathrm{H}, \mathrm{NH})$. ${ }^{13} \mathrm{C}$ - NMR $\left(100 \mathrm{MHz}\right.$, DMSO-d $\left.d_{6}\right) \delta$ ppm $22.0\left(\mathrm{CH}_{3}\right), 42.5\left(\mathrm{CH}_{2}\right), 43.0\left(\mathrm{CH}_{2}\right), 56.1\left(\mathrm{CH}_{3}\right), 59.7,60.1\left(\mathrm{CH}_{3}\right)$, $60.3\left(\mathrm{CH}_{2}\right), 102.7,119.1,123.8(\mathrm{Cq}), 127.3,136.1(\mathrm{Cq}), 136.7(\mathrm{Cq}), 138.6(\mathrm{Cq}), 143.1(\mathrm{Cq}), 143.2(\mathrm{Cq})$, $153.3(\mathrm{Cq}), 154.4(\mathrm{Cq}), 167.6(\mathrm{Cq})$. MS (70 eV) m/z (\%): 566 [M+1 ] (41), 524 (8), 496 (13), 481 (9), 251 (9), 43 (100). Anal. Calcd. $\mathrm{C}_{27} \mathrm{H}_{34} \mathrm{~N}_{8} \mathrm{O}_{6}$ : C, 57.23; H, 6.05; N, 19.78; Found: C, 57.29; H, 6.03; N, 19.80.

1-(3-(4-((4,6-bis((2-Hydroxyethyl)amino)-1,3,5-triazin-2-yl)amino)phenyl)-5-(4-chlorophenyl)-4,5-dihydro-1Hpyrazol-1-yl)ethanone (8e). Beige solid; 86\% yield; m.p. $174-176{ }^{\circ} \mathrm{C}$. FT-IR (ATR) v $\left(\mathrm{cm}^{-1}\right) 3443(\mathrm{~N}-\mathrm{H})$, $3288(\mathrm{O}-\mathrm{H}), 3104(=\mathrm{C}-\mathrm{H}), 1647(\mathrm{C}=\mathrm{O}), 1598$ and $1547(\mathrm{C}=\mathrm{N}$ and $\mathrm{C}=\mathrm{C}) .{ }^{1} \mathrm{H}-\mathrm{NMR}$ (400 MHz, DMSO- $\left.d_{6}\right)$ $\delta$ ppm $2.28\left(\mathrm{~s}, 3 \mathrm{H}, \mathrm{CH}_{3}\right), 3.10(\mathrm{dd}, J=18.0,4.6 \mathrm{~Hz}, 1 \mathrm{H}, \mathrm{H}-4), 3.28-3.36\left(\mathrm{~m}, 4 \mathrm{H}, \mathrm{CH}_{2}\right), 3.46-3.55(\mathrm{~m}$, $\left.4 \mathrm{H}, \mathrm{CH}_{2}\right), 3.81(\mathrm{dd}, J=18.0,11.8 \mathrm{~Hz}, 1 \mathrm{H}, \mathrm{H}-4), 4.76(\mathrm{bs}, 2 \mathrm{H}, \mathrm{OH}), 5.51(\mathrm{dd}, J=11.8,4.6 \mathrm{~Hz}, 1 \mathrm{H}$, H-5), 6.65 (bs, 1H, NH), 6.79 (bs, 1H, NH), $7.21(\mathrm{~d}, J=8.5 \mathrm{~Hz}, 2 \mathrm{H}, \mathrm{Ar}-\mathrm{H}), 7.38(\mathrm{~d}, J=8.5 \mathrm{~Hz}, 2 \mathrm{H}$, Ar-H), $7.64(\mathrm{~d}, J=8.0 \mathrm{~Hz}, 2 \mathrm{H}, \mathrm{Ar}-\mathrm{H}), 7.90(\mathrm{~d}, J=8.0 \mathrm{~Hz}, 2 \mathrm{H}, \mathrm{Ar}-\mathrm{H}), 9.18$ (bs, 1H, NH). ${ }^{13} \mathrm{C}-\mathrm{NMR}$ $\left(100 \mathrm{MHz}, \mathrm{DMSO}-d_{6}\right) \delta \mathrm{ppm} 21.7\left(\mathrm{CH}_{3}\right), 42.0\left(\mathrm{CH}_{2}\right), 42.9\left(\mathrm{CH}_{2}\right), 58.7,60.1\left(\mathrm{CH}_{2}\right), 118.9,127.1,127.5$, 128.6, $131.7(\mathrm{Cq}), 136.0(\mathrm{Cq}), 141.5(\mathrm{Cq}), 141.6(\mathrm{Cq}), 154.2(\mathrm{Cq}), 163.9(\mathrm{Cq}), 165.9(\mathrm{Cq}), 167.3(\mathrm{Cq})$. MS (70 eV) $m / z(\%): 510: 512\left[\mathrm{M}^{+}\right]:[\mathrm{M}+2]^{+}(18 / 6), 468$ (46), 440 (100), 55 (22), 43 (39). Anal. Calcd. $\mathrm{C}_{24} \mathrm{H}_{27} \mathrm{ClN}_{8} \mathrm{O}_{3}: \mathrm{C}, 56.41 ; \mathrm{H}, 5.33 ; \mathrm{N}, 21.93$; Found: C, 56.47; H, 5.38; N, 21.99.

1-(3-(4-((4,6-bis((2-Hydroxyethyl)amino)-1,3,5-triazin-2-yl)amino)phenyl)-5-(4-fluorophenyl)-4,5-dihydro-1Hpyrazol-1-yl)ethanone (8f). Beige solid; $55 \%$ yield; m.p. $132-134^{\circ} \mathrm{C}$. FT-IR (ATR) v $\left(\mathrm{cm}^{-1}\right)$ Not observed $(\mathrm{N}-\mathrm{H}), 3292(\mathrm{O}-\mathrm{H}), 3108(=\mathrm{C}-\mathrm{H}), 1645(\mathrm{C}=\mathrm{O}), 1602$ and $1568(\mathrm{C}=\mathrm{N}$ and $\mathrm{C}=\mathrm{C}) .{ }^{1} \mathrm{H}-\mathrm{NMR}(400 \mathrm{MHz}$, DMSO- $\left.d_{6}\right) \delta$ ppm $2.28\left(\mathrm{~s}, 3 \mathrm{H}, \mathrm{CH}_{3}\right), 3.10(\mathrm{dd}, J=17.9,4.4 \mathrm{~Hz}, 1 \mathrm{H}, \mathrm{H}-4), 3.28-3.38\left(\mathrm{~m}, 4 \mathrm{H}, \mathrm{CH}_{2}\right)$, 3.47-3.55 (m, 4H, CH 2$), 3.80(\mathrm{dd}, J=17.9,11.7 \mathrm{~Hz}, 1 \mathrm{H}, \mathrm{H}-4), 4.66(\mathrm{~s}, 2 \mathrm{H}, \mathrm{OH}), 5.52(\mathrm{dd}, J=11.7,4.4 \mathrm{~Hz}$, $1 \mathrm{H}, \mathrm{H}-5), 6.65$ (bs, $1 \mathrm{H}, \mathrm{NH}), 6.78(\mathrm{bs}, 1 \mathrm{H}, \mathrm{NH}), 7.14(\mathrm{t}, J=8.5 \mathrm{~Hz}, 2 \mathrm{H}, \mathrm{Ar}-\mathrm{H}), 7.22(\mathrm{dd}, J=8.5 \mathrm{~Hz}$ and $\left.\mathrm{J}_{\mathrm{HF}}=5.6 \mathrm{~Hz}, 2 \mathrm{H}, \mathrm{Ar}-\mathrm{H}\right), 7.64(\mathrm{~d}, J=8.6 \mathrm{~Hz}, 2 \mathrm{H}, \mathrm{Ar}-\mathrm{H}), 7.90(\mathrm{~d}, J=8.6 \mathrm{~Hz}, 2 \mathrm{H}, \mathrm{Ar}-\mathrm{H}), 9.17(\mathrm{bs}$, $1 \mathrm{H}, \mathrm{NH}) .{ }^{13} \mathrm{C}-\mathrm{NMR}\left(100 \mathrm{MHz}, \mathrm{DMSO}-d_{6}\right) \delta \mathrm{ppm} 21.7\left(\mathrm{CH}_{3}\right), 42.0\left(\mathrm{CH}_{2}\right), 42.8\left(\mathrm{CH}_{2}\right), 58.5,60.1\left(\mathrm{CH}_{2}\right)$, $115.3\left(\mathrm{~d},{ }^{2} J_{\mathrm{CF}}=21.4 \mathrm{~Hz}\right), 118.9,127.0$ (unresolved d), $127.6\left(\mathrm{~d},{ }^{3} J_{\mathrm{CF}}=8.2 \mathrm{~Hz}\right), 135.9(\mathrm{Cq}), 138.7(\mathrm{Cq})$, $142.9(\mathrm{Cq}), 147.0(\mathrm{Cq}), 154.1(\mathrm{Cq}), 161.2\left(\mathrm{~d},{ }^{1} \mathrm{~J}_{\mathrm{CF}}=242.7 \mathrm{~Hz}, \mathrm{C}-\mathrm{F}\right), 165.9(\mathrm{Cq}), 167.1(\mathrm{C}=\mathrm{O}) . \mathrm{MS}(70 \mathrm{eV})$ $m / z(\%): 494\left[\mathrm{M}^{+}\right]$(25), 423 (7), 210 (5), 60 (14), 69 (5), 43 (100). Anal. Calcd. $\mathrm{C}_{24} \mathrm{H}_{27} \mathrm{FN}_{8} \mathrm{O}_{3}: \mathrm{C}, 58.29 ; \mathrm{H}$, 5.50; N, 22.66; Found: C, 58.35; H, 5.58; N, 22.64.

1-(3-(4-((4,6-bis((2-Hydroxyethyl)amino)-1,3,5-triazin-2-yl)amino)phenyl)-5-(4-(trifluoromethyl)phenyl)-4,5dihydro-1H-pyrazol-1-yl)ethanone (8g). Beige solid; $66 \%$ yield; m.p. $136-138^{\circ} \mathrm{C}$. FT-IR (ATR) v $\left(\mathrm{cm}^{-1}\right)$ $3385(\mathrm{~N}-\mathrm{H}), 3290(\mathrm{O}-\mathrm{H}), 3103(=\mathrm{C}-\mathrm{H}), 1647(\mathrm{C}=\mathrm{O}), 1598$ and $1570(\mathrm{C}=\mathrm{N}$ and $\mathrm{C}=\mathrm{C}) .{ }^{1} \mathrm{H}-\mathrm{NMR}(400 \mathrm{MHz}$, DMSO- $\left.d_{6}\right) \delta$ ppm $2.30\left(\mathrm{~s}, 3 \mathrm{H}, \mathrm{CH}_{3}\right), 3.14(\mathrm{dd}, J=18.0,4.8 \mathrm{~Hz}, 1 \mathrm{H}, \mathrm{H}-4), 3.26-3.38\left(\mathrm{~m}, 4 \mathrm{H}, \mathrm{CH}_{2}\right)$, 3.47-3.55 (m, 4H, $\left.\mathrm{CH}_{2}\right), 3.85(\mathrm{dd}, J=18.0,11.9 \mathrm{~Hz}, 1 \mathrm{H}, \mathrm{H}-4), 4.66(\mathrm{~s}, 2 \mathrm{H}, \mathrm{OH}), 5.60(\mathrm{dd}, J=11.9,4.8 \mathrm{~Hz}$, $1 \mathrm{H}, \mathrm{H}-5), 6.66(\mathrm{bs}, 1 \mathrm{H}, \mathrm{NH}), 6.79(\mathrm{bs}, 1 \mathrm{H}, \mathrm{NH}), 7.41(\mathrm{~d}, J=8.1 \mathrm{~Hz}, 2 \mathrm{H}, \mathrm{Ar}-\mathrm{H}), 7.64(\mathrm{~d}, J=8.1 \mathrm{~Hz}, 2 \mathrm{H}$, Ar-H), 7.69 (d, $J=8.5 \mathrm{~Hz}, 2 \mathrm{H}, \mathrm{Ar}-\mathrm{H}), 7.91(\mathrm{~d}, J=8.5 \mathrm{~Hz}, 2 \mathrm{H}, \mathrm{Ar}-\mathrm{H}), 9.18$ (bs, 1H, NH). ${ }^{13} \mathrm{C}-\mathrm{NMR}$ $\left(100 \mathrm{MHz}, \mathrm{DMSO}-d_{6}\right) \delta$ ppm $21.7\left(\mathrm{CH}_{3}\right), 42.0\left(\mathrm{CH}_{2}\right), 42.8\left(\mathrm{CH}_{2}\right), 59.0,60.1\left(\mathrm{CH}_{2}\right), 119.0,122.9(\mathrm{Cq})$, $123.4(\mathrm{Cq}), 125.6\left(\mathrm{q},{ }^{3} J_{\mathrm{CF}}=3.6 \mathrm{~Hz}\right), 125.7\left(\mathrm{q},{ }^{1} J_{\mathrm{CF}}=237.3 \mathrm{~Hz}, \mathrm{CF}_{3}\right), 125.8(\mathrm{Cq}), 126.5,127.2$ (unresolved q), $127.9\left(\mathrm{q},{ }^{2} J_{\mathrm{CF}}=31.8 \mathrm{~Hz}, \mathrm{Cq}\right), 143.0(\mathrm{Cq}), 147.1(\mathrm{Cq}), 154.3(\mathrm{Cq}), 167.4(\mathrm{C}=\mathrm{O})$. MS (70 eV) $\mathrm{m} / \mathrm{z}(\%)$ : $544\left[\mathrm{M}^{+}\right]$(96), $513(20), 473(21), 458$ (10), 43 (100). Anal. Calcd. $\mathrm{C}_{25} \mathrm{H}_{27} \mathrm{~F}_{3} \mathrm{~N}_{8} \mathrm{O}_{3}: \mathrm{C}, 55.14 ; \mathrm{H}, 5.00 ; \mathrm{N}$, 20.58; Found: C, 55.18; H, 4.96; N, 20.53. 
3.2.5. General Procedure for the Synthesis of 5-(4-((4,6-bis((2-Hydroxyethyl) amino)-1,3,5-triazin-2-yl)amino)phenyl)-3-(aryl)-4,5-dihydro-1 $H$-pyrazol-1-carbaldehydes 9a-g

$\mathrm{N}$-Formylpyrazolines $\mathbf{9 a -} \mathbf{g}$ were synthesized using a similar methodology for obtaining $\mathrm{N}$-acetyl pyrazolines $\mathbf{8 a}-\mathbf{g}$, but formic acid was used instead of acetic anhydride. The solid obtained was filtered and washed with water. No further purification was required.

3-(4-((4,6-bis((2-Hydroxyethyl)amino)-1,3,5-triazin-2-yl)amino)phenyl)-5-phenyl-4,5-dihydro-1H-pyrazole-1carbaldehyde (9a). White solid; 93\% yield; m.p. $163-166^{\circ} \mathrm{C}$. FT-IR (ATR) v $\left(\mathrm{cm}^{-1}\right)$ Not observed $(\mathrm{N}-\mathrm{H})$, $3273(\mathrm{O}-\mathrm{H}), 3101(=\mathrm{C}-\mathrm{H}), 1649(\mathrm{C}=\mathrm{O}), 1593$ and $1564(\mathrm{C}=\mathrm{N}$ and $\mathrm{C}=\mathrm{C}) .{ }^{1} \mathrm{H}-\mathrm{NMR}\left(400 \mathrm{MHz}, \mathrm{DMSO}-d_{6}\right)$ $\delta$ ppm $3.15(\mathrm{dd}, J=18.0,4.7 \mathrm{~Hz}, 1 \mathrm{H}, \mathrm{H}-4), 3.26-3.40\left(\mathrm{~m}, 4 \mathrm{H}, \mathrm{CH}_{2}\right), 3.44-3.56\left(\mathrm{~m}, 4 \mathrm{H}, \mathrm{CH}_{2}\right), 3.68$ (bs, $2 \mathrm{H}, \mathrm{OH}), 3.88(\mathrm{dd}, J=18.0,11.7 \mathrm{~Hz}, 1 \mathrm{H}, \mathrm{H}-4), 5.50(\mathrm{dd}, J=11.7,4.7 \mathrm{~Hz}, 1 \mathrm{H}, \mathrm{H}-5), 6.66(\mathrm{bs}, 1 \mathrm{H}, \mathrm{NH})$, 6.79 (bs, 1H, NH), 7.30-7.20 (m, 3H, Ar-H), 7.31-7.37 (m, 2H, Ar-H), $7.65(\mathrm{~d}, J=8.8 \mathrm{~Hz}, 2 \mathrm{H}, \mathrm{Ar}-\mathrm{H})$, $7.91(\mathrm{~d}, J=8.8 \mathrm{~Hz}, 2 \mathrm{H}, \mathrm{Ar}-\mathrm{H}), 8.86(\mathrm{~s}, 1 \mathrm{H}, \mathrm{CHO}), 9.20(\mathrm{bs}, 1 \mathrm{H}, \mathrm{NH}) .{ }^{13} \mathrm{C}-\mathrm{NMR}\left(100 \mathrm{MHz}, \mathrm{DMSO}-d_{6}\right) \delta$ ppm $42.2\left(\mathrm{CH}_{2}\right), 42.7\left(\mathrm{CH}_{2}\right), 58.1,59.9\left(\mathrm{CH}_{2}\right), 118.7,125.5,126.9,127.2,127.4(\mathrm{Cq}), 128.5,130.4(\mathrm{Cq})$, $135.7(\mathrm{Cq}), 141.2(\mathrm{Cq}), 142.94(\mathrm{Cq}), 156.0(\mathrm{Cq}), 159.2 . \mathrm{MS}(70 \mathrm{eV}) \mathrm{m} / z(\%): 462\left[\mathrm{M}^{+}\right](100), 434(64)$, 406 (19), 91 (36), 69 (39), 43 (64). Anal. Calcd. $\mathrm{C}_{23} \mathrm{H}_{26} \mathrm{~N}_{8} \mathrm{O}_{3}: \mathrm{C}, 59.73 ; \mathrm{H}, 5.67 ; \mathrm{N}, 24.23$; Found: $\mathrm{C}, 59.80$; $\mathrm{H}, 6.00 ; \mathrm{N}, 24.27$.

3-(4-((4,6-bis((2-Hydroxyethyl)amino)-1,3,5-triazin-2-yl)amino)phenyl)-5-(p-tolyl)-4,5-dihydro-1H-pyrazole-1 -carbaldehyde $9 \mathrm{~b}$. White solid; $60 \%$ yield; m.p. $167-170{ }^{\circ} \mathrm{C}$. FT-IR (ATR) v $\left(\mathrm{cm}^{-1}\right)$ Not observed $(\mathrm{N}-\mathrm{H})$, $3269(\mathrm{O}-\mathrm{H}), 3108(=\mathrm{C}-\mathrm{H}), 1672(\mathrm{C}=\mathrm{O}), 1647$ and $1593(\mathrm{C}=\mathrm{N}$ and $\mathrm{C}=\mathrm{C}) .{ }^{1} \mathrm{H}-\mathrm{NMR}\left(400 \mathrm{MHz}, \mathrm{DMSO}-d_{6}\right)$ $\delta$ ppm $2.26\left(\mathrm{~s}, 3 \mathrm{H}, \mathrm{CH}_{3}\right), 3.12(\mathrm{dd}, J=18.0,4.6 \mathrm{~Hz}, 1 \mathrm{H}, \mathrm{H}-4), 3.26-3.39\left(\mathrm{~m}, 4 \mathrm{H}, \mathrm{CH}_{2}\right), 3.46-3.55(\mathrm{~m}$, $\left.4 \mathrm{H}, \mathrm{CH}_{2}\right), 3.85(\mathrm{dd}, J=18.0,11.6 \mathrm{~Hz}, 1 \mathrm{H}, \mathrm{H}-4), 3.93$ (bs, 2H, OH), 5.45 (dd, $\left.J=11.6,4.6 \mathrm{~Hz}, 1 \mathrm{H}, \mathrm{H}-5\right)$, $6.66(\mathrm{bs}, 1 \mathrm{H}, \mathrm{NH}), 6.79(\mathrm{bs}, 1 \mathrm{H}, \mathrm{NH}), 7.06-7.17(\mathrm{~m}, 4 \mathrm{H}, \mathrm{Ar}-\mathrm{H}), 7.64(\mathrm{~d}, J=8.7 \mathrm{~Hz}, 2 \mathrm{H}, \mathrm{Ar}-\mathrm{H}), 7.90(\mathrm{~d}$, $J=8.7 \mathrm{~Hz}, 2 \mathrm{H}, \mathrm{Ar}-\mathrm{H}), 8.84(\mathrm{~s}, 1 \mathrm{H}, \mathrm{CHO}), 9.19$ (bs, 1H, NH). ${ }^{13} \mathrm{C}-\mathrm{NMR}\left(100 \mathrm{MHz}\right.$, DMSO-d $\left.d_{6}\right) \delta \mathrm{ppm}$ $20.7\left(\mathrm{CH}_{3}\right), 42.4\left(\mathrm{CH}_{2}\right), 43.0\left(\mathrm{CH}_{2}\right), 58.1,60.1\left(\mathrm{CH}_{2}\right), 118.9,125.6,127.2,129.3,122.2(\mathrm{Cq}), 122.3(\mathrm{Cq})$, $136.7(\mathrm{Cq}), 138.6(\mathrm{Cq}), 143.1(\mathrm{Cq}), 156.1(\mathrm{Cq}), 159.3(\mathrm{Cq}), 163.7 . \mathrm{MS}(70 \mathrm{eV}) \mathrm{m} / z(\%): 476\left[\mathrm{M}^{+}\right](100)$, 448 (58), 420 (22), 118 (29), 91 (33), 43 (41). Anal. Calcd. $\mathrm{C}_{24} \mathrm{H}_{28} \mathrm{~N}_{8} \mathrm{O}_{3}$ : C, 60.49; H, 5.92; N, 23.51; Found: C, 60.53; H, 6.04; N, 23.53 .

3-(4-((4,6-bis((2-Hydroxyethyl)amino)-1,3,5-triazin-2-yl)amino)phenyl)-5-(4-methoxyphenyl)-4,5-dihydro-1Hpyrazole-1-carbaldehyde $9 \mathrm{c}$. White solid; $91 \%$ yield; m.p. $156-157^{\circ} \mathrm{C}$. FT-IR (ATR) v $\left(\mathrm{cm}^{-1}\right)$ Not observed $(\mathrm{N}-\mathrm{H}), 3228(\mathrm{O}-\mathrm{H}), 3101(=\mathrm{C}-\mathrm{H}), 1674(\mathrm{C}=\mathrm{O}), 1643(\mathrm{C}=\mathrm{N}), 1593(\mathrm{C}=\mathrm{C})$ and $1249(\mathrm{C}-\mathrm{O}) .{ }^{1} \mathrm{H}-\mathrm{NMR}$ $\left(400 \mathrm{MHz}, \mathrm{DMSO}-d_{6}\right) \delta \mathrm{ppm} 3.14(\mathrm{dd}, J=18.0,4.6 \mathrm{~Hz}, 1 \mathrm{H}, \mathrm{H}-4), 3.27-3.38\left(\mathrm{~m}, 4 \mathrm{H}, \mathrm{CH}_{2}\right), 3.51-3.55$ $\left(\mathrm{m}, 4 \mathrm{H}, \mathrm{CH}_{2}\right), 3.72\left(\mathrm{~s}, 3 \mathrm{H}, \mathrm{OCH}_{3}\right), 3.84(\mathrm{dd}, J=18.0,11.6 \mathrm{~Hz}, 1 \mathrm{H}, \mathrm{H}-4), 3.99(\mathrm{~s}, 2 \mathrm{H}, \mathrm{OH}), 5.44(\mathrm{dd}$, $J=11.6,4.6 \mathrm{~Hz}, 1 \mathrm{H}, \mathrm{H}-5), 6.66(\mathrm{bs}, 1 \mathrm{H}, \mathrm{NH}), 6.78(\mathrm{bs}, 1 \mathrm{H}, \mathrm{NH}), 6.89(\mathrm{~d}, J=8.7 \mathrm{~Hz}, 2 \mathrm{H}, \mathrm{Ar}-\mathrm{H}), 7.14(\mathrm{~d}$, $J=8.7 \mathrm{~Hz}, 2 \mathrm{H}, \mathrm{Ar}-\mathrm{H}), 7.64(\mathrm{~d}, J=8.8 \mathrm{~Hz}, 2 \mathrm{H}, \mathrm{Ar}-\mathrm{H}), 7.91(\mathrm{~d}, J=8.8 \mathrm{~Hz}, 2 \mathrm{H}, \mathrm{Ar}-\mathrm{H}), 8.83(\mathrm{~s}, 1 \mathrm{H}, \mathrm{CHO})$, 9.19 (bs, $1 \mathrm{H}, \mathrm{NH}) .{ }^{13} \mathrm{C}-\mathrm{NMR}\left(100 \mathrm{MHz}, \mathrm{DMSO}-d_{6}\right) \delta \mathrm{ppm} 42.3\left(\mathrm{CH}_{2}\right), 42.8\left(\mathrm{CH}_{2}\right), 55.1\left(\mathrm{CH}_{3}\right), 57.8$, $60.1\left(\mathrm{CH}_{2}\right), 114.1,118.9,123.2(\mathrm{Cq}), 127.0,127.2,127.3(\mathrm{Cq}), 133.5(\mathrm{Cq}), 156.1(\mathrm{Cq}), 158.6(\mathrm{Cq}), 159.3 . \mathrm{MS}$ (70 eV) $m / z(\%): 492\left[\mathrm{M}^{+}\right]$(27), 464 (35), 436 (100), 405 (41), 361 (31), 43 (36). Anal. Calcd. $\mathrm{C}_{24} \mathrm{H}_{28} \mathrm{~N}_{8} \mathrm{O}_{4}$ : C, 58.53; H, 5.73; N, 22.75; Found: C, 58.50; H, 5.75; N, 22.70.

3-(4-((4,6-bis((2-Hydroxyethyl)amino)-1,3,5-triazin-2-yl)amino)phenyl)-5-(3,4,5-trimethoxyphenyl)-4,5-dihydro -1H-pyrazole-1-carbaldehyde (9d). White solid; $40 \%$ yield; m.p. $154-156{ }^{\circ} \mathrm{C}$. FT-IR (ATR) v $\left(\mathrm{cm}^{-1}\right) 3483$ $(\mathrm{N}-\mathrm{H}), 3298(\mathrm{O}-\mathrm{H}), 3102(=\mathrm{C}-\mathrm{H}), 1662(\mathrm{C}=\mathrm{O}), 1583(\mathrm{C}=\mathrm{N}), 1562(\mathrm{C}=\mathrm{C})$ and $1234(\mathrm{C}-\mathrm{O}) .{ }^{1} \mathrm{H}-\mathrm{NMR}$ $\left(400 \mathrm{MHz}, \mathrm{DMSO}-d_{6}\right) \delta \mathrm{ppm} 3.18(\mathrm{dd}, J=18.0,5.1 \mathrm{~Hz}, 1 \mathrm{H}, \mathrm{H}-4), 3.29-3.44\left(\mathrm{~m}, 4 \mathrm{H}, \mathrm{CH}_{2}\right), 3.48-3.54(\mathrm{~m}$, $\left.4 \mathrm{H}, \mathrm{CH}_{2}\right), 3.63\left(\mathrm{~s}, 3 \mathrm{H}, \mathrm{OCH}_{3}\right), 3.73\left(\mathrm{~s}, 6 \mathrm{H}, \mathrm{OCH}_{3}\right), 3.84(\mathrm{dd}, J=18.0,11.5 \mathrm{~Hz}, 1 \mathrm{H}, \mathrm{H}-4), 4.69(\mathrm{~s}, 2 \mathrm{H}, \mathrm{OH})$, $5.43(\mathrm{dd}, J=11.5,5.1 \mathrm{~Hz}, 1 \mathrm{H}, \mathrm{H}-5), 6.50(\mathrm{~s}, 2 \mathrm{H}, \mathrm{Ar}-\mathrm{H}), 6.67$ (bs, 1H, NH), 6.78 (bs, 1H, NH), $7.64(\mathrm{~d}$, $J=8.7 \mathrm{~Hz}, 2 \mathrm{H}, \mathrm{Ar}-\mathrm{H}), 7.90(\mathrm{~d}, J=8.7 \mathrm{~Hz}, 2 \mathrm{H}, \mathrm{Ar}-\mathrm{H}), 8.88$ (s, 1H, CHO), 9.19 (bs, 1H, NH). ${ }^{13} \mathrm{C}-\mathrm{NMR}$ $\left(100 \mathrm{MHz}, \mathrm{DMSO}-d_{6}\right) \delta \mathrm{ppm} 42.4\left(\mathrm{CH}_{2}\right), 42.9\left(\mathrm{CH}_{2}\right), 55.9\left(\mathrm{CH}_{3}\right), 58.6,60.0\left(\mathrm{CH}_{3}\right), 60.1\left(\mathrm{CH}_{2}\right), 99.6(\mathrm{Cq})$, 102.8, 119.0, $126.0(\mathrm{Cq}), 127.2,136.0(\mathrm{Cq}), 136.7(\mathrm{Cq}), 137.2(\mathrm{Cq}), 143.0(\mathrm{Cq}), 153.1(\mathrm{Cq}), 156.1(\mathrm{Cq})$, 
159.6. MS (70 eV) m/z (\%): 552 [M+1 $(27), 524$ (28), 496 (100), 481 (60), 435 (29), 43 (61). Anal. Calcd. $\mathrm{C}_{26} \mathrm{H}_{32} \mathrm{~N}_{8} \mathrm{O}_{6}$ : C, 56.51; H, 5.84; N, 20.28; Found: $\mathrm{C}, 56.53 ; \mathrm{H}, 5.83 ; \mathrm{N}, 20.28$.

3-(4-((4,6-bis((2-Hydroxyethyl)amino)-1,3,5-triazin-2-yl)amino)phenyl)-5-(4-chlorophenyl)-4,5-dihydro-1Hpyrazole-1-carbaldehyde (9e). White solid; $65 \%$ yield; m.p. $165-167{ }^{\circ} \mathrm{C}$. FT-IR (ATR) v $\left(\mathrm{cm}^{-1}\right)$ Not observed $(\mathrm{N}-\mathrm{H}), 3271(\mathrm{O}-\mathrm{H}), 3097(=\mathrm{C}-\mathrm{H}), 1674(\mathrm{C}=\mathrm{O}), 1649$ and $1593(\mathrm{C}=\mathrm{N}$ and $\mathrm{C}=\mathrm{C}) .{ }^{1} \mathrm{H}-\mathrm{NMR}$ $\left(400 \mathrm{MHz}, \mathrm{DMSO}-d_{6}\right) \delta$ ppm $3.17(\mathrm{dd}, J=18.0,4.8 \mathrm{~Hz}, 1 \mathrm{H}, \mathrm{H}-4), 3.27-3.40\left(\mathrm{~m}, 4 \mathrm{H}, \mathrm{CH}_{2}\right), 3.45-3.56$ $\left(\mathrm{m}, 6 \mathrm{H}, \mathrm{CH}_{2}, \mathrm{OH}\right), 3.88(\mathrm{dd}, J=18.0,11.7 \mathrm{~Hz}, 1 \mathrm{H}, \mathrm{H}-4), 5.51(\mathrm{dd}, J=11.7,4.8 \mathrm{~Hz}, 1 \mathrm{H}, \mathrm{H}-5), 6.67$ (bs, $1 \mathrm{H}, \mathrm{NH}), 6.79(\mathrm{bs}, 1 \mathrm{H}, \mathrm{NH}), 7.26(\mathrm{~d}, J=8.5 \mathrm{~Hz}, 2 \mathrm{H}, \mathrm{Ar}-\mathrm{H}), 7.40(\mathrm{~d}, J=8.5 \mathrm{~Hz}, 2 \mathrm{H}, \mathrm{Ar}-\mathrm{H}), 7.65(\mathrm{~d}$, $J=8.6 \mathrm{~Hz}, 2 \mathrm{H}, \mathrm{Ar}-\mathrm{H}), 7.91(\mathrm{~d}, J=8.6 \mathrm{~Hz}, 2 \mathrm{H}, \mathrm{Ar}-\mathrm{H}), 8.86(\mathrm{~s}, 1 \mathrm{H}, \mathrm{CHO}), 9.20(\mathrm{bs}, 1 \mathrm{H}, \mathrm{NH}) .{ }^{13} \mathrm{C}-\mathrm{NMR}$ $\left(100 \mathrm{MHz}, \mathrm{DMSO}-d_{6}\right) \delta \mathrm{ppm} 42.1\left(\mathrm{CH}_{2}\right), 42.8\left(\mathrm{CH}_{2}\right), 57.7,60.1\left(\mathrm{CH}_{2}\right), 119.0,123.0(\mathrm{Cq}), 127.2,127.3$ (Cq), 127.8, 128.7, $131.9(\mathrm{Cq}), 135.9(\mathrm{Cq}), 140.4(\mathrm{Cq}), 143.2(\mathrm{Cq}), 156.0(\mathrm{Cq}), 159.4$. MS (70 eV) $\mathrm{m} / \mathrm{z}(\%)$ : 496:498 [M+ $\left.\mathrm{M}^{+}\right]:[\mathrm{M}+2](34 / 12), 468(46), 440$ (6), $391(20), 115$ (47), 43 (100). Anal. Calcd. $\mathrm{C}_{23} \mathrm{H}_{25} \mathrm{ClN}_{8} \mathrm{O}_{3}$ : C, 55.59; H, 5.07; N, 22.55; Found: C, 55.64; H, 4.98; N, 22.58.

3-(4-((4,6-bis((2-Hydroxyethyl)amino)-1,3,5-triazin-2-yl)amino)phenyl)-5-(4-fluorophenyl)-4,5-dihydro-1Hpyrazole-1-carbaldehyde (9f). White solid; 58\% yield; m.p. 167-169 ${ }^{\circ} \mathrm{C}$. FT-IR (ATR) v $\left(\mathrm{cm}^{-1}\right)$ Not observed $(\mathrm{N}-\mathrm{H}), 3273(\mathrm{O}-\mathrm{H}), 3105(=\mathrm{C}-\mathrm{H}), 1672(\mathrm{C}=\mathrm{O}), 1649$ and $1593(\mathrm{C}=\mathrm{N}$ and $\mathrm{C}=\mathrm{C}) .{ }^{1} \mathrm{H}-\mathrm{NMR}$ $\left(400 \mathrm{MHz}, \mathrm{DMSO}-d_{6}\right) \delta \mathrm{ppm} 3.16(\mathrm{dd}, J=18.0,4.8 \mathrm{~Hz}, 1 \mathrm{H}, \mathrm{H}-4), 3.27-3.39\left(\mathrm{~m}, 4 \mathrm{H}, \mathrm{CH}_{2}\right), 3.46-3.55$ $\left(\mathrm{m}, 6 \mathrm{H}, \mathrm{CH}_{2}, \mathrm{OH}\right), 3.86(\mathrm{dd}, J=18.0,11.7 \mathrm{~Hz}, 1 \mathrm{H}, \mathrm{H}-4), 5.51(\mathrm{dd}, J=11.7,4.8 \mathrm{~Hz}, 1 \mathrm{H}, \mathrm{H}-5), 6.66$ (bs, $1 \mathrm{H}, \mathrm{NH}), 6.78(\mathrm{bs}, 1 \mathrm{H}, \mathrm{NH}), 7.19-7.12(\mathrm{~m}, 2 \mathrm{H}, \mathrm{Ar}-\mathrm{H}), 7.30-7.23(\mathrm{~m}, 2 \mathrm{H}, \mathrm{Ar}-\mathrm{H}), 7.64(\mathrm{~d}, J=8.7 \mathrm{~Hz}$, 2H, Ar-H), 7.90 (d, J = 8.7 Hz, 2H, Ar-H), 8.85 (s, 1H, CHO), 9.19 (bs, 1H, NH). ${ }^{13} \mathrm{C}-\mathrm{NMR}(100 \mathrm{MHz}$, DMSO- $\left.d_{6}\right) \delta$ ppm $42.2\left(\mathrm{CH}_{2}\right), 42.9\left(\mathrm{CH}_{2}\right), 57.7,60.1\left(\mathrm{CH}_{2}\right), 115.5\left(\mathrm{~d},{ }^{2} J_{\mathrm{CF}}=21.5 \mathrm{~Hz}\right), 117.2(\mathrm{Cq}), 118.9$, $123.1(\mathrm{Cq}), 127.2,127.9\left(\mathrm{~d},{ }^{3} J_{\mathrm{CF}}=8.3 \mathrm{~Hz}\right), 137.7\left(\mathrm{~d},{ }^{4} J_{\mathrm{CF}}=3.0 \mathrm{~Hz}, \mathrm{Cq}\right), 143.2(\mathrm{Cq}), 145.7(\mathrm{Cq}), 156.1$ (Cq), $159.4(\mathrm{CH}=\mathrm{O}), 161.4\left(\mathrm{~d},{ }^{1} J_{\mathrm{CF}}=243.5 \mathrm{~Hz}\right) . \mathrm{MS}(70 \mathrm{eV}) \mathrm{m} / z(\%): 480\left[\mathrm{M}^{+}\right]$(45), $452(75), 424$ (100), 393 (43), 375 (23), 43 (14). Anal. Calcd. $\mathrm{C}_{23} \mathrm{H}_{25} \mathrm{FN}_{8} \mathrm{O}_{3}$ : C, 57.49; H, 5.24; N, 23.32; Found: C, 57.48; H, $5.20 ; \mathrm{N}, 23.39$.

3-(4-((4,6-bis((2-Hydroxyethyl)amino)-1,3,5-triazin-2-yl)amino)phenyl)-5-(4-(trifluoromethyl)phenyl)-4,5dihydro-1H-pyrazole-1-carbaldehyde (9g). White solid; 35\% yield; m.p. $160-164{ }^{\circ} \mathrm{C}$. FT-IR (ATR) v $\left(\mathrm{cm}^{-1}\right)$ Not observed $(\mathrm{N}-\mathrm{H}), 3279(\mathrm{O}-\mathrm{H}), 3099(=\mathrm{C}-\mathrm{H}), 1649(\mathrm{C}=\mathrm{O}), 1620$ and $1593(\mathrm{C}=\mathrm{N}$ and $\mathrm{C}=\mathrm{C}) .{ }^{1} \mathrm{H}-\mathrm{NMR}$ $\left(400 \mathrm{MHz}, \mathrm{DMSO}-d_{6}\right) \delta$ ppm $3.20(\mathrm{dd}, J=18.1,5.0 \mathrm{~Hz}, 1 \mathrm{H}, \mathrm{H}-4), 3.30-3.37\left(\mathrm{~m}, 4 \mathrm{H}, \mathrm{CH}_{2}\right), 3.47-3.55$ $\left(\mathrm{m}, 6 \mathrm{H}, \mathrm{CH}_{2}, \mathrm{OH}\right), 3.91(\mathrm{dd}, J=18.1,11.8 \mathrm{~Hz}, 1 \mathrm{H}, \mathrm{H}-4), 5.60(\mathrm{dd}, J=11.8,5.0 \mathrm{~Hz}, 1 \mathrm{H}, \mathrm{H}-5), 6.66$ (bs, 1H, NH), 6.79 (bs, 1H, NH), $7.46(\mathrm{~d}, J=7.15 \mathrm{~Hz}, 2 \mathrm{H}, \mathrm{Ar}-\mathrm{H}), 7.64(\mathrm{~d}, J=7.2 \mathrm{~Hz}, 2 \mathrm{H}, \mathrm{Ar}-\mathrm{H})$, $7.72(\mathrm{~d}, J=8.5 \mathrm{~Hz}, 2 \mathrm{H}, \mathrm{Ar}-\mathrm{H}), 7.90(\mathrm{~d}, J=8.5 \mathrm{~Hz}, 2 \mathrm{H}, \mathrm{Ar}-\mathrm{H}), 8.88$ (s, 1H, CHO), 9.19 (bs, 1H, NH). ${ }^{13} \mathrm{C}-\mathrm{NMR}\left(100 \mathrm{MHz}, \mathrm{DMSO}-d_{6}\right) \delta$ ppm $42.2\left(\mathrm{CH}_{2}\right), 42.9\left(\mathrm{CH}_{2}\right), 58.1,60.2\left(\mathrm{CH}_{2}\right), 119.0,122.9(\mathrm{Cq})$, $124.4\left(\mathrm{q},{ }^{1} J_{\mathrm{CF}}=276.4 \mathrm{~Hz}, \mathrm{CF}_{3}\right), 125.6(\mathrm{Cq}), 125.8\left(\mathrm{q},{ }^{3} J_{\mathrm{CF}}=3.9 \mathrm{~Hz}\right), 126.8,127.3$ (unresolved q), $128.2(\mathrm{~d}$, $\left.{ }^{2} J_{\mathrm{CF}}=31.7 \mathrm{~Hz}, \mathrm{Cq}\right), 143.2(\mathrm{Cq}), 143.3(\mathrm{Cq}), 146.0(\mathrm{Cq}), 156.2(\mathrm{Cq}), 159.6(\mathrm{CH}=\mathrm{O})$. MS (70 eV) $\mathrm{m} / \mathrm{z}(\%)$ : $530\left[\mathrm{M}^{+}\right]$(93), 499 (35), 487 (19), 443 (24), 69 (54), 43 (100). Anal. Calcd. $\mathrm{C}_{24} \mathrm{H}_{25} \mathrm{~F}_{3} \mathrm{~N}_{8} \mathrm{O}_{3}: \mathrm{C}, 54.34 ; \mathrm{H}$, $4.75 ; \mathrm{N}, 21.12$; Found: C, 54.36; H, 4.70; N, 21.17.

3.2.6. General Procedure for the Synthesis of 2,2'-((6-((4-(5-(aryl)-1-(3,5-Dichlorophenyl)-4,5dihydro-1H-pyrazol-3-yl)phenyll)amino)-1,3,5-triazine-2,4-diyl)bis(azanediyl))bis(ethanol)s 10a-g

A mixture of chalcone 7 ( $0.4 \mathrm{mmol})$ and 3,5-dichlorophenylhydrazine hydrochloride (2.6 mmol) in ethanol $(2.5 \mathrm{~mL})$ was subjected to reflux for $2 \mathrm{~h}$. The solid formed was filtered and washed with ethanol. No further purification was required.

2,2'-((6-((4-(1-(3,5-Dichlorophenyl)-5-phenyl-4,5-dihydro-1H-pyrazol-3-yl)phenyl)amino)-1,3,5-triazine-2,4diyl)bis(azanediyl))bis(ethanol) (10a). Yellow solid; 65\% yield; m.p. 207-208 ${ }^{\circ} \mathrm{C}$. FT-IR (ATR) $\mathrm{v}\left(\mathrm{cm}^{-1}\right)$ Not observed $(\mathrm{N}-\mathrm{H}), 3296(\mathrm{O}-\mathrm{H}), 3130(=\mathrm{C}-\mathrm{H}), 1647$ and $1587(\mathrm{C}=\mathrm{N}$ and $\mathrm{C}=\mathrm{C}) .{ }^{1} \mathrm{H}-\mathrm{NMR}(400 \mathrm{MHz}$, DMSO- $\left.d_{6}\right) \delta$ ppm $3.16(\mathrm{dd}, J=17.7,5.2 \mathrm{~Hz}, 1 \mathrm{H}, \mathrm{H}-4), 3.37-3.49\left(\mathrm{~m}, 4 \mathrm{H}, \mathrm{CH}_{2}\right), 3.52-3.63\left(\mathrm{~m}, 6 \mathrm{H}, \mathrm{CH}_{2}\right.$, $\mathrm{OH}), 3.94(\mathrm{dd}, J=17.7,12.1 \mathrm{~Hz}, 1 \mathrm{H}, \mathrm{H}-4), 5.58(\mathrm{dd}, J=12.1,5.2 \mathrm{~Hz}, 1 \mathrm{H}, \mathrm{H}-5), 6.80(\mathrm{t}, J=1.7 \mathrm{~Hz}, 1 \mathrm{H}$, 
Ar-H), $6.93(\mathrm{~d}, J=1.7 \mathrm{~Hz}, 2 \mathrm{H}, \mathrm{Ar}-\mathrm{H}), 7.23-7.30\left(\mathrm{~m}, 3 \mathrm{H}, \mathrm{H}_{\mathrm{p}}, \mathrm{Ar}-\mathrm{H}\right), 7.36(\mathrm{t}, J=7.3 \mathrm{~Hz}, 2 \mathrm{H}, \mathrm{Ar}-\mathrm{H})$, 7.81-7.71 (m, 4H, Ar-H), 8.23-8.84 (m, 2H, NH), $10.46(\mathrm{~s}, 1 \mathrm{H}, \mathrm{NH}) .{ }^{13} \mathrm{C}-\mathrm{NMR}\left(100 \mathrm{MHz}, \mathrm{DMSO}-d_{6}\right) \delta$ ppm $43.2\left(\mathrm{CH}_{2}\right), 59.0\left(\mathrm{CH}_{2}\right), 59.2\left(\mathrm{CH}_{2}\right), 62.4,99.5(\mathrm{Cq}), 110.8,116.9,120.9,125.8,126.8,127.8,129.2$, $134.4(\mathrm{Cq}), 141.4(\mathrm{Cq}), 145.7(\mathrm{Cq}), 149.8(\mathrm{Cq}) . \mathrm{MS}(70 \mathrm{eV}) \mathrm{m} / z(\%): 578: 580: 582\left[\mathrm{M}^{+}\right]:[\mathrm{M}+2]^{+}:[\mathrm{M}+4]^{+}$ (100/67/11), 341 (13), 69 (32), 55 (39), 44 (57), 43 (66), 41 (28). Anal. Calcd. $\mathrm{C}_{28} \mathrm{H}_{28} \mathrm{Cl}_{2} \mathrm{~N}_{8} \mathrm{O}_{2}$ : C, 58.04; $\mathrm{H}$, 4.87; N, 19.34; Found: C, 58.05; H, 4.89; N, 19.37.

2,2'-((6-((4-(1-(3,5-Dichlorophenyl)-5-(p-tolyl)-4,5-dihydro-1H-pyrazol-3-yl)phenyl)amino)-1,3,5-triazine-2,4diyl)bis(azanediyl))bis(ethanol) (10b). Yellow solid; 92\% yield; m.p. $218-219^{\circ} \mathrm{C}$. FT-IR (ATR) v $\left(\mathrm{cm}^{-1}\right)$ Not observed $(\mathrm{N}-\mathrm{H}), 3309(\mathrm{O}-\mathrm{H}), 3115(=\mathrm{C}-\mathrm{H}), 1647$ and $1585(\mathrm{C}=\mathrm{N}$ and $\mathrm{C}=\mathrm{C}) .{ }^{1} \mathrm{H}-\mathrm{NMR}(400 \mathrm{MHz}$, DMSO- $\left.d_{6}\right) \delta$ ppm $2.25\left(\mathrm{~s}, 3 \mathrm{H}, \mathrm{CH}_{3}\right), 3.12(\mathrm{dd}, J=17.6,5.1 \mathrm{~Hz}, 1 \mathrm{H}, \mathrm{H}-4), 3.41-3.49\left(\mathrm{~m}, 4 \mathrm{H}, \mathrm{CH}_{2}\right)$, 3.53-3.61 (m, 6H, CH, $\mathrm{OH}), 3.90(\mathrm{dd}, J=17.6,12.0 \mathrm{~Hz}, 1 \mathrm{H}, \mathrm{H}-4), 5.53(\mathrm{dd}, J=12.0,5.1 \mathrm{~Hz}, 1 \mathrm{H}, \mathrm{H}-5)$, $6.79(\mathrm{t}, J=1.7 \mathrm{~Hz}, 1 \mathrm{H}, \mathrm{Ar}-\mathrm{H}), 6.92(\mathrm{~d}, J=1.7 \mathrm{~Hz}, 2 \mathrm{H}, \mathrm{Ar}-\mathrm{H}), 7.19-7.11(\mathrm{~m}, 4 \mathrm{H}, \mathrm{Ar}-\mathrm{H}), 7.81-7.72(\mathrm{~m}, 4 \mathrm{H}$, Ar-H), 8.20-8.88 (m, 2H, NH), $10.46(\mathrm{~s}, 1 \mathrm{H}, \mathrm{NH}) .{ }^{13} \mathrm{C}-\mathrm{NMR}\left(100 \mathrm{MHz}, \mathrm{DMSO}-d_{6}\right) \delta \mathrm{ppm} 20.7\left(\mathrm{CH}_{3}\right)$, $43.2\left(\mathrm{CH}_{2}\right), 59.0\left(\mathrm{CH}_{2}\right), 62.2,99.5(\mathrm{Cq}), 110.8,111.0(\mathrm{Cq}), 116.8,120.9,121.0(\mathrm{Cq}), 125.7,126.7,126.8(\mathrm{Cq})$, 129.7, $134.4(\mathrm{Cq}), 137.0(\mathrm{Cq}), 138.4(\mathrm{Cq}), 145.7(\mathrm{Cq}), 149.8(\mathrm{Cq}) . \mathrm{MS}(70 \mathrm{eV}) \mathrm{m} / z(\%):$ 592:594:596 $\left[\mathrm{M}^{+}\right]:[\mathrm{M}+2]^{+}:[\mathrm{M}+4]^{+}(100 / 78 / 15), 501(13), 284$ (11), 117 (14), 91 (15), 69 (20), 55 (22), 44 (27), 43 (36). Anal. Calcd. $\mathrm{C}_{29} \mathrm{H}_{30} \mathrm{Cl}_{2} \mathrm{~N}_{8} \mathrm{O}_{2}$ : C, 58.69; H, 5.10; N, 18.88; Found: $\mathrm{C}, 58.74 ; \mathrm{H}, 5.11 ; \mathrm{N}, 18.83$.

2,2'-((6-((4-(1-(3,5-Dichlorophenyl)-5-(4-methoxyphenyl)-4,5-dihydro-1H-pyrazol-3-yl)phenyl)amino)-1,3,5triazine-2,4-diyl)bis(azanediyl))bis(ethanol) (10c). Yellow solid; 85\% yield; m.p. 226-228 ${ }^{\circ} \mathrm{C}$. FT-IR (ATR) $\mathrm{v}\left(\mathrm{cm}^{-1}\right)$ Not observed $(\mathrm{N}-\mathrm{H}), 3307(\mathrm{O}-\mathrm{H}), 3105(=\mathrm{C}-\mathrm{H}), 1647(\mathrm{C}=\mathrm{N}), 1585(\mathrm{C}=\mathrm{C})$ and $1251(\mathrm{C}-\mathrm{O})$. ${ }^{1} \mathrm{H}-\mathrm{NMR}\left(400 \mathrm{MHz}\right.$, DMSO- $\left.d_{6}\right) \delta$ ppm $3.12(\mathrm{dd}, J=17.6,5.1 \mathrm{~Hz}, 1 \mathrm{H}, \mathrm{H}-4), 3.40-3.48\left(\mathrm{~m}, 4 \mathrm{H}, \mathrm{CH}_{2}\right)$, 3.53-3.60 (m, 6H, $\left.\mathrm{CH}_{2}, \mathrm{OH}\right), 3.70\left(\mathrm{~s}, 3 \mathrm{H}, \mathrm{OCH}_{3}\right), 3.88(\mathrm{dd}, J=17.6,11.9 \mathrm{~Hz}, 1 \mathrm{H}, \mathrm{H}-4), 5.51(\mathrm{dd}, J=11.9$, $5.1 \mathrm{~Hz}, 1 \mathrm{H}, \mathrm{H}-5), 6.79(\mathrm{t}, J=1.7 \mathrm{~Hz}, 1 \mathrm{H}, \mathrm{Ar}-\mathrm{H}), 6.90(\mathrm{~d}, J=8.7 \mathrm{~Hz}, 2 \mathrm{H}, \mathrm{Ar}-\mathrm{H}), 6.93(\mathrm{~d}, J=1.7 \mathrm{~Hz}, 2 \mathrm{H}$, $\mathrm{Ar}-\mathrm{H}), 7.17(\mathrm{~d}, J=8.7 \mathrm{~Hz}, 2 \mathrm{H}, \mathrm{Ar}-\mathrm{H}), 7.81-7.72(\mathrm{~m}, 4 \mathrm{H}, \mathrm{Ar}-\mathrm{H}), 8.23-8.80(\mathrm{~m}, 2 \mathrm{H}, \mathrm{NH}), 10.45(\mathrm{~s}, 1 \mathrm{H}$, NH). ${ }^{13} \mathrm{C}-\mathrm{NMR}\left(100 \mathrm{MHz}, \mathrm{DMSO}-d_{6}\right) \delta \mathrm{ppm} 43.2\left(\mathrm{CH}_{2}\right), 55.1\left(\mathrm{CH}_{3}\right), 59.2\left(\mathrm{CH}_{2}\right), 61.9,99.6(\mathrm{Cq}), 110.9$, 114.6, 116.8, 120.9, $121.0(\mathrm{Cq}), 126.8,126.9(\mathrm{Cq}), 127.1,133.3(\mathrm{Cq}), 134.4(\mathrm{Cq}), 139.4(\mathrm{Cq}), 145.8(\mathrm{Cq})$, $149.8(\mathrm{Cq}), 158.7(\mathrm{Cq}) . \mathrm{MS}(70 \mathrm{eV}) \mathrm{m} / z(\%): 608: 610: 612\left[\mathrm{M}^{+}\right]:[\mathrm{M}+2]^{+}:[\mathrm{M}+4]^{+}(100 / 66 / 14), 501(31)$, 83 (13), 69 (36), 55 (43), 44 (54), 43 (74). Anal. Calcd. $\mathrm{C}_{29} \mathrm{H}_{30} \mathrm{Cl}_{2} \mathrm{~N}_{8} \mathrm{O}_{3}: \mathrm{C}, 57.15 ; \mathrm{H}, 4.96 ; \mathrm{N}, 18.38$; Found: C, 57.11; H, 5.03; N, 18.36 .

2,2'-((6-((4-(1-(3,5-Dichlorophenyl)-5-(3,4,5-trimethoxyphenyl)-4,5-dihydro-1H-pyrazol-3-yl)phenyl)amino) 1,3,5-triazine-2,4-diyl)bis(azanediyl))bis(ethanol) (10d). Yellow solid; 92\% yield; m.p. 202-204 ${ }^{\circ} \mathrm{C}$. FT-IR $($ ATR $) \mathrm{v}\left(\mathrm{cm}^{-1}\right)$ Not observed $(\mathrm{N}-\mathrm{H}), 3273(\mathrm{O}-\mathrm{H}), 3196(=\mathrm{C}-\mathrm{H}), 1641(\mathrm{C}=\mathrm{N}), 1585(\mathrm{C}=\mathrm{C})$ and 1228 (C-O). ${ }^{1} \mathrm{H}-\mathrm{NMR}\left(400 \mathrm{MHz}, \mathrm{DMSO}-d_{6}\right) \delta \mathrm{ppm} 3.22(\mathrm{dd}, J=17.6,6.2 \mathrm{~Hz}, 1 \mathrm{H}, \mathrm{H}-4), 3.40-3.48(\mathrm{~m}$, $\left.4 \mathrm{H}, \mathrm{CH}_{2}\right), 3.55-3.60\left(\mathrm{~m}, 6 \mathrm{H}, \mathrm{CH}_{2}, \mathrm{OH}\right), 3.63\left(\mathrm{~s}, 3 \mathrm{H}, \mathrm{OCH}_{3}\right), 3.70\left(\mathrm{~s}, 6 \mathrm{H}, \mathrm{OCH}_{3}\right), 3.92(\mathrm{dd}, J=17.6$, $12.0 \mathrm{~Hz}, 1 \mathrm{H}, \mathrm{H}-4), 5.43(\mathrm{dd}, J=12.0,6.2 \mathrm{~Hz}, 1 \mathrm{H}, \mathrm{H}-5), 6.60(\mathrm{~s}, 2 \mathrm{H}, \mathrm{Ar}-\mathrm{H}), 6.83(\mathrm{~s}, 1 \mathrm{H}, \mathrm{Ar}-\mathrm{H}), 6.97$ $(\mathrm{d}, J=1.6 \mathrm{~Hz}, 2 \mathrm{H}, \mathrm{Ar}-\mathrm{H}), 7.77(\mathrm{~s}, 4 \mathrm{H}, \mathrm{Ar}-\mathrm{H}), 8.19-8.82(\mathrm{~m}, 2 \mathrm{H}, \mathrm{NH}), 10.48(\mathrm{~s}, 1 \mathrm{H}, \mathrm{NH}) .{ }^{13} \mathrm{C}-\mathrm{NMR}$ $\left(100 \mathrm{MHz}, \mathrm{DMSO}-d_{6}\right) \delta \mathrm{ppm} 43.3\left(\mathrm{CH}_{2}\right), 56.0\left(\mathrm{CH}_{3}\right), 59.0\left(\mathrm{CH}_{2}\right), 60.0\left(\mathrm{CH}_{3}\right), 63.1,103.1,111.0,117.1$, 120.9, 126.8, $129.1(\mathrm{Cq}), 134.4(\mathrm{Cq}), 135.9(\mathrm{Cq}), 136.9(\mathrm{Cq}), 137.2(\mathrm{Cq}), 144.4(\mathrm{Cq}), 146.2(\mathrm{Cq}), 148.2(\mathrm{Cq})$, $150.1(\mathrm{Cq}), 153.4(\mathrm{Cq})$. MS (70 eV) $m / z(\%): 668: 670: 672\left[\mathrm{M}^{+}\right]:[\mathrm{M}+2]^{+}:[\mathrm{M}+4]^{+}(100 / 64 / 13), 501(28)$, 84 (33), 69 (42), 55 (52), 44 (83), 43 (79). Anal. Calcd. $\mathrm{C}_{31} \mathrm{H}_{34} \mathrm{Cl}_{2} \mathrm{~N}_{8} \mathrm{O}_{5}: \mathrm{C}, 55.61 ; \mathrm{H}, 5.12 ; \mathrm{N}, 16.74$; Found: C, $55.65 ; \mathrm{H}, 5.18 ; \mathrm{N}, 16.75$.

2,2'-((6-((4-(5-(4-Chlorophenyl)-1-(3,5-dichlorophenyl)-4,5-dihydro-1H-pyrazol-3-yl)phenyl)amino)-1,3,5triazine-2,4-diyl)bis(azanediyl))bis(ethanol) (10e). Yellow solid; $36 \%$ yield; m.p. 223-225 ${ }^{\circ} \mathrm{C}$. FT-IR (ATR) $\mathrm{v}\left(\mathrm{cm}^{-1}\right)$ Not observed $(\mathrm{N}-\mathrm{H}), 3269(\mathrm{O}-\mathrm{H}), 3086(=\mathrm{C}-\mathrm{H}), 1637$ and $1585(\mathrm{C}=\mathrm{N}$ and $\mathrm{C}=\mathrm{C}) .{ }^{1} \mathrm{H}-\mathrm{NMR}$ $\left(400 \mathrm{MHz}, \mathrm{DMSO}-d_{6}\right) \delta \mathrm{ppm} 3.17(\mathrm{dd}, J=17.6,4.8 \mathrm{~Hz}, 1 \mathrm{H}, \mathrm{H}-4), 3.36-3.49\left(\mathrm{~m}, 4 \mathrm{H}, \mathrm{CH}_{2}\right), 3.54-3.61(\mathrm{~m}$, $\left.6 \mathrm{H}, \mathrm{CH}_{2}\right), 3.93(\mathrm{dd}, J=17.6,12.0 \mathrm{~Hz}, 1 \mathrm{H}, \mathrm{H}-4), 5.63(\mathrm{dd}, J=12.0,4.8 \mathrm{~Hz}, 1 \mathrm{H}, \mathrm{H}-5), 6.81(\mathrm{~s}, 1 \mathrm{H}, \mathrm{Ar}-\mathrm{H})$, $6.93(\mathrm{~s}, 2 \mathrm{H}, \mathrm{Ar}-\mathrm{H}), 7.28(\mathrm{~d}, J=8.3 \mathrm{~Hz}, 2 \mathrm{H}, \mathrm{Ar}-\mathrm{H}), 7.42(\mathrm{~d}, J=8.3 \mathrm{~Hz}, 2 \mathrm{H}, \mathrm{Ar}-\mathrm{H}), 7.67-7.83(\mathrm{~m}, 4 \mathrm{H}$, Ar-H), 8.24-8.83 (m, 2H, NH), 10.46 (s, 1H, NH). ${ }^{13} \mathrm{C}-\mathrm{NMR}\left(100 \mathrm{MHz}, \mathrm{DMSO}-d_{6}\right) \delta$ ppm $42.9\left(\mathrm{CH}_{2}\right)$, 
$43.3\left(\mathrm{CH}_{2}\right), 59.1\left(\mathrm{CH}_{2}\right), 63.1,110.9,111.8(\mathrm{Cq}), 117.1,117.2(\mathrm{Cq}), 120.0,126.7(\mathrm{Cq}), 126.8,127.8,127.8$, 129.2, $132.3(\mathrm{Cq}), 134.5(\mathrm{Cq}), 140.3(\mathrm{Cq}), 145.6(\mathrm{Cq}), 149.9(\mathrm{Cq}) . \mathrm{MS}(70 \mathrm{eV}) \mathrm{m} / \mathrm{z}(\%):$ 612:614:616:618 $\left[\mathrm{M}^{+}\right]:[\mathrm{M}+2]^{+}:[\mathrm{M}+4]^{+}:[\mathrm{M}+6]^{+}(100 / 81 / 32 / 5), 284$ (16), 84 (30), 69 (50), 55 (60), 43 (82). Anal. Calcd. $\mathrm{C}_{28} \mathrm{H}_{27} \mathrm{Cl}_{3} \mathrm{~N}_{8} \mathrm{O}_{2}$ : C, 54.78; H, 4.43; N, 18.25; Found: C, 54.73; H, 4.47; N, 18.22.

2,2'-((6-((4-(1-(3,5-Dichlorophenyl)-5-(4-fluorophenyl)-4,5-dihydro-1H-pyrazol-3-yl)phenyl)amino)-1,3,5triazine-2,4-diyl)bis(azanediyl))bis(ethanol) (10f). Yellow solid; 68\% yield; m.p. 193-195 ${ }^{\circ} \mathrm{C}$. FT-IR (ATR) $\mathrm{v}\left(\mathrm{cm}^{-1}\right)$ Not observed $(\mathrm{N}-\mathrm{H}), 3282(\mathrm{O}-\mathrm{H}), 3116(=\mathrm{C}-\mathrm{H}), 1641$ and $1583(\mathrm{C}=\mathrm{N}$ and $\mathrm{C}=\mathrm{C}) .{ }^{1} \mathrm{H}-\mathrm{NMR}$ $\left(400 \mathrm{MHz}, \mathrm{DMSO}-d_{6}\right) \delta$ ppm $3.17(\mathrm{dd}, J=17.7,5.0 \mathrm{~Hz}, 1 \mathrm{H}, \mathrm{H}-4), 3.36-3.49\left(\mathrm{~m}, 4 \mathrm{H}, \mathrm{CH}_{2}\right), 3.53-3.62$ $\left(\mathrm{m}, 6 \mathrm{H}, \mathrm{CH}_{2}, \mathrm{OH}\right), 3.93(\mathrm{dd}, J=17.7,12.0 \mathrm{~Hz}, 1 \mathrm{H}, \mathrm{H}-4), 5.62(\mathrm{dd}, J=12.0,5.0 \mathrm{~Hz}, 1 \mathrm{H}, \mathrm{H}-5), 6.81(\mathrm{t}$, $J=1.7 \mathrm{~Hz}, 1 \mathrm{H}, \mathrm{Ar}-\mathrm{H}), 6.93(\mathrm{~d}, J=1.7 \mathrm{~Hz}, 2 \mathrm{H}, \mathrm{Ar}-\mathrm{H}), 7.19(\mathrm{t}, J=8.8 \mathrm{~Hz}, 2 \mathrm{H}, \mathrm{Ar}-\mathrm{H}), 7.31(\mathrm{dd}$, $J=8.2$ and $\left.\mathrm{J}_{\mathrm{HF}}=5.6 \mathrm{~Hz}, 2 \mathrm{H}, \mathrm{Ar}-\mathrm{H}\right), 7.82-7.72(\mathrm{~m}, 4 \mathrm{H}, \mathrm{Ar}-\mathrm{H}), 8.21-8.80(\mathrm{~m}, 2 \mathrm{H}, \mathrm{NH}), 10.46(\mathrm{~s}, 1 \mathrm{H}$, $\mathrm{NH}) .{ }^{13} \mathrm{C}-\mathrm{NMR}\left(100 \mathrm{MHz}, \mathrm{DMSO}-d_{6}\right) \delta \mathrm{ppm} 43.1\left(\mathrm{CH}_{2}\right), 43.3\left(\mathrm{CH}_{2}\right), 59.1\left(\mathrm{CH}_{2}\right), 61.7,110.9,116.0(\mathrm{~d}$, $\left.{ }^{2} J_{\mathrm{CF}}=21.5 \mathrm{~Hz}\right), 117.0,120.9,126.9,126.9(\mathrm{Cq}), 128.0\left(\mathrm{~d},{ }^{3} J_{\mathrm{CF}}=7.2 \mathrm{~Hz}\right), 134.5(\mathrm{Cq}), 135.9(\mathrm{Cq}), 137.6(\mathrm{~d}$, $\left.{ }^{4} J_{\mathrm{CF}}=2.7 \mathrm{~Hz}, \mathrm{Cq}\right), 145.6(\mathrm{Cq}), 145.8(\mathrm{Cq}), 149.6(\mathrm{Cq}), 149.9(\mathrm{Cq}), 161.5\left(\mathrm{~d},{ }^{1} J_{\mathrm{CF}}=243.6 \mathrm{~Hz}, \mathrm{C}-\mathrm{F}\right)$. MS (70 eV) $m / z(\%): 596: 598: 600\left[\mathrm{M}^{+}\right]:[\mathrm{M}+2]^{+}:[\mathrm{M}+4]^{+}$(100/67/11), 124 (21), 84 (14), 69 (22), 55 (24), 43 (40). Anal. Calcd. $\mathrm{C}_{28} \mathrm{H}_{27} \mathrm{Cl}_{2} \mathrm{FN}_{8} \mathrm{O}_{2}$ : C, 56.29; $\mathrm{H}, 4.56 ; \mathrm{N}, 18.75$; Found: $\mathrm{C}, 56.33 ; \mathrm{H}, 4.53 ; \mathrm{N}, 18.70$.

2,2'-((6-((4-(1-(3,5-Dichlorophenyl)-5-(4-(trifluoromethyl)phenyl)-4,5-dihydro-1H-pyrazol-3-yl)phenyl)-amino) -1,3,5-triazine-2,4-diyl)bis(azanediyl))bis(ethanol) (10g). Yellow solid; $68 \%$ yield; m.p. $222-223{ }^{\circ} \mathrm{C}$. FT-IR $\left(\right.$ ATR) v $\left(\mathrm{cm}^{-1}\right)$ Not observed $(\mathrm{N}-\mathrm{H}), 3307(\mathrm{O}-\mathrm{H}), 3126(=\mathrm{C}-\mathrm{H}), 1647$ and $1587(\mathrm{C}=\mathrm{N}$ and $\mathrm{C}=\mathrm{C})$. ${ }^{1} \mathrm{H}-\mathrm{NMR}\left(400 \mathrm{MHz}, \mathrm{DMSO}-d_{6}\right) \delta \mathrm{ppm} 3.22(\mathrm{dd}, J=17.7,4.8 \mathrm{~Hz}, 1 \mathrm{H}, \mathrm{H}-4), 3.37-3.48\left(\mathrm{~m}, 4 \mathrm{H}, \mathrm{CH}_{2}\right)$, 3.53-3.60 (m, 6H, CH $2, \mathrm{OH}), 3.97(\mathrm{dd}, J=17.7,12.1 \mathrm{~Hz}, 1 \mathrm{H}, \mathrm{H}-4), 5.75(\mathrm{dd}, J=12.1,4.8 \mathrm{~Hz}, 1 \mathrm{H}, \mathrm{H}-5)$, $6.83(\mathrm{~d}, J=1.6 \mathrm{~Hz}, 1 \mathrm{H}, \mathrm{Ar}-\mathrm{H}), 6.94(\mathrm{~d}, J=1.6 \mathrm{~Hz}, 2 \mathrm{H}, \mathrm{Ar}-\mathrm{H}), 7.48(\mathrm{~d}, J=8.0 \mathrm{~Hz}, 2 \mathrm{H}, \mathrm{Ar}-\mathrm{H}), 7.82-7.71$ $(\mathrm{m}, 6 \mathrm{H}, \mathrm{Ar}-\mathrm{H}), 8.08-8.76(\mathrm{~m}, 2 \mathrm{H}, \mathrm{NH}), 10.44(\mathrm{~s}, 1 \mathrm{H}, \mathrm{NH}) .{ }^{13} \mathrm{C}-\mathrm{NMR}\left(100 \mathrm{MHz}, \mathrm{DMSO}-d_{6}\right) \delta \mathrm{ppm}$ $42.9\left(\mathrm{CH}_{2}\right), 43.2\left(\mathrm{CH}_{2}\right), 59.0\left(\mathrm{CH}_{2}\right), 61.7,110.8,117.2,120.8,122.7(\mathrm{Cq}), 124.7\left(\mathrm{q},{ }^{1} J_{\mathrm{CF}}=243.5 \mathrm{~Hz}\right.$, $\left.\mathrm{CF}_{3}\right), 125.4(\mathrm{Cq}), 126.0(\mathrm{Cq}), 126.1\left(\mathrm{q},{ }^{4} J_{\mathrm{CF}}=3.5 \mathrm{~Hz}\right), 126.6(\mathrm{Cq}), 126.7,126.9$ (unresolved q), $128.3(\mathrm{q}$, $\left.{ }^{2} J_{\mathrm{CF}}=32.1 \mathrm{~Hz}\right), 134.5(\mathrm{Cq}), 145.5(\mathrm{Cq}), 146.0(\mathrm{Cq}), 150.0(\mathrm{Cq}) . \mathrm{MS}(70 \mathrm{eV}) \mathrm{m} / z(\%): 646: 648: 650\left[\mathrm{M}^{+}\right]:[\mathrm{M}$ $+2]^{+}:[\mathrm{M}+4]^{+}(100 / 66 / 14), 615$ (14), 124 (20), 69 (26), 55 (26), 43 (48). Anal. Calcd. $\mathrm{C}_{29} \mathrm{H}_{27} \mathrm{Cl}_{2} \mathrm{~F}_{3} \mathrm{~N}_{8} \mathrm{O}_{2}$ : C, 53.80; H, 4.20; N, 17.31; Found: C, 53.89; H, 4.21; N, 17.35 .

3.2.7. General Procedure for the Synthesis of 2,2'-((6-((4-(1-(4-Chlorophenyl)-5-(4-(aryl)-4,5dihydro-1H-pyrazol-3-yl)phenyl)amino)-1,3,5-triazine-2,4-diyl)bis(azanediyl))bis(ethanols) 11a-g

A mixture of chalcone $7(0.4 \mathrm{mmol})$ and 4-chlorophenylhydrazine hydrochloride $(2.6 \mathrm{mmol})$ in methanol $(2.5 \mathrm{~mL})$ was subjected to reflux for $2 \mathrm{~h}$. The solid formed was filtered and washed with methanol. No further purification was required.

2,2'-((6-((4-(1-(4-Chlorophenyl)-5-phenyl-4,5-dihydro-1H-pyrazol-3-yl)phenyl)amino)-1,3,5-triazine-2,4-diyl) bis(azanediyl))bis(ethanol) (11a). Yellow solid; 92\% yield; m.p. 225-226 ${ }^{\circ} \mathrm{C}$. FT-IR (ATR) v $\left(\mathrm{cm}^{-1}\right)$ Not observed $(\mathrm{N}-\mathrm{H}), 3290(\mathrm{O}-\mathrm{H}), 3099(=\mathrm{C}-\mathrm{H}), 1645$ and $1595(\mathrm{C}=\mathrm{N}$ and $\mathrm{C}=\mathrm{C}) .{ }^{1} \mathrm{H}-\mathrm{NMR}(400 \mathrm{MHz}$, DMSO- $\left.d_{6}\right) \delta$ ppm $3.10(\mathrm{dd}, J=17.5,5.9 \mathrm{~Hz}, 1 \mathrm{H}, \mathrm{H}-4), 3.39-3.50\left(\mathrm{~m}, 4 \mathrm{H}, \mathrm{CH}_{2}\right), 3.53-3.62\left(\mathrm{~m}, 6 \mathrm{H}, \mathrm{CH}_{2}\right.$, $\mathrm{OH}), 3.91(\mathrm{dd}, J=17.5,12.2 \mathrm{~Hz}, 1 \mathrm{H}, \mathrm{H}-4), 5.48(\mathrm{dd}, J=12.2,5.9 \mathrm{~Hz}, 1 \mathrm{H}, \mathrm{H}-5), 6.97(\mathrm{~d}, J=9.0 \mathrm{~Hz}, 2 \mathrm{H}$, Ar-H), $7.17(\mathrm{~d}, J=9.0 \mathrm{~Hz}, 2 \mathrm{H}, \mathrm{Ar}-\mathrm{H}), 7.22-7.29(\mathrm{~m}, 3 \mathrm{H}, \mathrm{Ar}-\mathrm{H}), 7.37-7.30(\mathrm{~m}, 2 \mathrm{H}, \mathrm{Ar}-\mathrm{H}), 7.69-7.79$ $(\mathrm{m}, 4 \mathrm{H}, \mathrm{Ar}-\mathrm{H}), 8.11-8.76(\mathrm{~m}, 2 \mathrm{H}, \mathrm{NH}), 10.44(\mathrm{~s}, 1 \mathrm{H}, \mathrm{NH}) .{ }^{13} \mathrm{C}-\mathrm{NMR}\left(100 \mathrm{MHz}, \mathrm{DMSO}-d_{6}\right) \delta \mathrm{ppm} 43.2$ $\left(\mathrm{CH}_{2}\right), 43.3\left(\mathrm{CH}_{2}\right), 59.1\left(\mathrm{CH}_{2}\right), 63.0,99.5(\mathrm{Cq}), 114.3,120.9,121.4(\mathrm{Cq}), 122.0(\mathrm{Cq}), 125.8,126.3,127.5$, 127.6 (Cq), 128.8, 129.1, $135.9(\mathrm{Cq}), 142.1(\mathrm{Cq}), 143.1(\mathrm{Cq}), 147.8(\mathrm{Cq}) . \mathrm{MS}(70 \mathrm{eV}) \mathrm{m} / \mathrm{z}(\%): 544: 546$ $\left[\mathrm{M}^{+}\right]:[\mathrm{M}+2]^{+}(100 / 36), 467$ (10), 284 (7), 125 (22), 90 (11), 43 (20). Anal. Calcd. $\mathrm{C}_{28} \mathrm{H}_{29} \mathrm{ClN}_{8} \mathrm{O}_{2}: \mathrm{C}$, 61.70; H, 5.36; N, 20.56; Found: C, 61.68; H, 5.40; N, 20.53.

2,2'-((6-((4-(1-(4-Chlorophenyl)-5-(p-tolyl)-4,5-dihydro-1H-pyrazol-3-yl)phenyl)amino)-1,3,5-triazine-2,4-diyl) bis(azanediyl))bis(ethanol) (11b). Yellow solid; $55 \%$ yield; m.p. $184-186{ }^{\circ} \mathrm{C}$. FT-IR (ATR) v $\left(\mathrm{cm}^{-1}\right)$ Not observed (N-H), $3290(\mathrm{O}-\mathrm{H}), 3184(=\mathrm{C}-\mathrm{H}), 1651$ and $1597(\mathrm{C}=\mathrm{N}$ and $\mathrm{C}=\mathrm{C}) .{ }^{1} \mathrm{H}-\mathrm{NMR}(400 \mathrm{MHz}$, 
DMSO- $\left.d_{6}\right) \delta$ ppm $2.24\left(\mathrm{~s}, 3 \mathrm{H}, \mathrm{CH}_{3}\right), 3.07(\mathrm{dd}, J=17.4,5.9 \mathrm{~Hz}, 1 \mathrm{H}, \mathrm{H}-4), 3.34-3.48\left(\mathrm{~m}, 4 \mathrm{H}, \mathrm{CH}_{2}\right)$, 3.54-3.62 (m, 6H, CH, $\mathrm{OH}), 3.88$ (dd, $J=17.4,12.2 \mathrm{~Hz}, 1 \mathrm{H}, \mathrm{H}-4), 5.43(\mathrm{dd}, J=12.2,5.9 \mathrm{~Hz}, 1 \mathrm{H}, \mathrm{H}-5)$, $6.97(\mathrm{~d}, J=8.9 \mathrm{~Hz}, 2 \mathrm{H}, \mathrm{Ar}-\mathrm{H}), 7.21-7.09(\mathrm{~m}, 6 \mathrm{H}, \mathrm{Ar}-\mathrm{H}), 7.67-3.79(\mathrm{~m}, 4 \mathrm{H}, \mathrm{Ar}-\mathrm{H}), 8.17-8.79(\mathrm{~m}, 2 \mathrm{H}$, $\mathrm{NH}), 10.43(\mathrm{~s}, 1 \mathrm{H}, \mathrm{NH}) .{ }^{13} \mathrm{C}-\mathrm{NMR}\left(100 \mathrm{MHz}, \mathrm{DMSO}-d_{6}\right) \delta \mathrm{ppm} 20.7\left(\mathrm{CH}_{3}\right), 43.1\left(\mathrm{CH}_{2}\right), 43.2\left(\mathrm{CH}_{2}\right)$, $59.0\left(\mathrm{CH}_{2}\right), 62.8,114.3,120.9,121.0(\mathrm{Cq}), 121.9(\mathrm{Cq}), 125.8,126.3,126.5(\mathrm{Cq}), 127.4(\mathrm{Cq}), 128.6,129.6$, $136.7(\mathrm{Cq}), 139.1(\mathrm{Cq}), 143.1(\mathrm{Cq}), 147.8(\mathrm{Cq}), 151.0(\mathrm{Cq}) . \mathrm{MS}(70 \mathrm{eV}) \mathrm{m} / z(\%): 558: 560\left[\mathrm{M}^{+}\right]^{+}:[\mathrm{M}+2]^{+}$ (100/35), 467 (16), 284 (8), 125 (21), 91 (13), 44(23), 43 (35). Anal. Calcd. $\mathrm{C}_{29} \mathrm{H}_{31} \mathrm{ClN}_{8} \mathrm{O}_{2}$ : C, 62.30; H, 5.59; N, 20.04; Found: C, 62.36; H, 5.60; N, 20.08.

2,2'-((6-((4-(1-(4-Chlorophenyl)-5-(4-methoxyphenyl)-4,5-dihydro-1H-pyrazol-3-yl)phenyl)amino)-1,3,5-triazine -2,4-diyl)bis(azanediyl))bis(ethanol) (11c). Yellow solid; 83\% yield; m.p. $160-163{ }^{\circ} \mathrm{C}$. FT-IR (ATR) v $\left(\mathrm{cm}^{-1}\right)$ Not observed $(\mathrm{N}-\mathrm{H}), 3286(\mathrm{O}-\mathrm{H}), 3093(=\mathrm{C}-\mathrm{H}), 1622(\mathrm{C}=\mathrm{N}), 1595(\mathrm{C}=\mathrm{C})$ and $1244(\mathrm{C}-\mathrm{O}) .{ }^{1} \mathrm{H}-\mathrm{NMR}$ $\left(400 \mathrm{MHz}, \mathrm{DMSO}-d_{6}\right) \delta \mathrm{ppm} 3.07(\mathrm{dd}, J=17.4,5.9 \mathrm{~Hz}, 1 \mathrm{H}, \mathrm{H}-4), 3.37-3.48\left(\mathrm{~m}, 4 \mathrm{H}, \mathrm{CH}_{2}\right), 3.54-3.61(\mathrm{~m}$, $\left.6 \mathrm{H}, \mathrm{CH}_{2}, \mathrm{OH}\right), 3.70\left(\mathrm{~s}, 3 \mathrm{H}, \mathrm{OCH}_{3}\right), 3.86(\mathrm{dd}, J=17.4,12.1 \mathrm{~Hz}, 1 \mathrm{H}, \mathrm{H}-4), 5.42(\mathrm{dd}, J=12.1,5.9 \mathrm{~Hz}, 1 \mathrm{H}$, $\mathrm{H}-5), 6.88(\mathrm{~d}, J=8.8 \mathrm{~Hz}, 2 \mathrm{H}, \mathrm{Ar}-\mathrm{H}), 6.98(\mathrm{~d}, J=8.8 \mathrm{~Hz}, 2 \mathrm{H}, \mathrm{Ar}-\mathrm{H}), 7.13-7.20(\mathrm{~m}, 4 \mathrm{H}, \mathrm{Ar}-\mathrm{H}), 7.67-7.79$ (m, 4H, Ar-H), 8.19-8.75 (m, 2H, NH), $10.43(\mathrm{~s}, 1 \mathrm{H}, \mathrm{NH}) .{ }^{13} \mathrm{C}-\mathrm{NMR}\left(100 \mathrm{MHz}, \mathrm{DMSO}-d_{6}\right) \delta \mathrm{ppm} 43.2$ $\left(\mathrm{CH}_{2}\right), 43.3\left(\mathrm{CH}_{2}\right), 55.1\left(\mathrm{CH}_{3}\right), 59.1\left(\mathrm{CH}_{2}\right), 62.6,114.4,114.4,121.0,121.1(\mathrm{Cq}), 122.0(\mathrm{Cq}), 126.3,126.7$ (Cq), 127.1, $127.6(\mathrm{Cq}), 128.6,133.9(\mathrm{Cq}), 136.0(\mathrm{Cq}), 143.1(\mathrm{Cq}), 147.8(\mathrm{Cq}), 158.6(\mathrm{Cq}) . \mathrm{MS}(70 \mathrm{eV})$ $m / z(\%): 574: 576\left[\mathrm{M}^{+}\right]:[\mathrm{M}+2]^{+}(100 / 34), 467$ (26), 377 (40), 125 (42), 55 (58), 43 (98). Anal. Calcd. $\mathrm{C}_{29} \mathrm{H}_{31} \mathrm{ClN}_{8} \mathrm{O}_{3}: \mathrm{C}, 60.57 ; \mathrm{H}, 5.43 ; \mathrm{N}, 19.49$; Found: C, 60.60; H, 5.40; N, 19.55 .

2,2'-((6-((4-(1-(4-Chlorophenyl)-5-(3,4,5-trimethoxyphenyl)-4,5-dihydro-1H-pyrazol-3-yl)phenyl)amino)-1,3,5triazine-2,4-diyl)bis(azanediyl))bis(ethanol) (11d). Yellow solid; $64 \%$ yield; m.p. $176-178{ }^{\circ} \mathrm{C}$. FT-IR (ATR) $\mathrm{v}\left(\mathrm{cm}^{-1}\right)$ Not observed $(\mathrm{N}-\mathrm{H}), 3275(\mathrm{O}-\mathrm{H}), 3086(=\mathrm{C}-\mathrm{H}), 1637(\mathrm{C}=\mathrm{N}), 1591(\mathrm{C}=\mathrm{C})$ and $1228(\mathrm{C}-\mathrm{O})$. ${ }^{1} \mathrm{H}-\mathrm{NMR}\left(400 \mathrm{MHz}\right.$, DMSO- $\left.d_{6}\right) \delta \mathrm{ppm} 3.14(\mathrm{dd}, J=17.5,7.0 \mathrm{~Hz}, 1 \mathrm{H}, \mathrm{H}-4), 3.35-3.50\left(\mathrm{~m}, 4 \mathrm{H}, \mathrm{CH}_{2}\right)$, 3.52-3.61 (m, $\left.6 \mathrm{H}, \mathrm{CH}_{2}, \mathrm{OH}\right), 3.62\left(\mathrm{~s}, 3 \mathrm{H}, \mathrm{OCH}_{3}\right), 3.69\left(\mathrm{~s}, 6 \mathrm{H}, \mathrm{OCH}_{3}\right), 3.88(\mathrm{dd}, J=17.5,12.1 \mathrm{~Hz}, 1 \mathrm{H}$, $\mathrm{H}-4), 5.33$ (dd, $J=12.1,7.0 \mathrm{~Hz}, 1 \mathrm{H}, \mathrm{H}-5), 6.58(\mathrm{~s}, 2 \mathrm{H}, \mathrm{Ar}-\mathrm{H}), 7.01(\mathrm{~d}, J=9.0 \mathrm{~Hz}, 2 \mathrm{H}, \mathrm{Ar}-\mathrm{H}), 7.20$ (d, $J=9.0 \mathrm{~Hz}, 2 \mathrm{H}, \mathrm{Ar}-\mathrm{H}), 7.68-7.79(\mathrm{~m}, 4 \mathrm{H}, \mathrm{Ar}-\mathrm{H}), 8.09-8.75(\mathrm{~m}, 2 \mathrm{H}, \mathrm{NH}), 10.41(\mathrm{~s}, 1 \mathrm{H}, \mathrm{NH}) .{ }^{13} \mathrm{C}-\mathrm{NMR}$ (100 MHz, DMSO- $\left.d_{6}\right) \delta$ ppm $43.3\left(\mathrm{CH}_{2}\right), 55.9\left(\mathrm{CH}_{3}\right), 59.1\left(\mathrm{CH}_{2}\right), 59.9\left(\mathrm{CH}_{3}\right), 99.6(\mathrm{Cq}), 102.9,114.5$, $118.6(\mathrm{Cq}), 120.9,122.8(\mathrm{Cq}), 125.9(\mathrm{Cq}), 126.4,127.3(\mathrm{Cq}), 128.7,128.8(\mathrm{Cq}), 135.9(\mathrm{Cq}), 136.6(\mathrm{Cq}), 137.9$ (Cq), $143.6(\mathrm{Cq}), 148.2(\mathrm{Cq}), 153.3(\mathrm{Cq}) . \mathrm{MS}(70 \mathrm{eV}) \mathrm{m} / z(\%): 634: 636\left[\mathrm{M}^{+}\right]:[\mathrm{M}+2]^{+}(60 / 22), 439(33)$, 437 (86), 270 (24), 125 (56), 43 (100). Anal. Calcd. $\mathrm{C}_{31} \mathrm{H}_{35} \mathrm{ClN}_{8} \mathrm{O}_{5}: \mathrm{C}, 58.63 ; \mathrm{H}, 5.55 ; \mathrm{N}, 17.64$; Found: $\mathrm{C}$, $58.68 ; \mathrm{H}, 5.48 ; \mathrm{N}, 17.55$.

2,2'-((6-((4-(1,5-bis(4-Chlorophenyl)-4,5-dihydro-1H-pyrazol-3-yl)phenyl)amino)-1,3,5-triazine-2,4-diyl)-bis (azanediyl))bis(ethanol) (11e). Yellow solid; 63\% yield; m.p. 229-230 ${ }^{\circ} \mathrm{C}$. FT-IR (ATR) $\mathrm{v}\left(\mathrm{cm}^{-1}\right)$ Not observed $(\mathrm{N}-\mathrm{H}), 3292(\mathrm{O}-\mathrm{H}), 3099(=\mathrm{C}-\mathrm{H}), 1643$ and $1593(\mathrm{C}=\mathrm{N}$ and $\mathrm{C}=\mathrm{C}) .{ }^{1} \mathrm{H}-\mathrm{NMR}(400 \mathrm{MHz}$, DMSO- $\left.d_{6}\right) \delta$ ppm $3.12(\mathrm{dd}, J=17.4,5.7 \mathrm{~Hz}, 1 \mathrm{H}, \mathrm{H}-4), 3.36-3.50\left(\mathrm{~m}, 4 \mathrm{H}, \mathrm{CH}_{2}\right), 3.52-3.65\left(\mathrm{~m}, 6 \mathrm{H}, \mathrm{CH}_{2}\right.$, $\mathrm{OH}), 3.91(\mathrm{dd}, J=17.4,12.1 \mathrm{~Hz}, 1 \mathrm{H}, \mathrm{H}-4), 5.52(\mathrm{dd}, J=12.1,5.7 \mathrm{~Hz}, 1 \mathrm{H}, \mathrm{H}-5), 6.97(\mathrm{~d}, J=8.9 \mathrm{~Hz}, 2 \mathrm{H}$, Ar-H), $7.19(\mathrm{~d}, J=8.9 \mathrm{~Hz}, 2 \mathrm{H}, \mathrm{Ar}-\mathrm{H}), 7.28(\mathrm{~d}, J=8.3 \mathrm{~Hz}, 2 \mathrm{H}, \mathrm{Ar}-\mathrm{H}), 7.40(\mathrm{~d}, J=8.3 \mathrm{~Hz}, 2 \mathrm{H}, \mathrm{Ar}-\mathrm{H})$, 3.66-3.81 (m, $4 \mathrm{H}, \mathrm{Ar}-\mathrm{H}), 8.23-8.80(\mathrm{~m}, 2 \mathrm{H}, \mathrm{NH}), 10.44(\mathrm{~s}, 1 \mathrm{H}, \mathrm{NH}) .{ }^{13} \mathrm{C}-\mathrm{NMR}\left(100 \mathrm{MHz}, \mathrm{DMSO}-d_{6}\right) \delta$ ppm $42.9\left(\mathrm{CH}_{2}\right), 43.3\left(\mathrm{CH}_{2}\right), 59.0,62.3\left(\mathrm{CH}_{2}\right), 114.3,120.9,121.0(\mathrm{Cq}), 122.2,123.3(\mathrm{Cq}), 126.4,127.8$, 127.9 (Cq), 128.7, 129.0, $132.0(\mathrm{Cq}), 139.8(\mathrm{Cq}), 141.0(\mathrm{Cq}), 142.9(\mathrm{Cq}), 147.9(\mathrm{Cq}) . \mathrm{MS}(70 \mathrm{eV}) \mathrm{m} / \mathrm{z}(\%)$ : 578:580 [M+ $]:[\mathrm{M}+2]^{+}:[\mathrm{M}+4]^{+}(100 / 63 / 12), 467$ (12), 284 (10), 125 (38), 90 (17), 43 (36). Anal. Calcd. $\mathrm{C}_{28} \mathrm{H}_{28} \mathrm{Cl}_{2} \mathrm{~N}_{8} \mathrm{O}_{2}$ : C, 58.04; $\mathrm{H}, 4.87 ; \mathrm{N}, 19.34$; Found: $\mathrm{C}, 58.07 ; \mathrm{H}, 4.81 ; \mathrm{N}, 19.32$.

2,2'-((6-((4-(1-(4-Chlorophenyl)-5-(4-fluorophenyl)-4,5-dihydro-1H-pyrazol-3-yl)phenyl)amino)-1,3,5-triazine-2, 4-diyl)bis(azanediyl))bis(ethanol) (11f). Yellow solid; $90 \%$ yield; m.p. $129-230{ }^{\circ} \mathrm{C}$. FT-IR (ATR) v $\left(\mathrm{cm}^{-1}\right.$ ) Not observed (N-H), $3292(\mathrm{O}-\mathrm{H}), 3101(=\mathrm{C}-\mathrm{H}), 1645$ and $1595(\mathrm{C}=\mathrm{N}$ and $\mathrm{C}=\mathrm{C}) .{ }^{1} \mathrm{H}-\mathrm{NMR}(400 \mathrm{MHz}$, DMSO- $\left.d_{6}\right) \delta$ ppm $3.10(\mathrm{dd}, J=17.5,5.8 \mathrm{~Hz}, 1 \mathrm{H}, \mathrm{H}-4), 3.39-3.49\left(\mathrm{~m}, 4 \mathrm{H}, \mathrm{CH}_{2}\right), 3.55-3.61\left(\mathrm{~m}, 6 \mathrm{H}, \mathrm{CH}_{2}\right.$, $\mathrm{OH}), 3.90(\mathrm{dd}, J=17.5,12.1 \mathrm{~Hz}, 1 \mathrm{H}, \mathrm{H}-4), 5.51(\mathrm{dd}, J=12.1,5.8 \mathrm{~Hz}, 1 \mathrm{H}, \mathrm{H}-5), 6.97(\mathrm{~d}, J=9.0 \mathrm{~Hz}$, $2 \mathrm{H}, \mathrm{Ar}-\mathrm{H}), 7.22-7.12(\mathrm{~m}, 4 \mathrm{H}, \mathrm{Ar}-\mathrm{H}), 7.29\left(\mathrm{dd}, J=8.0\right.$ and $\left.\mathrm{J}_{\mathrm{HF}}=5.7 \mathrm{~Hz}, 2 \mathrm{H}, \mathrm{Ar}-\mathrm{H}\right), 7.69-7.79(\mathrm{~m}, 4 \mathrm{H}$, 
Ar-H), 8.11-8.78 (m, 2H, NH), $10.43(\mathrm{~s}, 1 \mathrm{H}, \mathrm{NH}) .{ }^{13} \mathrm{C}-\mathrm{NMR}\left(100 \mathrm{MHz}, \mathrm{DMSO}-d_{6}\right) \delta \mathrm{ppm} 43.1\left(\mathrm{CH}_{2}\right)$, $43.3\left(\mathrm{CH}_{2}\right), 59.1\left(\mathrm{CH}_{2}\right), 62.3,114.4,115.9\left(\mathrm{~d},{ }^{2} J_{\mathrm{CF}}=21.8 \mathrm{~Hz}\right), 120.9,121.0(\mathrm{Cq}), 122.2(\mathrm{Cq}), 126.4,127.4$ $(\mathrm{Cq}), 128.0\left(\mathrm{~d},{ }^{3} J_{\mathrm{CF}}=8.5 \mathrm{~Hz}\right), 128.7,136.0(\mathrm{Cq}), 138.2\left(\mathrm{~d},{ }^{4} J_{\mathrm{CF}}=2.48 \mathrm{~Hz}, \mathrm{Cq}\right), 143.0(\mathrm{Cq}), 144.2(\mathrm{Cq})$, $147.9(\mathrm{Cq}), 161.4\left(\mathrm{~d},{ }^{1} J_{\mathrm{CF}}=243.1 \mathrm{~Hz}, \mathrm{C}-\mathrm{F}\right) . \mathrm{MS}(70 \mathrm{eV}) \mathrm{m} / z(\%): 562: 564\left[\mathrm{M}^{+}\right]:[\mathrm{M}+2]^{+}(100 / 37), 467$ (11), 284 (8), 125 (26), 69 (14), 44 (20), 43 (24). Anal. Calcd. $\mathrm{C}_{28} \mathrm{H}_{28} \mathrm{ClFN}_{8} \mathrm{O}_{2}: \mathrm{C}, 59.73 ; \mathrm{H}, 5.01 ; \mathrm{N}, 19.90$; Found: $\mathrm{C}, 59.76 ; \mathrm{H}, 4.97 ; \mathrm{N}, 20.06$.

2,2'-((6-((4-(1-(4-Chlorophenyl)-5-(4-(trifluoromethyl)phenyl)-4,5-dihydro-1H-pyrazol-3-yl)phenyl)amino)-1,3, 5-triazine-2,4-diyl)bis(azanediyl))bis(ethanol) (11g). Yellow solid; $24 \%$ yield; m.p. 197-199 ${ }^{\circ} \mathrm{C}$. FT-IR (ATR) $\mathrm{v}\left(\mathrm{cm}^{-1}\right)$ Not observed $(\mathrm{N}-\mathrm{H}), 3288(\mathrm{O}-\mathrm{H}), 3095(=\mathrm{C}-\mathrm{H}), 1645$ and $1599(\mathrm{C}=\mathrm{N}$ and $\mathrm{C}=\mathrm{C}) .{ }^{1} \mathrm{H}-\mathrm{NMR}$ $\left(400 \mathrm{MHz}, \mathrm{DMSO}-d_{6}\right) \delta \mathrm{ppm} 3.16(\mathrm{dd}, J=17.7,5.8 \mathrm{~Hz}, 1 \mathrm{H}, \mathrm{H}-4), 3.36-3.49\left(\mathrm{~m}, 4 \mathrm{H}, \mathrm{CH}_{2}\right), 3.53-3.61$ $\left(\mathrm{m}, 6 \mathrm{H}, \mathrm{CH}_{2}, \mathrm{OH}\right), 3.95(\mathrm{dd}, J=17.7,12.2 \mathrm{~Hz}, 1 \mathrm{H}, \mathrm{H}-4), 5.63(\mathrm{dd}, J=12.2,5.8 \mathrm{~Hz}, 1 \mathrm{H}, \mathrm{H}-5), 6.97(\mathrm{~d}$, $J=9.0 \mathrm{~Hz}, 2 \mathrm{H}, \mathrm{Ar}-\mathrm{H}), 7.20(\mathrm{~d}, J=9.0 \mathrm{~Hz}, 2 \mathrm{H}, \mathrm{Ar}-\mathrm{H}), 7.48(\mathrm{~d}, J=8.0 \mathrm{~Hz}, 2 \mathrm{H}, \mathrm{Ar}-\mathrm{H}), 7.67-7.83(\mathrm{~m}, 6 \mathrm{H}$, Ar-H), 8.07-8.80 (m, 2H, NH), $10.42(\mathrm{~s}, 1 \mathrm{H}, \mathrm{NH}) .{ }^{13} \mathrm{C}-\mathrm{NMR}\left(100 \mathrm{MHz}, \mathrm{DMSO}-d_{6}\right) \delta \mathrm{ppm} 42.6\left(\mathrm{CH}_{2}\right)$, $42.9\left(\mathrm{CH}_{2}\right), 58.8\left(\mathrm{CH}_{2}\right), 62.1,114.3,121.0,124.2\left(\mathrm{q},{ }^{1} J_{\mathrm{CF}}=286.1 \mathrm{~Hz}, \mathrm{CF}_{3}\right), 126.1\left(\mathrm{~d},{ }^{4} J_{\mathrm{CF}}=3.14 \mathrm{~Hz}\right)$, 126.5, 126.8, $128.0(\mathrm{Cq}), 128.5\left(\mathrm{~d},{ }^{2} J_{\mathrm{CF}}=26.9 \mathrm{~Hz}, \mathrm{Cq}\right), 128.8$ (unresolved q), $133.9(\mathrm{Cq}), 134.4(\mathrm{Cq})$, $\left.135.9(\mathrm{Cq}), 136.0(\mathrm{Cq}), 142.8(\mathrm{Cq}), 146.7(\mathrm{Cq}), 148.0(\mathrm{Cq}) . \mathrm{MS}(70 \mathrm{eV}) \mathrm{m} / z(\%): 612: 614 \mathrm{CM}^{+}\right]:[\mathrm{M}+2]^{+}$ (100/35), 581 (11), 284 (9), 125 (24), 111 (14), 69 (16), 43 (26). Anal. Calc. $\mathrm{C}_{29} \mathrm{H}_{28} \mathrm{ClF}_{3} \mathrm{~N}_{8} \mathrm{O}_{2}$ : C, 56.82; $\mathrm{H}$, 4.60 ; N, 18.28; Found: C, 56.86; H, 4.63; N, 18.20 .

\subsection{Anticancer Activity}

The human cancer cell lines of the cancer screening panel were grown in an RPMI-1640 medium containing $5 \%$ fetal bovine serum and $2 \mathrm{mM} \mathrm{L}$-glutamine. For a typical screening experiment, cells were inoculated into 96-well microtiter plates. After cell inoculation, the microtiter plates were incubated at $37{ }^{\circ} \mathrm{C}, 5 \% \mathrm{CO}_{2}, 95 \%$ air, and $100 \%$ relative humidity for $24 \mathrm{~h}$ prior to the addition of the tested compounds. After $24 \mathrm{~h}$, two plates of each cell line were fixed in situ with TCA, to represent a measurement of the cell population for each cell line at the time of sample addition (Tz). The samples were solubilized in dimethyl sulfoxide (DMSO) at 400-fold the desired final maximum test concentration and stored frozen prior to use. At the time of compound addition, an aliquot of frozen concentrate was thawed and diluted to twice the desired final maximum test concentration with complete medium containing $50 \mu \mathrm{g} / \mathrm{mL}$ gentamicin. An additional four 10 -fold or $1 / 2 \log$ serial dilutions were made to provide a total of five drug concentrations plus the control. Aliquots of $100 \mu \mathrm{L}$ of these different sample dilutions were added to the appropriate microtiter wells already containing $100 \mu \mathrm{L}$ of medium, resulting in the required final sample concentrations [37-39]. After the tested compounds were added, the plates were incubated for an additional $48 \mathrm{~h}$ at $37{ }^{\circ} \mathrm{C}, 5 \% \mathrm{CO}_{2}, 95 \%$ air, and $100 \%$ relative humidity. For adherent cells, the assay was terminated by the addition of cold TCA. Cells were fixed in situ by the gentle addition of $50 \mu \mathrm{L}$ of cold $50 \%(w / v)$ TCA (final concentration, 10\% TCA) and incubated for $60 \mathrm{~min}$ at $4{ }^{\circ} \mathrm{C}$. The supernatant was discarded, and plates were washed five times with tap water and air dried. Sulforhodamine B (SRB) solution $(100 \mu \mathrm{L})$ at $0.4 \%(w / v)$ in $1 \%$ acetic acid was added to each well, and plates were incubated for $10 \mathrm{~min}$ at room temperature. After staining, unbound dye was removed by washing five times with $1 \%$ acetic acid and the plates were air dried. Bound stain was subsequently solubilized with $10 \mathrm{mM}$ trizma base, and the absorbance was read on an automated plate reader at a wavelength of $515 \mathrm{~nm}$. Using the seven absorbance measurements [time zero (Tz), control growth in the absence of drug, and test growth in the presence of drug at the five concentration levels (Ti)], the percentage growth was calculated at each of the drug concentrations levels. Percentage growth inhibition was calculated as: $[(\mathrm{Ti}-\mathrm{Tz}) /(\mathrm{C}-\mathrm{Tz})] \times 100$ for concentrations for which $\mathrm{Ti}>\mathrm{Tz}$, and $[(\mathrm{Ti}-\mathrm{Tz}) / \mathrm{Tz}] \times 100$ for concentrations for which $\mathrm{Ti}<\mathrm{Tz}$. Two dose-response parameters were calculated for each compound. Growth inhibition of $50 \%\left(\mathrm{GI}_{50}\right)$ was calculated from $[(\mathrm{Ti}-\mathrm{Tz}) /(\mathrm{C}-\mathrm{Tz})]$ $\times 100=50$, which is the drug concentration resulting in a 50\% lower net protein increase in the treated cells (measured by SRB staining) as compared to the net protein increase seen in the control cells and the $\mathrm{LC}_{50}$ (concentration of drug resulting in a $50 \%$ reduction in the measured protein at the end of the 
drug treatment as compared to that at the beginning), indicating a net loss of cells; calculated from $[(\mathrm{Ti}-\mathrm{Tz}) / \mathrm{Tz}] \times 100=-50)$. Values were calculated for each of these two parameters if the level of activity is reached; however, if the effect was not reached or was exceeded, the value for that parameter was expressed as greater or less than the maximum or minimum concentration tested [37-39,41].

\section{Conclusions}

In summary, the trisubstituted [1,3,5]-triazine precursor 5 was obtained in good yield under microwave irradiation after a short reaction time. Then, starting from 5 and mediated by chalcone intermediates 7, four new series of 1,3,5-triazine-2-pyrazoline hybrids (8-11)a-g were successfully prepared in acceptable to excellent yields through a multistep method. Seventeen of the obtained compounds were subjected under evaluation of their in vitro growth inhibition properties at one- and five-dose levels against a panel of 58 human cancer cell lines by the U.S. NCI. The screening results showed that chalcone $\mathbf{7 g}$ and 3,5-dichlorophenylpyrazolines 10d,e,g exhibited the more remarkable activities against several cancer cell lines (i.e., renal, cns and breast), with $\mathrm{GI}_{50}$ values in the range of $0.569-16.6 \mu \mathrm{M}$ and low toxicity. Therefore, compounds $7 \mathrm{~g}$ and $\mathbf{1 0 d}, \mathbf{e}, \mathbf{g}$ are promising building blocks for further structural modifications in order to improve their activities and hence develop possible new antitumor agent leaders.

Author Contributions: B.I. designed the experiments; L.M.M. and J.R.P. performed the experiments; L.M.M., J.Q., R.A., J.R.P. and B.I. analyzed and discussed the experimental and biological results, all spectral data and wrote the manuscript. All authors read and approved the final manuscript.

Funding: This work was financially supported by Colciencias, Universidad del Valle and the Science, Technology and Innovation Fund-General Royalties System (FCTeI-SGR) under contract No. BPIN 2013000100007.

Acknowledgments: The authors thank The Developmental Therapeutics Program (DTP) of the National Cancer Institute of the United States for performing the anticancer screening of the obtained compounds.

Conflicts of Interest: The authors declare no conflicts of interest.

\section{References}

1. Abbot, V.; Sharma, P.; Dhiman, S.; Noolvi, M.; Patel, H.; Bhardwaj, V. Small hybrid heteroaromatics: Resourceful biological tools in cancer research. RSC Adv. 2017, 7, 28313-28349. [CrossRef]

2. Kerru, N.; Singh, P.; Koorbanally, N.; Raj, R.; Kumar, V. Recent advances (2015-2016) in anticancer hybrids. Eur. J. Med. Chem. 2017, 142, 179-212. [CrossRef] [PubMed]

3. Park, S.; Hye, E.; Kim, J.; Hwan, S.; Kim, I. Biological evaluation of indolizine-chalcone hybrids as new anticancer agents. Eur. J. Med. Chem. 2018, 144, 435-443. [CrossRef] [PubMed]

4. Brzozowski, Z.; Saczewski, F.; Gdaniec, M. Synthesis, structural characterization and antitumor activity of novel 2,4-diamino-1,3,5-triazine derivatives. Eur. J. Med. Chem. 2000, 35, 1053-1064. [CrossRef]

5. Abd El-All, A.; Osman, S.; Roaiah, H.; Abdalla, M.; Abd El Aty, A.; AbdEl-Hady, W. Potent anticancer and antimicrobial activities of pyrazole, oxazole and pyridine derivatives containing 1,2,4-triazine moiety. Med. Chem. Res. 2015, 24, 4093-4104. [CrossRef]

6. Saleh, M.; Abbott, S.; Perron, V.; Lauzon, C.; Penney, C.; Zacharie, B. Synthesis and antimicrobial activity of 2-fluorophenyl-4,6-disubstituted [1,3,5]triazines. Bioorg. Med. Chem. Lett. 2010, 20, 945-949. [CrossRef] [PubMed]

7. Zhang, T.; Li, C.; Tian, Y.; Li, J.; Sun, L.; Zheng, C.; Piao, H. Synthesis and biological evaluation of dihydrotriazine derivatives as potential antibacterial agents. Chin. Chem. Lett. 2017, 28, 1737-1742. [CrossRef]

8. Sharma, A.; Ghabbour, H.; Tabrez, S.; De la Torre, B.; Albericio, F.; El-faham, A. Novel pyrazolyl-S-triazine derivatives, molecular structure and antimicrobial activity. J. Mol. Struct. 2017, 1145, 244-253. [CrossRef]

9. Singh, B.; Bhat, H.; Kumawat, M.; Singh, U. Structure-guided discovery of 1,3,5-triazine-pyrazole conjugates as antibacterial and antibiofilm agent against pathogens causing human diseases with favorable metabolic fate. Bioorg. Med. Chem. Lett. 2014, 24, 3321-3325. [CrossRef] [PubMed]

10. Dandia, A.; Arya, K.; Sati, M.; Sarawgi, P. Green chemical synthesis of fluorinated 1,3,5-triaryl-s-triazines in aqueous medium under microwaves as potential antifungal agents. J. Fluor. Chem. 2004, 125, 1273-1277. [CrossRef] 
11. Elshemy, H.; Abdelall, E.; Azouz, A.; Moawad, A.; Ali, W.; Safwat, N. Synthesis, anti-inflammatory, cyclooxygenases inhibitions assays and histopathological study of poly-substituted 1,3,5-triazines: Confirmation of regiospecific pyrazole cyclization by HMBC. Eur. J. Med. Chem. 2017, 127, 10-21. [CrossRef] [PubMed]

12. Jameel, E.; Meena, P.; Maqbool, M.; Kumar, J.; Hoda, N.; Ahmed, W.; Mumtazuddin, S.; Tiwari, M.; Jayaram, B. Rational design, synthesis and biological screening of triazine-triazolopyrimidine hybrids as multitarget anti-Alzheimer agents. Eur. J. Med. Chem. 2017, 136, 36-51. [CrossRef] [PubMed]

13. Carbone, A.; Cascioferro, S.; Parrino, B.; Span, V.; Montalbano, A.; Barraja, P.; Diana, P.; Cirrincione, G. 1,3,5-Triazines: A promising scaffold for anticancer drugs development. Eur. J. Med. Chem. 2017, 142, 523-549.

14. Kothayer, H.; Spencer, S.; Tripathi, K.; Westwell, A.; Palle, K. Synthesis and in vitro anticancer evaluation of some 4,6-diamino-1,3,5-triazine-2-carbohydrazides as Rad6 ubiquitin conjugating enzyme inhibitors. Bioorg. Med. Chem. Lett. 2016, 26, 2030-2034. [CrossRef] [PubMed]

15. Singla, P.; Luxami, V.; Paul, K. Triazine-benzimidazole hybrids: Anticancer activity, DNA interaction and dihydrofolate reductase inhibitors. Bioorg. Med. Chem. 2015, 23, 1691-1700. [CrossRef] [PubMed]

16. Chan, J.; Loizzi, V.; Manetta, A.; Berman, M. Oral altretamine used as salvage therapy in recurrent ovarian cancer. Gynecol. Oncol. 2004, 92, 368-371. [CrossRef] [PubMed]

17. Guan, H.; Mi, B.; Li, Y.; Wu, W.; Tan, P.; Fang, Z.; Li, J.; Zhang, Y.; Li, F. Decitabine represses osteoclastogenesis through inhibition of RANK and NF-Kb. Cell Signal. 2015, 27, 969-977. [CrossRef] [PubMed]

18. Salim, O.; Toptas, T.; Avsar, E.; Kemal, O.; Ozturk, E.; Ferhanoglu, B.; Geduk, A.; Mehtap, O.; Tombak, A.; Naci, E.; et al. Azacitidine versus decitabine in patients with refractory anemia with excess blast-Results of multicenter study. Leuk. Res. 2016, 45, 82-89. [CrossRef] [PubMed]

19. Gul, H.; Yamali, C.; Sakagami, H.; Angeli, A.; Leitans, J.; Kazaks, A.; Tars, K.; Ozgun, D.; Supuran, C. New anticancer drug candidates sulfonamides as selective hCA IX or hCA XII inhibitors. Bioorg. Chem. 2018, 77, 411-419. [CrossRef] [PubMed]

20. Weber, J.; Buss, J.; Rech, K.; Moraes, L.; Reisdorfer, F.; Martin, C.; Pereira, P.; Collares, T.; Kömmling, F. Antitumor potential of 1-thiocarbamoyl-3,5-diaryl-4,5-dihydro-1H-pyrazoles in human bladder cancer cells. Biomed. Pharmacother. 2017, 94, 37-46.

21. Akhtar, J.; Ahmed, A.; Ali, Z.; Prasad, R.; Rafi, M.; Hassan, Q.; Akhtar, S.; Siddiqui, A.; Partap, S.; Pasha, S.; et al. Synthesis of stable benzimidazole derivatives bearing pyrazole as anticancer and EGFR receptor inhibitors. Bioorg. Chem. 2018, 78, 158-169. [CrossRef] [PubMed]

22. Bao, H.; Zhang, Q.; Du, Y.; Zhang, C.; Xu, H.; Zhu, Z.; Yan, Z. Apoptosis induction in K562 human myelogenous leukaemia cells is connected to the modulation of Wnt/ $\beta$-catenin signalling by BHX, a novel pyrazoline derivative. Cell Prolif. 2018, 51, e12433. [CrossRef] [PubMed]

23. Luan, S.; Zhonga, H.; Zhao, X.; Yang, J.; Jing, Y.; Liu, D.; Zhao, L. Synthesis, anticancer evaluation and pharmacokinetic study of novel 10-O-phenyl ethers of dihydroartemisinin. Eur. J. Med. Chem. 2017, 141, 584-595. [CrossRef] [PubMed]

24. Wei, Q.; Ning, J.; Dai, X.; Gao, Y.; Su, L.; Zhao, B.; Miao, J. Discovery of novel HSP90 inhibitors that induced apoptosis and impaired autophagic flux in A549 lung cancer cells. Eur. J. Med. Chem. 2018, 145, 551-558. [CrossRef] [PubMed]

25. Lin, R.; Chiu, G.; Yu, Y.; Connolly, P.; Li, S.; Lu, Y.; Adams, M.; Fuentes-Pesquera, A.; Emanuel, S.; Greenberger, L. Design, synthesis, and evaluation of 3,4-disubstituted pyrazole analogues as anti-tumor CDK inhibitors. Bioorg. Med. Chem. Lett. 2007, 17, 4557-4561. [CrossRef] [PubMed]

26. Manna, F.; Chimenti, F.; Fioravanti, R.; Bolasco, A.; Secci, D.; Chimenti, P.; Ferlinib, C.; Scambia, G. Synthesis of some pyrazole derivatives and preliminary investigation of their affinity binding to P-glycoprotein. Bioorg. Med. Chem. Lett. 2005, 15, 4632-4635. [CrossRef] [PubMed]

27. Madhavi, S.; Sreenivasulu, R.; Yazala, J.; Raju, R. Synthesis of chalcone incorporated quinazoline derivatives as anticancer agents. Saudi Pharm. J. 2017, 25, 275-279. [CrossRef] [PubMed]

28. Wang, G.; Qiu, J.; Xiao, X.; Cao, A.; Zhou, F. Synthesis, biological evaluation and molecular docking studies of a new series of chalcones containing naphthalene moiety as anticancer agents. Bioorg. Chem. 2018, 76, 249-257. [CrossRef] [PubMed] 
29. Wang, Y.; Zhou, D.; He, F.; Chen, J.; Chen, Y.; Gan, X.; Hu, D.; Song, B. Synthesis and antiviral bioactivity of novel chalcone derivatives containing purine moiety. Chin. Chem. Lett. 2018, 29, 127-130. [CrossRef]

30. Pingaew, R.; Saekee, A.; Mandi, P.; Nantasenamat, C.; Prachayasittikul, S.; Ruchirawat, S.; Prachayasittikul, V. Synthesis, biological evaluation and molecular docking of novel chalcone-coumarin hybrids as anticancer and antimalarial agents. Eur. J. Med. Chem. 2014, 85, 65-76. [CrossRef] [PubMed]

31. Vanangamudi, G.; Subramanian, M.; Thirunarayanan, G. Synthesis, spectral linearity, antimicrobial, antioxidant and insect antifeedant activities of some 2,5-dimethyl-3-thienyl chalcones. Arab. J. Chem. 2017, 10, S1254-S1266. [CrossRef]

32. Insuasty, B.; Montoya, A.; Becerra, D.; Quiroga, J.; Abonia, R.; Robledo, S.; Vélez, I.; Upegui, Y.; Nogueras, M.; Cobo, J. Synthesis of novel analogs of 2-pyrazoline obtained from [(7-chloroquinolin-4-yl)amino]chalcones and hydrazine as potential antitumor and antimalarial agents. Eur. J. Med. Chem. 2013, 67, 252-262. [CrossRef] [PubMed]

33. Ramírez-Prada, J.; Robledo, S.; Vélez, I.; Crespo, M.P.; Quiroga, J.; Abonia, R.; Montoya, A.; Svetaz, L.; Zacchino, S.; Insuasty, B. Synthesis of novel quinoline-based 4,5-dihydro- $1 H$-pyrazoles as potential anticancer, antifungal, antibacterial and antiprotozoal agents. Eur. J. Med. Chem. 2017, 131, 237-254. [CrossRef] [PubMed]

34. Insuasty, B.; Tigreros, A.; Orozco, F.; Quiroga, J.; Abonia, R.; Nogueras, M.; Sanchez, A.; Cobo, J. Synthesis of novel pyrazolic analogues of chalcones and their 3-aryl-4-(3-aryl-4,5-dihydro -1H-pyrazol-5-yl)-1-phenyl-1H-pyrazole derivatives as potential antitumor agents. Bioorg. Med. Chem. 2010, 18, 4965-4974. [CrossRef] [PubMed]

35. Kathiriya, P.; Purohit, D.; Shree, M.; Road, K. Synthesis and antimicrobial activity of 2-\{4'-[(6"-aryl)2"-amino-3", $4^{\prime \prime}$-dihydro-pyrimidine-4"'-yl]-phenyl amino\}-6-[bis(2"' -chloroethyl)amino]4-methoxy-1,3,5-triazine. J. Chem. Pharm. Res. 2012, 4, 383-386.

36. For Information about the COMPARE Program. Available online: https://dtp.cancer.gov/databases_tools/ compare.htm (accessed on 28 July 2018).

37. Hubbard, W.C.; Alley, M.C.; Gray, G.N.; Green, K.C.; McLemore, T.L.; Boyd, M.R. Evidence for prostanoid biosynthesis as a biochemical feature of certain subclasses of non-small cell carcinomas of the lung as determined in established cell lines derived from human lung tumors. Cancer Res. 1989, 49, 826-832. [PubMed]

38. Monks, A.P.; Scudiero, D.A.; Skehan, P.; Shoemaker, R.H.; Paull, K.D.; Vistica, C.; Hose, C.; Langley, J.; Cronise, P.; Vaigro-Wolff, A.; et al. Feasibility of a high-flux anticancer drug screen using a diverse panel of cultured human tumor cell lines. J. Natl. Cancer Inst. 1991, 83, 757-766. [CrossRef] [PubMed]

39. Weinstein, J.N.; Myers, T.G.; O'Connor, P.M.; Friend, S.H.; Fornace, A.J.; Kohn, K.W.; Fojo, T.; Bates, S.E.; Rubinstein, L.V.; Anderson, N.L.; et al. An information-intensive approach to the molecular pharmacology of cancer. Science 1997, 275, 343-349. [PubMed]

40. Vandenbroucke, T.; Verheecke, M.; Fumagalli, M.; Lok, C.; Amant, F. Effects of cancer treatment during pregnancy on fetal and child development. Lancet Child Adolesc. Health 2017, 1, 302-310. [CrossRef]

41. Grever, M.R.; Schepartz, S.A.; Chabner, B.A. The National Cancer Institute: Cancer drug discovery and development program. Semin. Oncol. 1992, 19, 622-638. [PubMed]

Sample Availability: Not available. 